\title{
CHRISTIANO MACHADO
}

\section{Estudo comparativo da resposta protetora do tecido renal em rins de doadores vivos submetidos à nefrectomia laparoscópica ou aberta na doação de órgãos}

Tese apresentada à Faculdade de Medicina da Universidade de São Paulo para obtenção de título de Doutor em Ciências

Programa de Urologia

Orientador: Prof. Doutor William Carlos Nahas

Co-orientadora: Dra. Francine Brambate Carvalhinho Lemos

São Paulo 2011 


\section{CHRISTIANO MACHADO}

\section{Estudo comparativo da resposta protetora do tecido renal em rins de doadores vivos submetidos à nefrectomia laparoscópica ou aberta na doação de órgãos}

Tese apresentada à Faculdade de Medicina da Universidade de São Paulo para obtenção de título de Doutor em Ciências

Programa de Urologia

Orientador: Prof. Doutor William Carlos Nahas

Co-orientadora: Dra. Francine Brambate Carvalhinho Lemos

São Paulo 2011 
Dados Internacionais de Catalogação na Publicação (CIP)

Preparada pela Biblioteca da

Faculdade de Medicina da Universidade de São Paulo

Creprodução autorizada pelo autor

\section{Machado, Christiano}

Estudo comparativo da resposta protetora do tecido renal em rins de doadores vivos submetidos à nefrectomia laparoscópica ou aberta na doação de orgãos / Christiano Machado. -- São Paulo, 2011.

Tese(doutorado)--Faculdade de Medicina da Universidade de São Paulo.

Programa de Urologia.

Orientador: William Carlos Nahas

Co-orientadora: Francine Brambate Carvalhinho Lemos.

Descritores: 1.Transplante de rim 2.Traumatismo por reperfusão 3.Expressão gênica 4.Apoptose 5.Laparoscopia 6.Estudo comparativo

USP/FM/DBD-382/11 


\section{À Deus}

"Só em Deus repousa minha alma, d'Ele vem a minha salvação"

Salmo 62

À Ana Paula e Christiano Filho, lanterna a iluminar o meu caminho, razão da minha alegria, meu esteio e alento. 


\section{Agradecimentos}

\section{"A virtude nunca está sozinha. Está destinada a ter vizinhos."}

\section{Confúcio}

Ao Prof. Dr. William Carlos Nahas, médico e professor exemplar que desde o primeiro momento apoiou e confiou nesta ideia.

À Dra. Francine Brambate Carvalhinho Lemos, que com dedicação e paciência ensinou-me, pelo seu exemplo inspirador, o real significado de ser pesquisador, mostrando minhas limitações e ajudando a superá-las.

À Dra. Denise Maria Avancini Costa Malheiros, incentivadora constante, pelos ensinamentos e grande auxílio na execução desta pesquisa.

Ao Prof Dr. Miguel Srougi, que pela suas mãos generosas me aceitou neste Serviço e me pôs diante de pessoas tão especiais.

Prof. Dr. Homero Bruschini, pela permanente porta aberta, amiga e conselheira.

À Sra. lara Corradini, pela ajuda inestimável nos momentos de grande dificuldade.

À Elisa de Arruda Cruz, pela simpatia que sempre me atendeu, auxiliando nas questões burocráticas.

Ao Sr. Jair Martins, por auxiliar-me na difícil tarefa de contabilidade junto à FAPESP.

À Fátima de Jesus Alexandra Libanio, pelo levantamento de dados da pesquisa. 
À Sra. Veneranda Pedroza, Fabiana Agena e Raquel Tange Bojikian, sou grato pelo apoio logístico.

Aos Colegas Cirurgiões da Unidade de Transplante da Santa Casa de Misericórdia de Curitiba e HCFMUSP pelo companheirismo e apoio durante realização deste estudo.

Aos Residentes de Urologia da Santa Casa de Misericórdia de Curitiba e HCFMUSP que muito contribuíram para execução das biópsias renais e pelo cuidado com os pacientes.

Aos Professores Dr. Agenor Ferreira da Silva Filho e Dr. Renato Tâmbara Filho, pela oportunidade de compartilhar experiências com colegas do mais elevado nível no Hospital da Santa Casa de Misericórdia de Curitiba.

À Dra. Regina de Paula Xavier Gomes, que de forma desprendida auxiliou na execução desta pesquisa.

Ao Prof. Dr. Cícero de Andrade Urban pela amizade durante anos de convívio - é um orgulho tê-lo como amigo e conselheiro.

Ao Dr. Ari Adamy Jr, pela amizade e colaboração.

À Neila Aparecida de Souza Silva, pelo esmero nas reações de imunoistoquímica.

Aos Amigos do Laboratório de Imunologia do InCor pela acolhida amiga e estímulo durante o período de convivência.

À CAPES e FAPESP pelo apoio institucional 
Este projeto contou com apoio financeiro da Fundação de Amparo à Pesquisa do Estado de São Paulo - FAPESP Projeto 2008/54855-9 
"A viagem da descoberta consiste não em achar novas paisagens, mas em ver com novos olhos."

Marcel Proust 
Esta tese está de acordo com as seguintes normas, em vigor no momento desta puplicação:

Referências: adaptado de International Committe of Medical Journals Editions (Vancouver).

Universidade de São Paulo. Faculdade de Medicina. Serviço de Biblioteca e Documentação. Guia de apresentação e dissertações, teses e monografias. Elaborado por Anneliese Carneiro da Cunha, Maria Julia de A. L. Freddi, MariaF. Crestana, Marinalva de Souza Aragão, Suely Campos Cardoso, Valéria Vilhena. $2^{a}$ ed. São Paulo: Serviço de Biblioteca e Documentação; 2005.

Abreviaturas dos títulos dos periódicos de acordo com List of Journals Indexed in Index Medicus. 
Lista de Figuras

Lista de Tabelas

Resumo

Summary

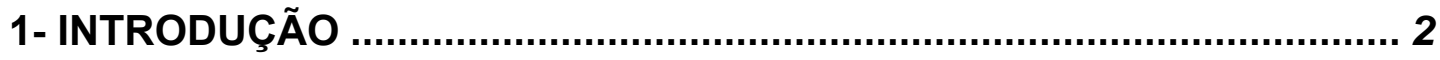

1.1- NEFRECTOMIA LAPAROSCÓPICA PARA DOAÇÃO RENAL............. 2

1.2- LESÃO DE ISQUEMIA E REPERFUSÃO......................................... 3

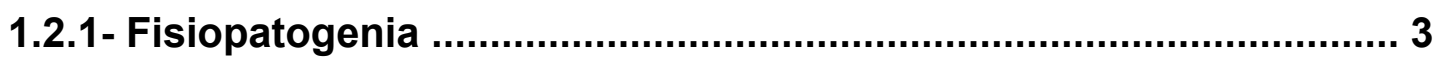

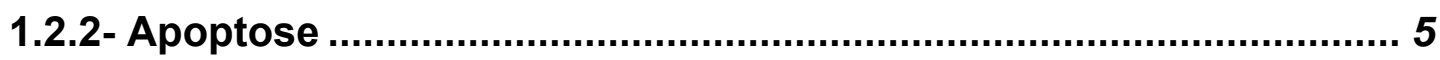

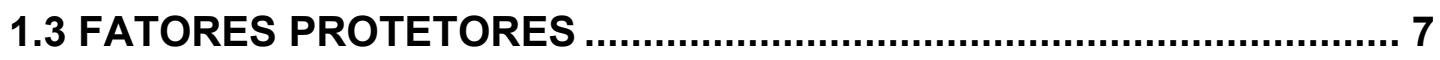

1.3.1-Heme-oxigenase-1 - HO-1 ...................................................... 8

1.3.2. Proteína de choque térmico 70 - Hsp70 ....................................... 9

1.3.3. Fator de crescimento endotelial vascular - VEGF ....................... 10

1.4 LAPAROSCOPIA E LESÃO DE ISQUEMIA E REPERFUSÃO............. 11

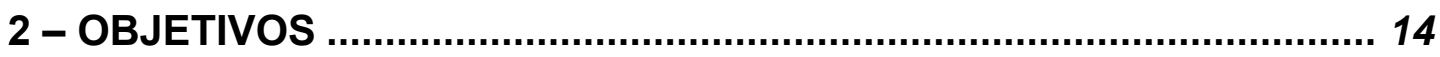

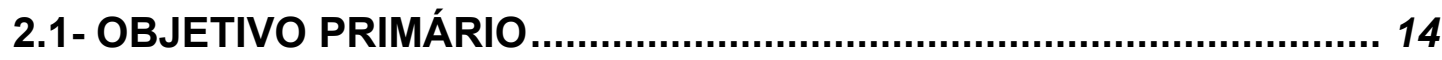

2.2- OBJETIVOS SECUNDÁRIOS......................................................... 14

3 - CASUÍSTICA E MÉTODO ........................................................... 16

3.1 - RECEPTORES PARA TRANSPLANTE RENAL ............................ 18

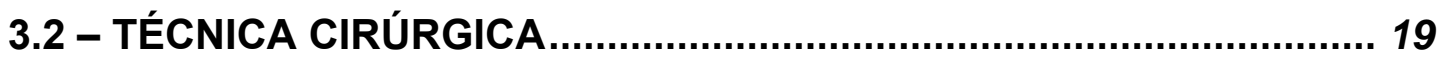

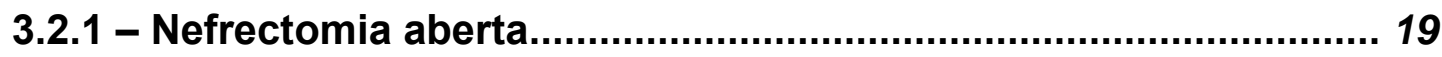

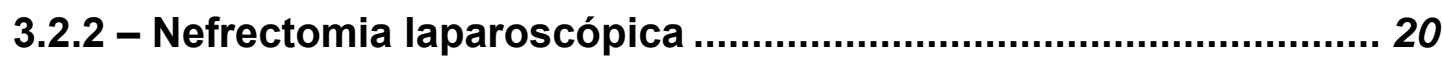

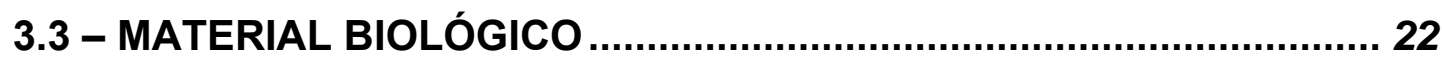

3.4 - MÉTODOS

3.4.1 - Isolamento de RNA e Síntese de DNAc..................................... 22

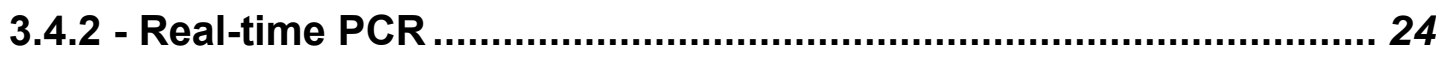

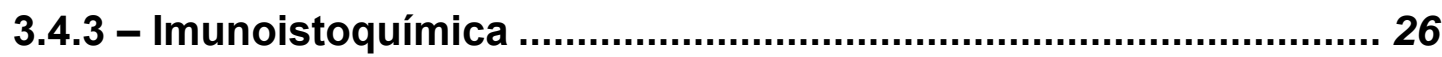

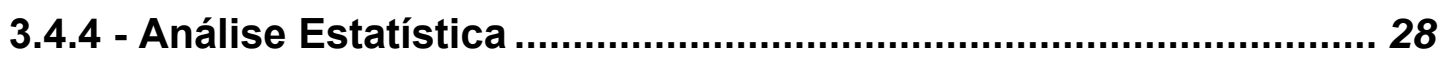

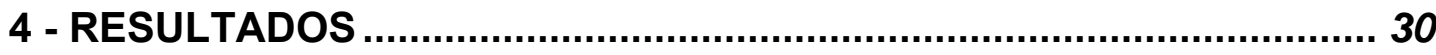

4.1 - RESULTADOS CLÍNICOS ............................................................ 30

4.1.1 - Dados demográficos dos pacientes e doadores ........................ 30

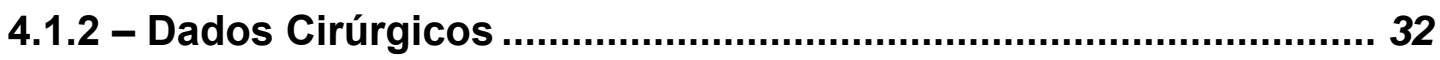


4.1.3 - Avaliação da função renal

4.1.4 -Área sob a curva de creatinina ( $\mathrm{ASC}_{\mathrm{cr}}$ ) e dados demográficos .. 36

4.1.5 - Função retardada do enxerto (FRE) e função retardada do enxerto funcional (FREF) e dados demográficos

4.1.6 - Tempo de isquemia quente (TIQ) e função retardada do enxerto (FRE) e função retardada do enxerto funcional (FREF.

4.1.7 - Tempo de isquemia quente (TIQ) e área sob a curva de

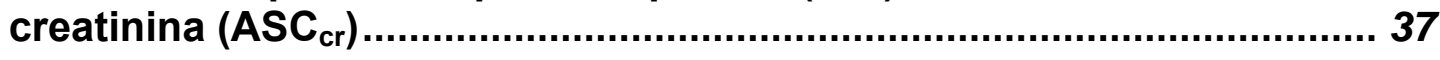

4.2 - EXPRESSÃO DE RNA .......................................................... 38

4.2.1 - Padronização e viabilidade das amostras ……........................ 38

4.2.2 - Expressão de RNA de genes antiapoptóticos e citoprotetores. 40

4.2.3 - Expressão de RNA de genes inflamatórios e de transcrição.... 50

4.2.4 - Expressão dos genes e dados cirúrgicos e clínicos .................... 58

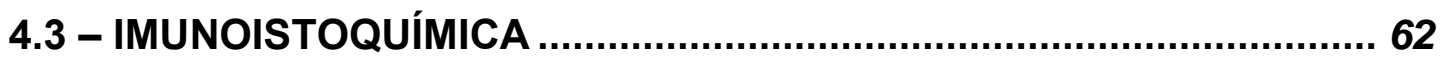

4.3.1- Bcl-2

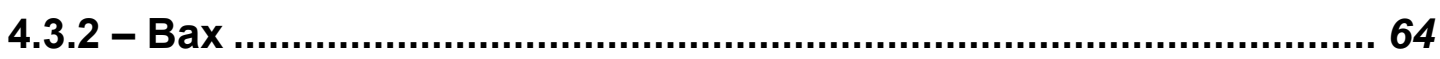

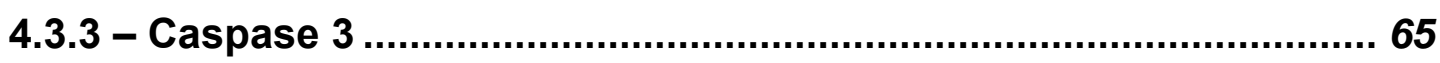

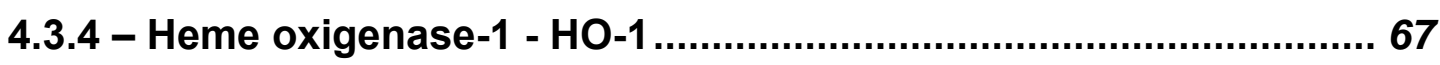

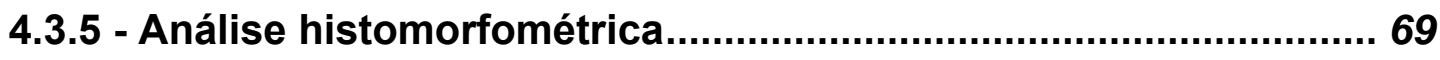

4.3.6 -Expressão protéica (imunoistoquímica) e resultados clínicos... 72

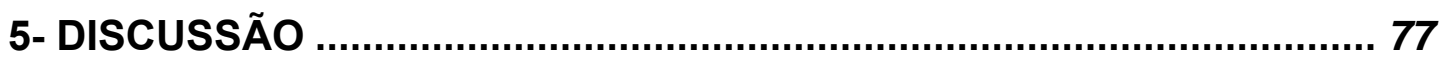

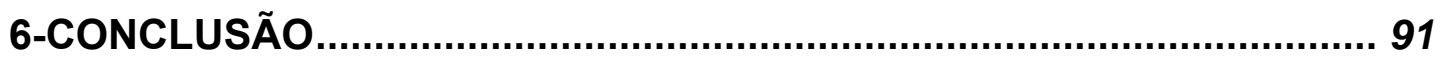

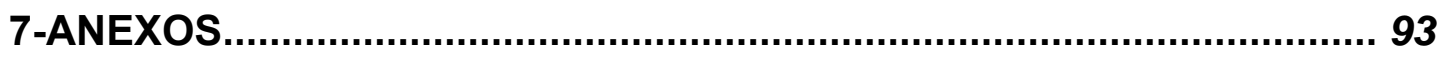

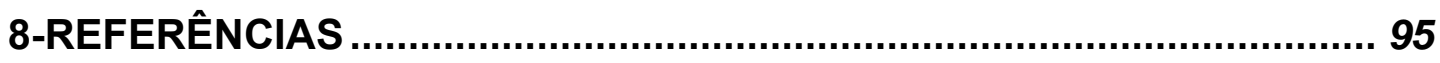

Apêndices 


\section{Lista de Figuras}

Figura 1: Panorama das vias de apoptose: em decorrência de estímulos de estresse celular como hipóxia, a via intrínseca mitocondrial é ativada pela translocação da proteína Bax para a membrana mitocondrial, que provoca permeabilização da mitocôndria e liberação de citocromo c, que se associa a caspase-9 e Apaf-1 para formar o apoptossoma e estimular a caspase-3. A via extrínseca é iniciada ao se acionar os receptores de morte celular Fas ou TNFR, os quais vão ativar a caspase 8 , que por sua vez ativa a caspase-3.

Figura 2: Ação da HO-1 sobre o radical heme, formando seus metabólitos com seus efeitos protetores celulares.

Figura 3: Momento da realização das biópsias de acordo com a dinâmica do transplante, representando os momentos de isquemia e reperfusão. TIQ=tempo de isquemia quente.

Figura 4: A) Incisão de lombotomia clássica (Hospital Santa Casa de Misericórdia de Curitiba) e B) Incisão subcostal (HCFMUSP) ..................................................20

Figura 5: Posicionamento do paciente na cirurgia laparoscópica 21

Figura 6: Distribuição do trocárter primário e trocárteres secundários $-(X)=5 \mathrm{~mm}$, (0) $=10 \mathrm{~mm}$ e posição da incisão de Pfannentiel.

Figura 7: RNA total em gel de agarose $1 \%$ de amostras submetidas a isolamento de RNA por meio de TRizol, demonstrando integridade do RNA.

Figura 8: Curva da média e desvio padrão da creatinina no pós-operatório. 36

Figura 9: Diagrama de dispersão para tempo de isquemia quente (TIQ) e área sob a curva de creatinina $\left(\mathrm{ASC}_{\mathrm{cr}}\right)$ no grupo aberta.

Figura 10: Diagrama de dispersão para tempo de isquemia quente (TIQ) e área sob a curva de creatinina $\left(\mathrm{ASC}_{\mathrm{cr}}\right)$ no grupo laparoscópica....

Figura 11: Valores individuais para $\Delta \mathrm{Ct}$ do gene $\mathrm{Bcl}-2$ nos grupos aberta $(A B)$ e laparoscópica (LAP) em seus respectivos momentos $\mathrm{T}-1=$ momento após retirada e $T+1=$ momento após reperfusão

Figura 12: Observação da cinética da expressão de RNAm do gene Bcl-2 através do $\Delta$ Ct nos grupos aberta (AB) e laparoscópica (LAP).

Figura 13: Expressão do gene $\mathrm{Bcl}-2$ no momento $\mathrm{T}+1$ avaliada pelaQR em relação ao momento $\mathrm{T}-1$, mostrando valores abaixo de 0,5 (diminuição da expressão) e maiores que 2 (aumento da expressão).

Figura 14 : Valores individuais para $\Delta C t$ do gene Hsp70 nos grupos aberta $(A B)$ e laparoscópica (LAP) em seus respectivos momentos $\mathrm{T}-1=$ momento após retirada e $\mathrm{T}+1=$ momento após reperfusão 
Figura 15: Observação da cinética da expressão de RNAm do gene Hsp70 através do $\Delta \mathrm{Ct}$ nos grupos aberta (AB) e laparoscópica (LAP).

Figura 16: Expressão do gene Hsp70 no momento $T+1$ avaliada pela $Q R$ em relação ao momento $T-1$, mostrando valores abaixo de 0,5 (diminuição da expressão) e maiores que 2 (aumento da expressão), com grande variabilidade...45

Figura 17: Valores individuais para $\triangle C$ t do gene VEGF nos grupos aberta $(A B)$ e laparoscópica (LAP) em seus respectivos momentos $\mathrm{T}-1=$ momento após retirada e $\mathrm{T}+1=$ momento após reperfusão

Figura 18: Observação da cinética da expressão de RNAm do gene VEGF através do $\Delta \mathrm{Ct}$ nos grupos aberta (AB) e laparoscópica (LAP).

Figura 19: Expressão do gene VEGF no momento $T+1$ avaliada pela $Q R$ em relação ao momento $T-1$, mostrando valores abaixo de 0,5 (diminuição da expressão) e maiores que 2 (aumento da expressão) ...........................................47

Figura 20: Valores individuais para $\triangle \mathrm{Ct}$ do gene $\mathrm{HO}-1$ nos grupos aberta $(A B)$ e laparoscópica (LAP) em seus respectivos momentos $\mathrm{T}-1=$ momento após retirada e $\mathrm{T}+1=$ momento após reperfusão

Figura 21: Observação da cinética da expressão de RNAm do gene HO-1 através do $\Delta$ Ct nos grupos aberta (AB) e laparoscópica (LAP)

Figura 22: Expressão do gene HO-1 no momento $T+1$ avaliada pela $Q R$ em relação ao momento $T-1$, mostrando valores abaixo de 0,5 (diminuição da expressão) e maiores que 2 (aumento da expressão). 50

Figura 23: Valores individuais para $\triangle \mathrm{Ct}$ do gene TNFa nos grupos aberta $(A B)$ e laparoscópica (LAP) em seus respectivos momentos $\mathrm{T}-1=$ momento após retirada e $\mathrm{T}+1=$ momento após reperfusão

Figura 24: Observação da cinética da expressão de RNAm do gene TNFa através do $\Delta$ Ct nos grupos aberta (AB) e laparoscópica (LAP).

Figura 25: Expressão do gene TNFa no momento $T+1$ avaliada pela $Q R$ em relação ao momento $T-1$, mostrando valores abaixo de 0,5 (diminuição da expressão) e maiores que 2 (aumento da expressão).

Figura 26: Valores individuais para $\triangle C t$ do gene II-6 nos grupos aberta $(A B)$ e laparoscópica (LAP) em seus respectivos momentos T-1=momento após retirada e $\mathrm{T}+1=$ momento após reperfusão

Figura 27: Observação da cinética da expressão de RNAm do gene IL-6 através do $\Delta$ Ct nos grupos aberta (AB) e laparoscópica (LAP).

Figura 28: Expressão do gene IL-6 no momento $T+1$ avaliada pela $Q R$ em relação ao momento $\mathrm{T}-1$, mostrando valores abaixo de 0,5 (diminuição da expressão) e maiores que 2 (aumento da expressão). 
Figura 29: Valores individuais para $\triangle \mathrm{Ct}$ do gene HIF1a nos grupos aberta $(A B)$ e laparoscópica (LAP) em seus respectivos momentos $\mathrm{T}-1=$ momento após retirada e $T+1=$ momento após reperfusão

Figura 30: Observação da cinética da expressão de RNAm do gene HIF1 $\alpha$ através do $\Delta$ Ct nos grupos aberta (AB) e laparoscópica (LAP)

Figura 31: Expressão do gene HIF1a no momento $T+1$ avaliada pela $Q R$ em relação ao momento $T-1$, mostrando valores abaixo de 0,5 (diminuição da expressão) e maiores que 2 (aumento da expressão)........................................5

Figura 32: Diagramas de dispersão para os genes Bcl2, HO1, HIF,Hsp70, VEGF, TNF e IL6 e TIQ (tempo de isquemia quente).

Figura 33: Diagramas de dispersão para os genes Bcl2, HIF1a, HO1, Hsp70,

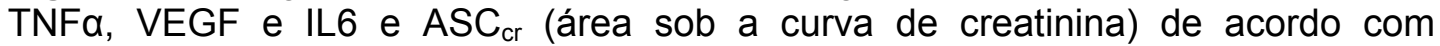
respectivos momentos isquemia ( $T-1)$ e reperfusão $(T+1)$.

Figura 34: Reação de imunoistoquímica positiva para $\mathrm{Bcl}-2$ em células de túbulos renais. Magnificação 400x.

Figura 35: Médias \pm 1 desvio padrão para $\mathrm{Bcl}-2$ (sem diferença estatística, ANOVA), comparando-se os grupos e respectivos momentos

Figura 36: Reação de imunoistoquímica positiva para Bax em células de túbulos renais. Magnioficação 400x.

Figura 37: Médias \pm 1 desvio padrão para Bax comparando os grupos e momentos sem diferença estatística (ANOVA)....

Figura 38: A) Reação de imunoistoquímica negativa para Caspase-3, B) Positividade focal da Caspase-3 em células de túbulos renais. Magnificação $400 \mathrm{x}$

Figura 39: Comparação de positividade de Caspase-3 entre os grupos e momentos $\mathrm{T}-1$ (após retirada) e T+1 (após reperfusão).

Figura 40: Reação de imunoistoquímica apresentando positividade para $\mathrm{HO}-1 \mathrm{em}$ células de túbulos renais. Magnificação 400x.

Figura 41: Comparação de positividade de HO-1 entre os grupos aberta $(A B)$ e laparoscópica (LAP) e momentos T-1 (após retirada) e T+1 (após reperfusão) .......68

Figura 42: Exemplos histológicos de NTA focal (A), NTA moderada (B) e NTA difusa (C) em biópsias de tempo T-1. 


\section{Lista de Tabelas}

Tabela 1 - Seqüência dos nucleotídeos utilizada.

Tabela 2 - Dados demográficos e Características clínicas dos receptores

Tabela 3 - Características demográficas e clínicas dos doadores no momento do transplante.

Tabela 4 - Dados cirúrgicos no momento do transplante

Tabela 5 - Função retardada do enxerto e função retardada do enxerto funcional .34

Tabela 6 - Função renal avaliada pelos níveis de creatinina no pós-operatório nos grupos aberto vs laparoscópico

Tabela 7 - Valores de QR de Bcl-2 para cirugia laparoscópica, com relação à cirurgia aberta

Tabela 8 - Valores de QR de Hsp70 para cirugia laparoscópica, com relação à cirurgia aberta

Tabela 9 - Valores de QR de VEGF para cirugia laparoscópica, com relação à cirurgia aberta

Tabela 10 - Valores de QR de HO-1 para cirugia laparoscópica, com relação à cirurgia aberta

Tabela 11 - Valores de QR de TNFa para cirugia laparoscópica, com relação à cirurgia aberta.

Tabela 12 - Valores de QR de II-6 para cirugia laparoscópica, com relação à cirurgia aberta

Tabela 13 - Valores de QR de HIF1a para cirugia laparoscópica, com relação à cirurgia aberta

Tabela 14 - Expressão gênica dos genes testados no grupo laparoscópica em relação ao grupo aberta e o momento T-1.

Tabela 15 - Coeficientes de correlação de Pearson para os valores de QR em relação aos genes e tempo de isquemia quente.

Tabela 16 - Coeficientes de correlação linear de Pearson entre os genes testados e ASC (área sob a curva de creatinina) na cirurgia laparoscópica

Tabela 17 - Valores da média para Bcl-2 nos grupos de cirurgia aberta e laparoscópica nos momentos $\mathrm{T}-1$ (após retirada) e $\mathrm{T}+1$ (após reperfusão) .63 
Tabela 18 - Valores da média para Bax nos grupos de cirurgia aberta e laparoscópica nos momentos T-1 (após retirada) e T+1 (após reperfusão). 65

Tabela 19 - Achados histológicos nos pacientes do Hospital das Clínicas da FMUSP e correlação com evento clínico de retardo da função renal 71

Tabela 20 - Coeficiente de correlação linear de Pearson entre tempo de isquemia quente e expressão das proteínas Bax e Bcl2 no grupo aberta nos momentos T-1 e $\mathrm{T}+1$.

Tabela 21 - Coeficiente de correlação linear de Pearson entre tempo de isquemia quente e expressão das proteínas Bax e Bcl2 no grupo laparoscópica nos momentos $\mathrm{T}-1$ e $\mathrm{T}+1$. .

Tabela 22 - Resultados para associação de Caspase e tempo de isquemia quente, comparando os grupos de cirurgia e respectivos momentos $\mathrm{T}-1$ e $\mathrm{T}+1$.

Tabela 23 - Resultados associação de HO-1 e tempo de isquemia quente, comparando os grupos de cirurgia e respectivos momentos

Tabela 24 - Correlações de Pearson entre cirurgias, respectivos momentos e nível descritivo do teste - ASC $_{\mathrm{cr}}$ (área sob a curva de creatinina)

Tabela 25 - Resultados para associação de Caspase 3 e ASC $_{\text {cr }}$ (área sob a curva de creatinina) entre os grupos de cirurgia e momentos avaliados.

Tabela 26 - Resultados para associação de HO-1 e ASC $_{c r}$ (área sob a curva de creatinina) entre os grupos de cirurgia e momentos avaliados. 


\section{RESUMO}

Machado C. Estudo comparativo da resposta protetora do tecido renal em rins de doadores vivos submetidos à nefrectomia laparoscópica ou aberta na doação de órgãos (tese). São Paulo: Faculdade de Medicina, Universidade de São Paulo; 2011. 106p

INTRODUÇÃO: Estudos iniciais observaram um funcionamento mais lento do enxerto renal na primeira semana em rins retirados por laparoscopia. Todavia, a sobrevida do enxerto de cirurgia laparoscópica a longo prazo parece ser semelhante quando comparada à cirurgia aberta. Estudos experimentais sugerem que a cirurgia laparoscópica possa exercer uma ação sobre a lesão de isquemia e reperfusão, porém até o momento seus efeitos na expressão tecidual de fatores protetores e inflamatórios são pouco conhecidos. OBJETIVO: Avaliar a expressão tecidual de fatores protetores e inflamatórios em rins extraídos de doadores vivos, por cirurgia laparoscópica ou aberta, em dois diferentes momentos da cirurgia do transplante: após a retirada do rim e após a reperfusão e correlacionar estes achados com a função do enxerto renal por meio da medida da creatinina sérica no pósoperatório. CASUíSTICA E MÉTODOS: Foram analisados pacientes transplantados renais submetidos a biópsias renais em 2 momentos, logo após a retirada do rim (T-1) e 45 min após reperfusão $(T+1)$. Compararamse dois grupos: pacientes que receberam rins de nefrectomia laparoscópica e receptores de rins provenientes de cirurgia aberta. Foram analisados os dados clínicos e a função renal através da medida da creatinina sérica do $1^{\circ}$ ao $7^{\circ} \mathrm{dia}, 30^{\circ} \mathrm{dia}, 3^{\circ}$ e $6^{\circ}$ mês pós-operatório. A expressão de RNAm de Bcl2, Hsp70, HO-1, VEGF, TNFa, IL-6 e HIF1a foi quantificada por PCR em tempo real, e a expressão protéica de $\mathrm{HO}-1, \mathrm{Bcl}-2$, Caspase 3 e BAx foram analisadas por imunoistoquímica. RESULTADOS: Foram analisados 55 receptores renais, dos quais em 29 pacientes o enxerto era proveniente de nefrectomia aberta e em 26 pacientes o rim doado foi retirado por via laparoscópica. O tempo de isquemia quente foi maior no grupo laparoscópico $(p=0,005)$. A função renal medida pela área sob a curva de creatinina $\left(\mathrm{ASC}_{\mathrm{cr}}\right)$ e a incidência de retardo de função do enxerto renal no pós-operatório foi semelhante entre os grupos. Com relação à expressão dos fatores protetores ou inflamatórios não houve diferença entre os grupos aberta e laparoscópica. Porém, houve uma menor expressão gênica no grupo laparoscópico no momento após a reperfusão $(T+1)$ dos fatores $\mathrm{Bcl}-2$ $(p=0,007)$ e VEGF $(p=0,034)$. Observou-se uma correlação de VEGF e ASC $_{\text {cr }}$ (Pearson $r=0,885 ; p=0,019$ ) e de HO-1 e tempo de isquemia quente (Pearson $r=0,773 ; p=0,042$ ).CONCLUSÕES: Não houve diferença entre o grupo aberta e laparoscópica com relação à expressão de fatores protetores e inflamatórios da lesão de isquemia e reperfusão. No grupo laparoscópica, houve redução da expressão gênica de Bcl-2 e VEGF após reperfusão. Além disso, a expressão gênica de VEGF após reperfusão está associada a um declínio mais lento da creatinina.

Descritores: 1.Transplante de rim 2.Traumatismo por reperfusão 3.Expressão gênica 4.Apoptose 5.Laparoscopia 6.Estudo comparativo 


\section{SUMMARY}

Machado C. Comparative study of renal tissue protective response in living donors kidneys that undergone laparoscopic or open nephrectomy in organ donation (thesis). São Paulo:"Faculdade de Medicina, Universidade de São Paulo"; 2011. 106p

INTRODUCTION: Laparoscopically harvested kidneys regain normal function slowly than open recruited organs. However, long term graft survival seems to be similar between two approaches. Experimental studies suggest that laparoscopic surgery may play a role in ischemia reperfusion injury, but at this moment its effects in tissue expression of protective and inflammatory factors are unknown. OBJECTIVES: Evaluate tissue expression of protective and inflammatory factors in living donor kidneys harvested by laparoscopic or open surgery at two time points: after kidney retrieval and after reperfusion and correlate these findings with renal allograft function through postoperative serum creatinine level. METHODS: It was analyzed live renal recipients submitted to renal biopsies at two time points, after kidney retrieval $(\mathrm{T}-1)$ and $45 \mathrm{~min}$ after reperfusion $(\mathrm{T}+1)$. Two groups were compared: patients that received kidneys from laparoscopic nephrectomy and recipients of kidneys from open surgery. It was analyzed clinical data and renal function through serum creatinine level of $1^{\text {st }}$ to $7^{\text {th }}$ day, $30^{\text {th }}$ day, $3^{\text {rd }}$ and $6^{\text {th }}$ postoperative month. The mRNA expression of Bcl-2, Hsp70, HO-1, VEGF, TNFa, IL-6 e HIF1 $\alpha$ were quantified by real time PCR, and protein expression of HO-1, Bcl-2, Caspase 3 and Bax were analyzed by immunohistochemistry. RESULTS: Fifty five recipients were analyzed, twenty nine patients from open nephrectomy and twenty six patients from laparoscopic nephrectomy. We observed warm ischemia time was longer in laparoscopic donor nephrectomy than open donor nephrectomy $(p=0,005)$. The renal function measured by area under curve of creatinine and incidence of delayed graft function were similar in laparoscopic and open groups. There was no difference in protective and inflammatory gene expression between groups, but in laparoscopic group, mRNA expression of Bcl-2 and VEGF have been decreased after reperfusion in comparison to moment $T-1(p=0,007, p=0,034$, respectively). Furthermore, $\mathrm{HO}-1$ was correlated with warm ischemia time (Pearson $r=0,773, p=0,042$ ) and VEGF was correlated with creatinine AUC (Pearson $r=0,885 ; p=0,019)$.CONCLUSION: Protective and inflammatory factors of ischemia reperfusion injury were not different between open and laparoscopic groups. In laparoscopic group, there was a lower gene expression of $\mathrm{Bcl}-2$ and VEGF after reperfusion. The mRNA expression of VEGF after reperfusion was correlated with slow decline of creatinine.

Descriptors: 1. Kidney transplantation 2. Reperfusion injury 3. Gene expression 4. Apoptosis 5. Laparoscopy 6. Comparative Study 


\section{1 - INTRODUÇÃO}




\section{1- INTRODUÇÃO}

\section{1- NEFRECTOMIA LAPAROSCÓPICA PARA DOAÇÃO RENAL}

Apesar da cirurgia de transplante renal ser realizada há aproximadamente 50 anos, ainda há uma grande carência de órgãos disponíveis, levando a uma grande espera para receber um rim de doador falecido. Mesmo com a utilização cada vez maior de doadores cadavéricos limítrofes, é indispensável utilizar-se de doadores vivos ${ }^{(1)}$, portanto há grande necessidade de incentivo à doação intervivos.

Tradicionalmente, a retirada do rim na doação intervivos vinha sendo realizada exclusivamente por meio de nefrectomia aberta. Embora relativamente segura, a nefrectomia aberta causa ao doador um grau de morbidade significativo, o que muitas vezes pode dissuadi-lo de realizar o procedimento. Atualmente, utiliza-se também a nefrectomia laparoscópica como técnica para retirada dos rins de doadores vivos. A partir da primeira nefrectomia de doador laparoscópica, realizada em 1995 e após progressivas modificações da técnica, este novo método evoluiu e ganhou

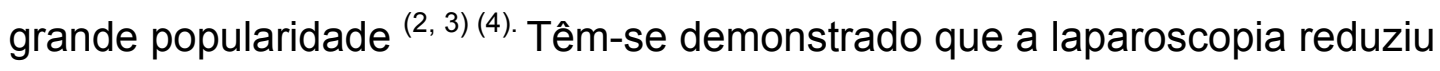
de forma significativa a necessidade de uso de analgésicos parenterais e orais em vista da mudança do local e do tamanho da incisão ${ }^{(5,6)}$. Com isso, a estadia hospitalar foi reduzida e o retorno ao trabalho também ocorre de maneira mais precoce do que na cirurgia aberta ${ }^{(7)}$. Além disso, a utilização de uma incisão menor do tipo Pfannenstiel para a retirada do rim resulta em uma cicatriz esteticamente mais favorável ${ }^{(8)}$. Assim, a nefrectomia de doador laparoscópica vem substituindo o método convencional em centros de excelência devido às vantagens que apresenta ${ }^{(9)}$.

O Hospital das Clínicas da Faculdade de Medicina da USP HCFMUSP é pioneiro no Brasil neste procedimento, tendo iniciado sua experiência em nefrectomia laparoscópica para doação em 2000. Nos primeiros 50 casos realizados, os resultados cirúrgicos iniciais foram bastante favoráveis. Observou-se um tempo médio de cirurgia de 179,5 min, 
tempo de isquemia quente de 227,4 segundos e sangramento médio estimado de $141,1 \mathrm{ml}$. A cirurgia foi bem tolerada pelos pacientes, exceto em dois pacientes que necessitaram opióides para controle da dor no período pós-operatório, todos os demais utilizaram apenas dipirona sódica via oral como analgésico ${ }^{(10)}$.

Embora já seja amplamente utilizada, a nefrectomia laparoscópica tem recebido críticas, pois este procedimento esteve mais relacionado a complicações ureterais, tempo de isquemia prolongado e recuperação mais lenta do enxerto renal ${ }^{(11)}$. Em uma análise de 735 pacientes submetidos à nefrectomia laparoscópica com sucesso, Jacobs et al $^{(12)}$ observaram retardo da função do enxerto em $13,3 \%$. Neste estudo, os autores consideraram retardo da função do enxerto a falha em alcançar níveis de creatinina menor que $3 \mathrm{mg} / \mathrm{dl} \mathrm{em} 7$ dias. Interessante notar que alguns centros nacionais têm experiência diferente com relação à evolução da função renal. No Hospital Santa Casa de Misericórdia de Curitiba, a comparação da função renal de 60 enxertos renais retirados por laparoscopia e 49 casos de nefrectomia aberta mostrou que o clearance de creatinina calculado foi semelhante entre os grupos. A média do clearance de creatinina no $5^{\circ}$ dia pós-operatório foi de $65,33 \mathrm{ml} / \mathrm{min} / 1,73 \mathrm{~m}^{2}$ nos pacientes que receberam o rim extraído por cirurgia laparoscópica e $69,56 \mathrm{ml} / \mathrm{min} / 1,73 \mathrm{~m}^{2}$ nos casos de cirurgia aberta $^{(13)}$. Ademais, estudos recentes tem demonstrado resultados funcionais equivalentes entre cirurgia laparoscópica e aberta com relação a creatinina no $7^{\circ}$ dia, primeiro mês e um ano, além de retardo da função renal e sobrevida do enxerto no primeiro ano sem diferença estatística entre as técnicas laparoscópica e aberta ${ }^{(14)}$.

\section{2- LESÃO DE ISQUEMIA E REPERFUSÃO}

\subsection{1- Fisiopatogenia}

A lesão de isquemia e reperfusão é um fenômeno complexo, inerente ao transplante de órgãos e que envolve uma série de eventos isquêmicos e 
inflamatórios ocorridos durante o período de retirada, preservação, implantação e reperfusão do enxerto ${ }^{(15)}$. Acredita-se que a cascata de eventos iniciada durante a isquemia do enxerto seja potencializada pela resposta inflamatória deflagrada pela reoxigenação do tecido, agravando ainda mais os danos sobre a microcirculação e os túbulos renais.

Durante o período de isquemia, ao ocorrer privação prolongada de oxigênio no tecido renal, há depleção de ATP intracelular com prejuízo da capacidade de manutenção do potencial de membrana e excitabilidade celular, que ocasiona um influxo de sódio e água em grande quantidade para o citoplasma, produzindo edema ${ }^{(16,17)}$. Da mesma forma, as organelas citoplasmáticas, tais como retículo endoplasmático, complexo de Golgi e mitocôndrias também têm suas membranas alteradas resultando em aumento da sua permeabilidade ${ }^{(18)}$. O edema das células endoteliais por sua vez contribui para a obstrução capilar prolongando a isquemia local ${ }^{(19)}$. No momento iniciais da isquemia observa-se uma sobrecarga de cálcio intracelular devido à redistribuição de cálcio das reservas do retículo endosplamático. O excesso de cálcio intracelular é um dos fatores chaves na lesão hipóxica das células epiteliais renais, já que pode ativar proteases, fosfolipases, óxido nítrico sintetases e endonucleases que por sua vez podem provocar danos ao citoesqueleto, lesar proteínas celulares e de membrana e causar degradação de DNA ${ }^{(20)}$.

Na reperfusão do enxerto, a expressão de moléculas de adesão e a liberação de espécies reativas de oxigênio e citocinas pró-inflamatórias aumentam a adesão, infiltração e a ativação de leucócitos ${ }^{(21,22)}$. Após recrutamento e ativação, os leucócitos liberam mais radicais livres de oxigênio e mediadores pró-inflamatórios, gerando desta maneira um ciclo inflamatório na microcirculação ${ }^{(23-25)}$.

O dano causado à microcirculação é um importante mecanismo fisiopatológico no processo crônico de deterioração da função renal após a lesão de isquemia e reperfusão. Em modelos experimentais, tem-se demonstrado que a isquemia de rins nativos pode levar à redução permanente dos capilares peritubulares, associado a alterações na 
capacidade de concentração renal e desenvolvimento de fibrose intersticial (26).

\subsection{2- Apoptose}

A apoptose representa um dos fatores de morte celular tubular associados à lesão de isquemia e reperfusão e várias moléculas estão envolvidas na sua gênese. Existem duas vias intracelulares que desencadeiam a apoptose: 1) perturbação da homeostasia intracelular (via intrínseca) e 2) ligação a receptores de morte da membrana plasmática (via extrínseca) (Figura1).

A via intrínseca é regulada pela família $\mathrm{Bcl}-2$, que comumente é dividida em três classes. Um classe inibidora da apoptose (Bcl-2, $\mathrm{Bcl}-\mathrm{xL})$ e uma segunda classe que promove a apoptose (Bax e BAK) e uma terceira classe de moléculas que mantém somente um domínio BH3 (BID, BAD) que ao se ligar com as proteínas BcL-2, regula a função destas proteínas, inativando membros antiapoptóticos ${ }^{(27)}$.

$\mathrm{Na}$ via intrínseca há o envolvimento de organelas intracelulares, principalmente a mitocôndria. Em células renais hipóxicas, a proteína Bax colabora para permeabilização da membrana mitocondrial externa, favorecendo a liberação de proteínas intermembrana como a citocromo C que inicia a cascata de apoptose ao facilitar a oligomerização do fator ativador da protease apoptótica 1 (Apaf-1) e caspase-9 no apoptosomo, resultando na ativação da caspase- 9 que é clivada e aciona as caspases efetoras ${ }^{(28)}$. O processo de apoptose se completa através da ativação das caspases efetoras 3, 6 e 7, que promovem a clivagem de vários substratos levando à fragmentação de DNA cromossomal e alterações morfológicas

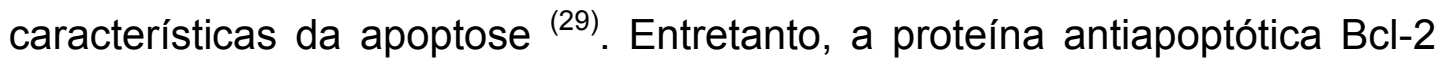
pode inibir a permeabilização mitocondrial e manter a viabilidade celular ${ }^{(30)}$.

$\mathrm{Na}$ via extrínseca, ocorre ativação dos receptores de morte celular (membros da família do fator de necrose tumoral, tais como Fas e TNFR-1) os quais recrutam e ativam a Caspase 8 , que subsequentemente aciona as 
caspases efetoras 3, 6 e 7, não havendo participação direta da família Bcl-2 (31).

Em rins transplantados, observou-se apoptose aumentada nos casos de disfunção precoce do enxerto comparada aos rins com funcionamento imediato. Este aumento da apoptose ocorreu devido ao aumento da expressão de proteínas pró-apoptóticas Bax e BAD e diminuição da expressão de proteínas antiapoptóticas $\mathrm{BcL}-2$ e Bcl-xL, além da liberação de citocromo $\mathrm{C}$ da mitocôndria para o citoplasma de células epiteliais tubulares (32). Outros estudos confirmam que a apoptose em transplante renal ocorre em grande parte pela via mitocondrial, com maior expressão de Bax, liberação de citocromo $\mathrm{C}$ no citoplasma em pacientes que recebiam o rim de doadores falecidos que naqueles de doadores vivos, havendo uma correlação entre tempo de isquemia fria e maior apoptose ${ }^{(33)}$. 
Via intrínseca

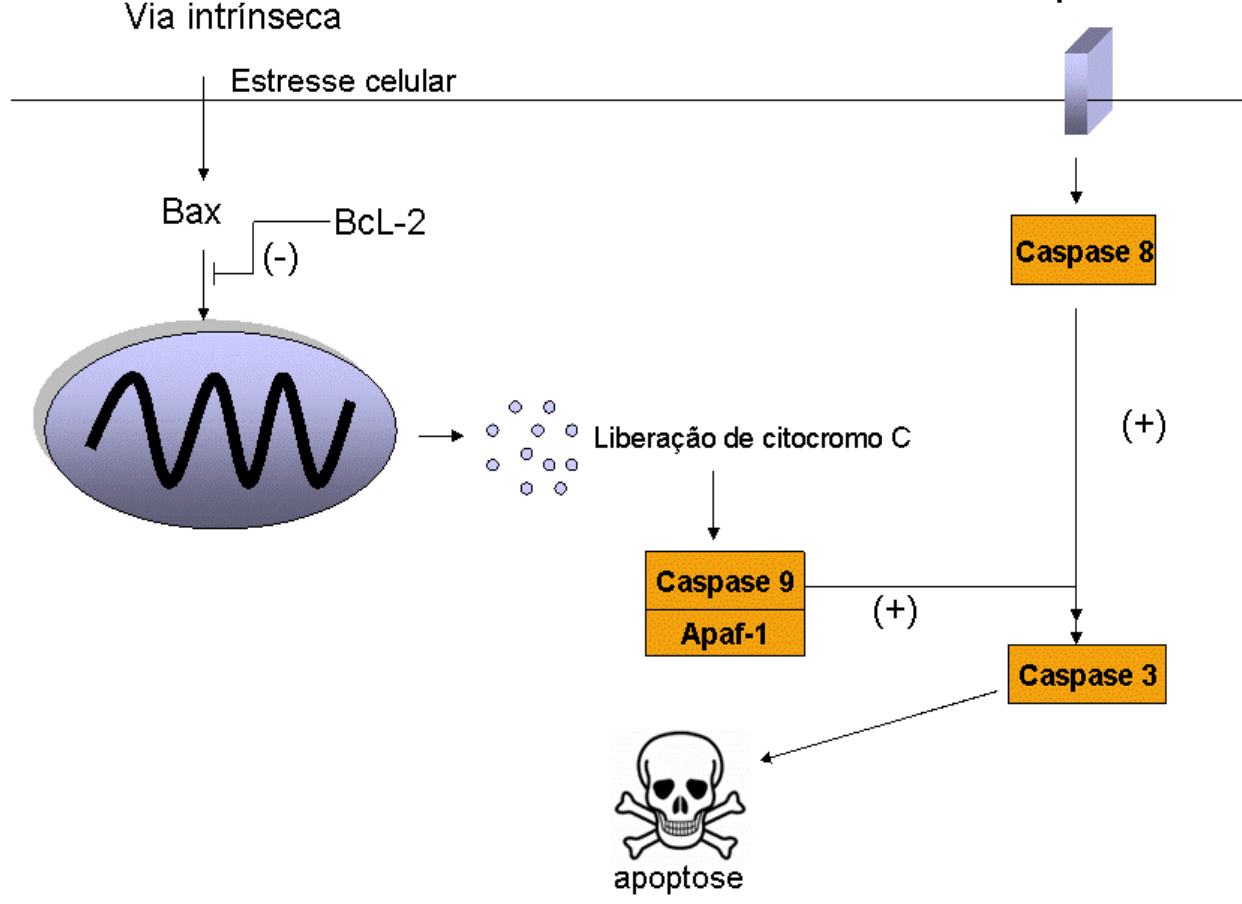

Figura 1: Panorama das vias de apoptose: em decorrência de estímulos de estresse celular como hipóxia, a via intrínseca mitocondrial é ativada pela translocação da proteína Bax para a membrana mitocondrial, que provoca permeabilização da mitocôndria e liberação de citocromo c, que se associa a caspase-9 e Apaf-1 para formar o apoptossoma e estimular a caspase-3. A via extrínseca é iniciada ao se acionar os receptores de morte celular Fas ou TNFR, os quais vão ativar a caspase 8 , que por sua vez ativa a caspase-3.

Adaptado de Youle, RL e Strasser, A. Mol Cell Biol. 2008; 9(1): 47-59

\subsection{FATORES PROTETORES}

Acredita-se que o dano final ao enxerto sofra influência não somente da intensidade da resposta inflamatória gerada durante a isquemia e reperfusão, mas também da resposta protetora adaptativa que o enxerto apresenta frente a esta condição. Potencialmente, uma resposta protetora apropriada poderia atenuar os eventos inflamatórios e reduzir os danos causados pela isquemia e reperfusão. 


\subsection{1-Heme-oxigenase-1 - HO-1}

O controle desta resposta protetora parece ser mediado pela expressão de uma série de proteínas, entre elas a heme-oxigenase-1 (HO1). O radical heme tem papel importante no dano celular, pois durante a lesão tecidual o excesso de heme catalisa a formação de radicais livres de oxigênio, que por sua vez promovem a ativação e acúmulo de células polimorfonucleares. No período de reperfusão o aumento de eritrócitos lesados aumenta a viscosidade e resistência do fluxo, com a lise de eritrócitos ocorre liberarão de hemoglobina e consequentemente de heme livre que exacerba o processo oxidativo ${ }^{(34)}$. A heme-oxigenase-1 é uma proteína de choque térmico (Hsp32) cuja ação enzimática é responsável pela conversão do heme em monóxido de carbono, $\mathrm{Fe}^{++}$e biliverdina (figura 2). Estes metabólitos exercem importantes funções antioxidante, antiinflamatória e antiapoptótica além de participar do controle do tônus vascular $(35,36)$

Em animais, o efeito citoprotetor da HO-1 durante a isquemia e reperfusão tem sido descrito em diferentes modelos de transplante de órgãos ${ }^{(37,38)}$. Soares et al ${ }^{(39)}$, estudando enxertos cardíacos, avaliaram que a expressão de gene da $\mathrm{HO}-1$ está funcionalmente associada à sobrevida do enxerto, Otterbein et $\mathrm{al}^{(40)}$ demonstraram que as propriedades antiinflamatórias do monóxido de carbono poderiam servir como base para citoproteção atribuída à HO-1. Katori et al $^{(41)}$ induziram ao aumento da expressão de HO-1 em ratos por meio de metaloporfirinas, produzindo um aumento de fatores antiapoptóticos Bcl-2 e Bag-1 e conseqüente redução da apoptose em transplantes de coração. Da mesma forma, Tullius et al ${ }^{(42)} \mathrm{e}$ Wagner et al $^{(43)}$ observaram em modelo de transplante renal uma melhora da função do enxerto e inibição da lesão de isquemia reperfusão através da indução de HO-1. 


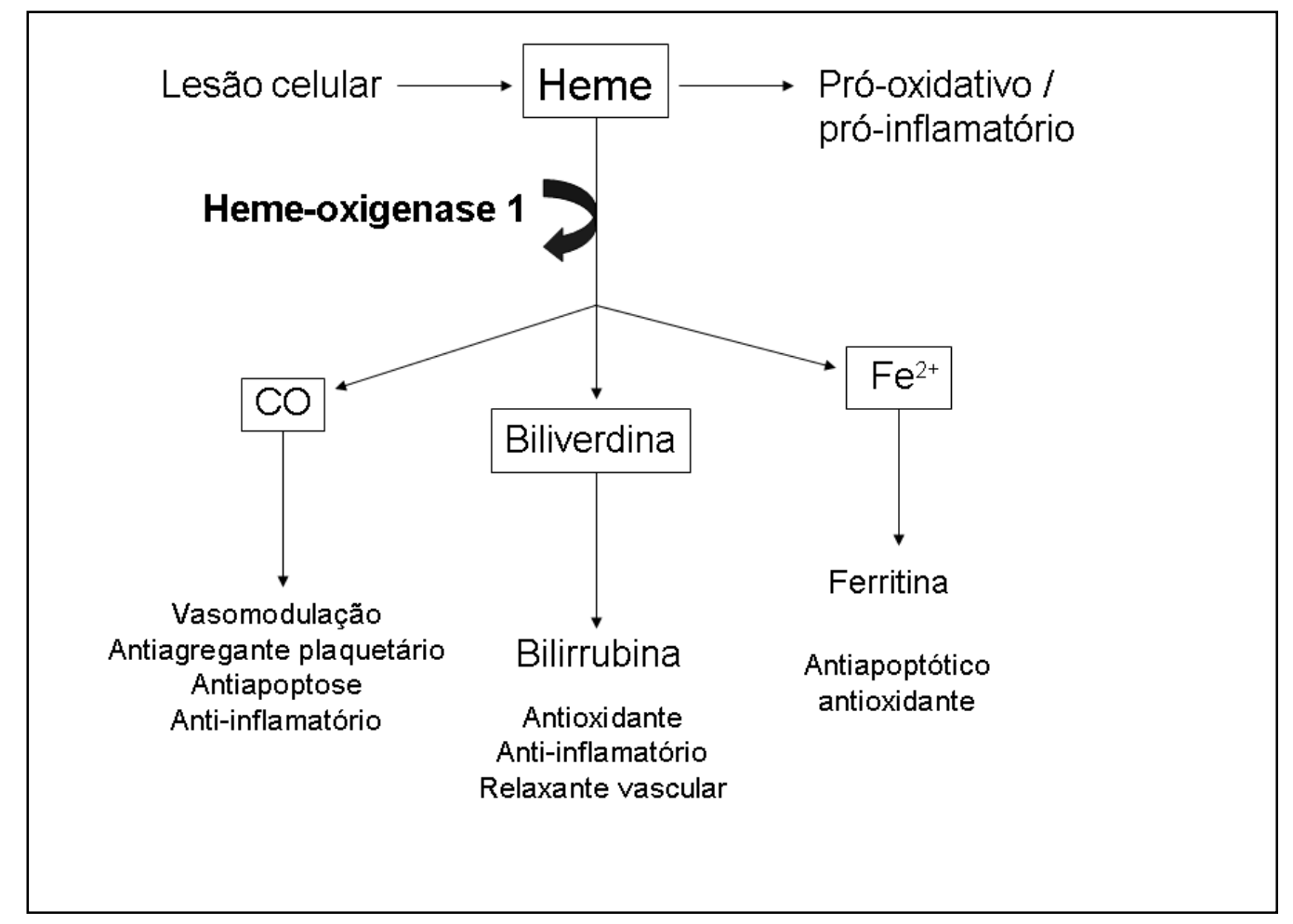

Figura 2: Ação da HO-1 sobre o radical heme, formando seus metabólitos com seus efeitos protetores celulares

\subsubsection{Proteína de choque térmico 70 - Hsp70}

A proteína de choque térmico 70 está envolvida em múltiplas funções celulares, tais como degradação de proteínas e mecanismos de sinalização celular, além disso, são chamadas chaperonas moleculares, ou seja, proteínas que medeiam a dobradura de outros peptídeos e a ligação delas a estruturas oligoméricas. As proteínas de choque térmico trabalham de forma a regular a resposta celular junto à mitocôndria para montar e desmontar estruturas e providenciar um serviço de transporte molecular para polipeptídeos. Ao auxiliar no transporte de outras proteínas imaturas previne o dobramento e acoplamento inadequado da estrutura, conferindo um caráter protetor às células ${ }^{(44)}$.

$\mathrm{Na}$ presença de isquemia renal, a Hsp70 pode conferir proteção contra apoptose por meio de sua função de chaperona além de colaborar 
com os mecanismos envolvidos na restauração da integridade do citoesqueleto e polaridade celular ${ }^{(45,}{ }^{46)}$. Estudos em animais têm demonstrado aumento da expressão de Hsp70 frente à lesão de isquemia e reperfusão ${ }^{(47,48)}$. Em biópsias de tempo zero, imediatamente antes da realização da anastomose vascular de transplantes renais humanos, observou-se uma correlação entre a expressão de Hsp70 e o tempo de isquemia fria, com maior expressão em tempos prolongados, fazendo crer que haja uma indução de Hsp70 no transplante renal ${ }^{(49)}$. Estudos experimentais com pré-condicionamento por hipertermia têm demonstrado uma ação benéfica protetora da Hsp70 na função renal de enxertos submetidos a essa técnica, e, portanto, o aumento de sua expressão pode auxiliar na prevenção da lesão de isquemia e reperfusão renal ${ }^{(50)}$.

\subsubsection{Fator de crescimento endotelial vascular - VEGF}

O VEGF é outro fator potencialmente envolvido na resposta protetora do rim, principalmente na preservação da integridade e reparo da microcirculação. A resolução da resistência vascular após isquemia e reperfusão é um componente importante na recuperação da lesão isquêmica renal e no restabelecimento da função renal. Por ser um fator indutor da angiogênese, o VEGF é crucial na manutenção dos capilares peritubulares, garantindo o aporte sanguíneo adequado para os túbulos renais e interstício ${ }^{(51-53)}$. A expressão de VEGF é regulada por diversos mecanismos, entre eles a redução da tensão de oxigênio, sendo que HIF-1a está intimamente implicado na ativação da transcrição do gene VEGF durante a hipóxia ${ }^{(54)}$. Em modelos de nefropatia crônica, a redução da expressão de VEGF está diretamente relacionada à diminuição da densidade de capilares peritubulares e o desenvolvimento de fibrose intersticial e atrofia tubular ${ }^{(55)}$. Estudos recentes observaram que a variabilidade do gene da HO-1 e do VEGF estão associados à sobrevida tardia do enxerto renal. Receptores de rim que eram altos produtores de VEGF ou que haviam recebido um rim de 
doador com perfil genético para alta produção de HO-1 apresentavam melhor sobrevida do enxerto após cinco anos de transplante renal ${ }^{(56,57)}$.

A resposta protetora do enxerto mostrou-se diferente em rins submetidos a tempos prolongados de isquemia fria. Rins de doadores cadavéricos, frequentemente expostos a longos períodos de isquemia fria, apresentam resposta adaptativa frente à lesão de isquemia e reperfusão significativamente menor comparada aos rins de doadores vivos ${ }^{(58)}$. A expressão de transcritos gênicos da HO-1 e do VEGF foi pelo menos três vezes menor nos rins de doadores cadavéricos comparado aos rins de doadores vivos.

\subsection{LAPAROSCOPIA E LESÃO DE ISQUEMIA E REPERFUSÃO}

Estudos experimentais endereçando a fisiologia renal durante a laparoscopia têm sido realizados com o intuito de elucidar aspectos funcionais da ação do pneumoperitônio sobre a lesão de isquemia e reperfusão renal. Durante o pneumoperitônio ocorre um aumento da pressão intra-abdominal que pode interferir na função renal, resultando em diminuição da taxa de filtração glomerular, redução do fluxo sanguíneo renal, menor perfusão cortical com oligúria transitória ${ }^{(59)}$. Além disso, sabe-se que outros estímulos levam ao aumento da vasoconstrição renal e podem contribuir com as alterações hemodinâmicas renais, tais como o aumento da resposta neuroendócrina devido à elevação da secreção de hormônio antidiurético, estímulo simpático causado por acidose respiratória, ou por elevação de endotelina-1 ${ }^{(60)}$. Burgos et al $^{(61)}$ observaram em porcos submetidos à nefrectomia laparoscópica para autotransplante, uma redução do fluxo sanguíneo renal intraoperatório e revascularização mais lenta após isquemia fria de 24 horas, quando comparado ao grupo controle (cirurgia aberta). Além disso, neste estudo foi observada a diminuição mais vagarosa da creatinina na primeira semana após o transplante.

O efeito da cirurgia laparoscópica na resposta inflamatória após o transplante tem sido investigado por alguns autores. Estudos mostram que 
na cirurgia laparoscópica ocorre redução de citocinas séricas e peritoniais em comparação à cirurgia aberta, porém sua repercussão no transplante renal ainda não foi estabelecida ${ }^{(62,63)}$. Kurian et al ${ }^{(64)}$ encontraram expressão de vários genes ligados à inflamação aguda e lesão de isquemia em biópsias renais de pacientes submetidos à nefrectomia laparoscópica de doador, que potencialmente poderiam resultar em lesão renal e resposta imune aumentada no enxerto pós-transplante. A lesão de isquemia e reperfusão pode induzir ao aumento de imunogenicidade de órgãos por aumentar a expressão de moléculas de apresentação de antígenos ${ }^{(65)}$. Este mecanismo exemplifica uma das vias pela qual a lesão de isquemia e reperfusão pode predispor à rejeição aguda e nefropatia crônica do enxerto.

Por fim, há evidências que, em razão do pneumoperitônio, ocorra um aumento do estresse oxidativo em decorrência da redução do fluxo arterial e venoso esplâncnico, merecendo estudos mais detalhados quanto a alterações teciduais de fatores relacionados à lesão de isquemia e reperfusão ${ }^{(66,67)}$. Além do mais, a cirurgia laparoscópica, apesar de amplamente utilizada para doação renal, não foi ainda estudada quanto à interferência sobre fatores protetores da lesão de isquemia e reperfusão. Justifica-se, portanto, a investigação da expressão de fatores protetores já que a compreensão destas questões pode trazer grande contribuição ao entendimento e manejo da isquemia e reperfusão do enxerto renal durante o procedimento de cirurgia laparoscópica. 


\section{2 - OBJETIVOS}




\section{2 - OBJETIVOS}

\section{1- OBJETIVO PRIMÁRIO}

Avaliar a expressão tecidual de genes protetores e inflamatórios antes e após a preservação do enxerto renal de doadores vivos submetidos à nefrectomia laparoscópica e aberta.

\section{2- OBJETIVOS SECUNDÁRIOS}

a) Avaliar a expressão tecidual de fatores protetores e inflamatórios em rins extraídos de doadores vivos, por cirurgia laparoscópica ou aberta, em dois diferentes momentos da cirurgia do transplante: após a retirada do rim e após a reperfusão.

b) Correlacionar a expressão tecidual de genes protetores e inflamatórios antes e após a reperfusão do enxerto renal com a função do enxerto renal por meio da creatinina sérica medida nos dias $1^{\circ}, 2^{\circ}, 3^{\circ}, 4^{\circ}, 5^{\circ}$, $6^{\circ}, 7^{\circ}$ e $30^{\circ}$ dias, $3^{\circ}$ e $6^{\circ}$ mês após o transplante. 


\section{3 - CASUÍSTICA E MÉTODOS}

Esta pesquisa procurou investigar a expressão de fatores protetores e inflamatórios no tecido renal de rins de doadores vivos submetidos à nefrectomia aberta e laparoscópica, durante a lesão da isquemia e reperfusão no transplante de rim.

Foram avaliados dois grupos de pacientes: 1) grupo de pacientes transplantados com rins extraídos de doadores vivos por cirurgia laparoscópica (grupo de estudo), 2) grupo de pacientes transplantados com rins extraídos de doadores vivos por cirurgia aberta tradicional (grupo controle). A expressão tecidual de genes protetores e inflamatórios foi comparada entre os dois grupos. Os rins extraídos foram biopsiados em dois momentos: após a retirada, em banco, e após a reperfusão. O objetivo de realizar biópsias em dois diferentes momentos foi de avaliar a cinética da expressão tecidual de genes protetores e inflamatórios após a retirada do órgão do doador (momento que refletiria o período de isquemia quente ocorrido durante a nefrectomia) e após a reperfusão do enxerto renal (momento que refletiria os períodos de isquemia fria e reperfusão). Como representado na Figura 3, as biópsias ocorreram nos momentos: i) T-1: após a retirada do rim do doador, 5-7 min após perfusão com solução de preservação Euro-collins e ii) $\mathrm{T}+1$ : após 45 minutos do desclampeamento vascular (reperfusão). Definiu-se tempo de isquemia quente (TIQ) como período iniciado no clampeamento arterial até imersão do rim em gelo.

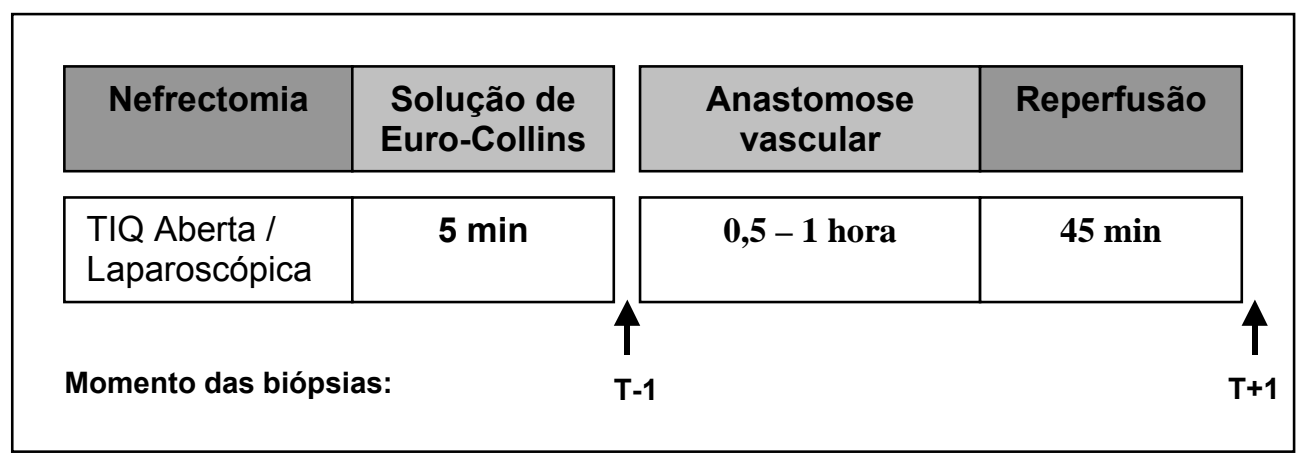

Figura 3: Momento da realização das biópsias de acordo com a dinâmica do transplante, representando os momentos de isquemia e reperfusão. TIQ=tempo de isquemia quente 
Os fragmentos de tecido renal foram avaliados quanto à expressão de RNA mensageiro (por PCR em tempo real) e proteína (por imunoistoquímica) dos seguintes fatores:

1 - Fatores envolvidos na resposta protetora do enxerto: HO-1, HSP70, VEGF, proteína com atividade antiapoptótica Bcl-2.

2 - Fatores pró-apoptóticos: proteína pró-apoptótica Bax.

3 - Fatores inflamatórios: IL-6, TNFa.

4 - Fator de transcrição: HIF1 1 .

A expressão tecidual destes fatores no momento que precede a isquemia fria e após a reperfusão foram correlacionadas com os seguintes eventos clínicos:

a) Função renal do enxerto do $1^{\circ}$ ao $7^{\circ}$ dia, $30^{\circ}$ dia, $3^{\circ}$ mês e $6^{\circ}$ mês após o transplante.

b) Ocorrência de função retardada do enxerto, definida como necessidade de diálise na primeira semana após o transplante.

c) Ocorrência de função retardada funcional do enxerto, definida como decréscimo da creatinina inferior a $10 \%$ ao dia em 3 dias consecutivos na primeira semana pós-transplante.

d) Não funcionamento primário do enxerto, na ausência de diminuição da creatinina que resultasse na perda do enxerto.

e) Função imediata do enxerto: diurese imediata do rim transplantado.

A hipótese que este estudo deseja investigar é se existe lentidão na recuperação da função renal do enxerto e se ocorre diferença na expressão tecidual de fatores protetores nos rins de doadores laparoscópicos em relação à nefrectomia aberta. Frente a uma possível maior agressão durante a retirada do rim por laparoscopia, a hipótese é que exista também diferença na resposta adaptativa da expressão tecidual de fatores protetores nos rins de doadores vivos laparoscópicos em relação à nefrectomia aberta. Para o cálculo do tamanho amostral, foi utilizado estudo prévio publicado recentemente pela co-orientadora desta tese ${ }^{(58)}$. Na subanálise deste estudo prévio, a investigadora teve acesso a biópsias renais de doadores vivos extraídos tanto por cirurgia laparoscópica como por cirurgia aberta e 
comparou a expressão tecidual de fatores inflamatórios e protetores. Esta subanálise não foi detalhada na publicação referida, mas foi utilizada no projeto proposto para o cálculo do tamanho amostral. A investigadora observou uma diferença da expressão de RNA mensageiro de Bcl-2 em rins de doadores laparoscópicos comparado aos rins de doadores abertos. $\mathrm{O}$ valor da média da expressão relativa de Bcl-2 foi 12,6 em doadores laparoscópicos $(n=29)$ comparado a 8,0 em doadores abertos $(n=9 p<0,05)$. Para o cálculo do número de amostras necessárias para o estudo, assumiuse que a expressão destes fatores no doador vivo laparoscópico seja duas vezes maior em relação ao doador convencional nos dois momentos (doação e reperfusão). Trabalhando com nível de significância de 5\% e valor de poder igual a $80 \%$, foi estimada a necessidade de inclusão de 25 amostras de cada grupo em cada momento estudado: momento da doação e momento após reperfusão.

\section{1 - RECEPTORES PARA TRANSPLANTE RENAL}

Os receptores dos rins são pacientes portadores de insuficiência renal crônica submetidos a transplante com doador vivo provenientes dos serviços de transplante renal do Hospital das Clínicas da Faculdade de Medicina da USP - HCFMUSP e da Santa Casa de Misericórdia de Curitiba. Os dados clínicos do receptor foram acessados através de seu prontuário médico. A pesquisa e o termo de consentimento livre e esclarecido (TCLE) foram aprovados pela comissão de ética para Análise de Projetos de Pesquisa CAPPesq da diretoria clínica do Hospital das Clínicas e da Faculdade de Medicina da Universidade de São Paulo sob protocolo de pesquisa $n^{\circ}$. 0593/08.

-Critérios de inclusão e exclusão:

Somente os pacientes adultos, esclarecidos sobre a pesquisa e que assinaram o TCLE foram incluídos no estudo. Os casos em que houve necessidade de conversão da via laparoscópica para aberta foram excluídos do estudo. 


\section{2 - TÉCNICA CIRÚRGICA}

\subsection{1 - Nefrectomia aberta}

A técnica para realização de nefrectomia aberta variou de acordo com o centro transplantador. No Hospital Santa Casa de Misericórdia de Curitiba foi realizada incisão de lombotomia clássica com ressecção parcial da $12^{\mathrm{a}}$ costela como forma de acesso ao espaço extraperitoneal (Figura 4). Em seguida, realizava-se liberação do rim de suas aderências, dissecção ureteral e do pedículo renal e, após ligadura do ureter, procedia-se com o clampeamento de artéria e veia separadamente e retirada do rim. No Hospital de Clínicas da Faculdade de Medicina da USP a via de acesso para nefrectomia aberta foi subcostal. $\mathrm{O}$ paciente era posicionado em decúbito dorsal oblíquo a $30^{\circ}$, a incisão era realizada da ponta da $12^{\mathrm{a}}$ costela até a borda do músculo reto abdominal, realizava-se então a dissecção renal, ureteral e do pedículo renal. Após ligadura do ureter, realizava-se o clampeamento dos vasos renais e extração renal. 

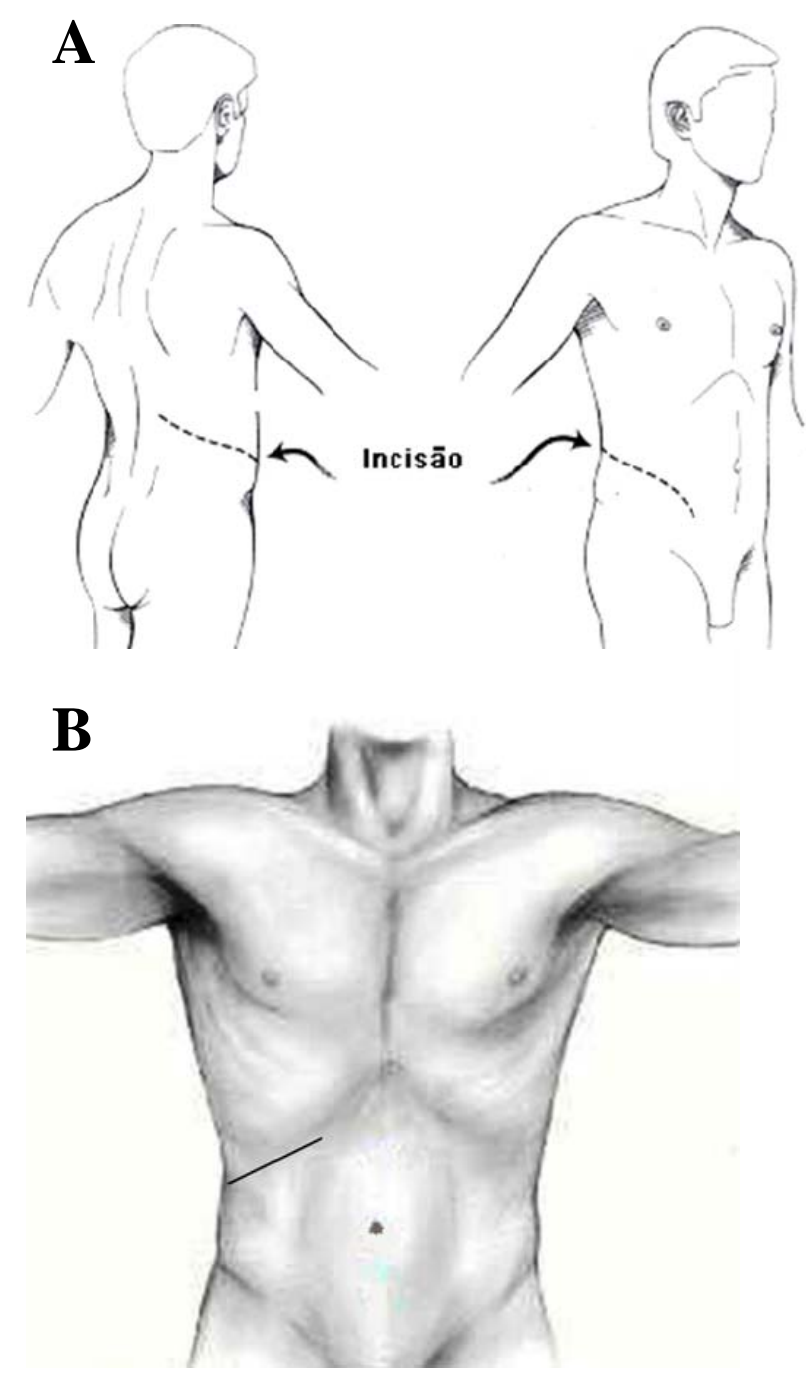

Figura 4: A) Incisão de lombotomia clássica (Hospital Santa Casa de Misericórdia de Curitiba) e B) Incisão subcostal (HCFMUSP)

\subsection{2 - Nefrectomia laparoscópica}

Nos dois centros de transplante realizou-se a nefrectomia laparoscópica de forma semelhante, com pequenas variações em relação à disposição dos trocarteres secundários. Sucintamente descreveremos os passos principais da técnica realizada. O paciente era colocado em posição de decúbito oblíquo a $45^{\circ}$, realizado confecção de pneumoperitônio por agulha de Veress com dióxido de carbono $\left(\mathrm{CO}_{2}\right)$ a uma pressão de 15 $\mathrm{cmH}_{2} \mathrm{O}$. Em seguida o trocarter primário de $10-12 \mathrm{~mm}$ era introduzido em cicatriz umbilical e colocados três trocarteres secundários (Figuras 5 e 6). 0 cólon esquerdo era mobilizado e deslocado medialmente expondo o rim, 
seguido de abertura da fáscia renal, dissecção do ureter junto à veia gonadal, dissecção da artéria e veia renal com controle de vasos acessórios.

Após a ligadura do ureter e liberação do rim de suas aderências laterais e do polo superior, realizava-se incisão de Pfannenstiel. O controle vascular do pedículo renal era realizado por meio de clipes de polipropilene (Hem-o-lok, Weck, USA) e o rim era extraído manualmente.

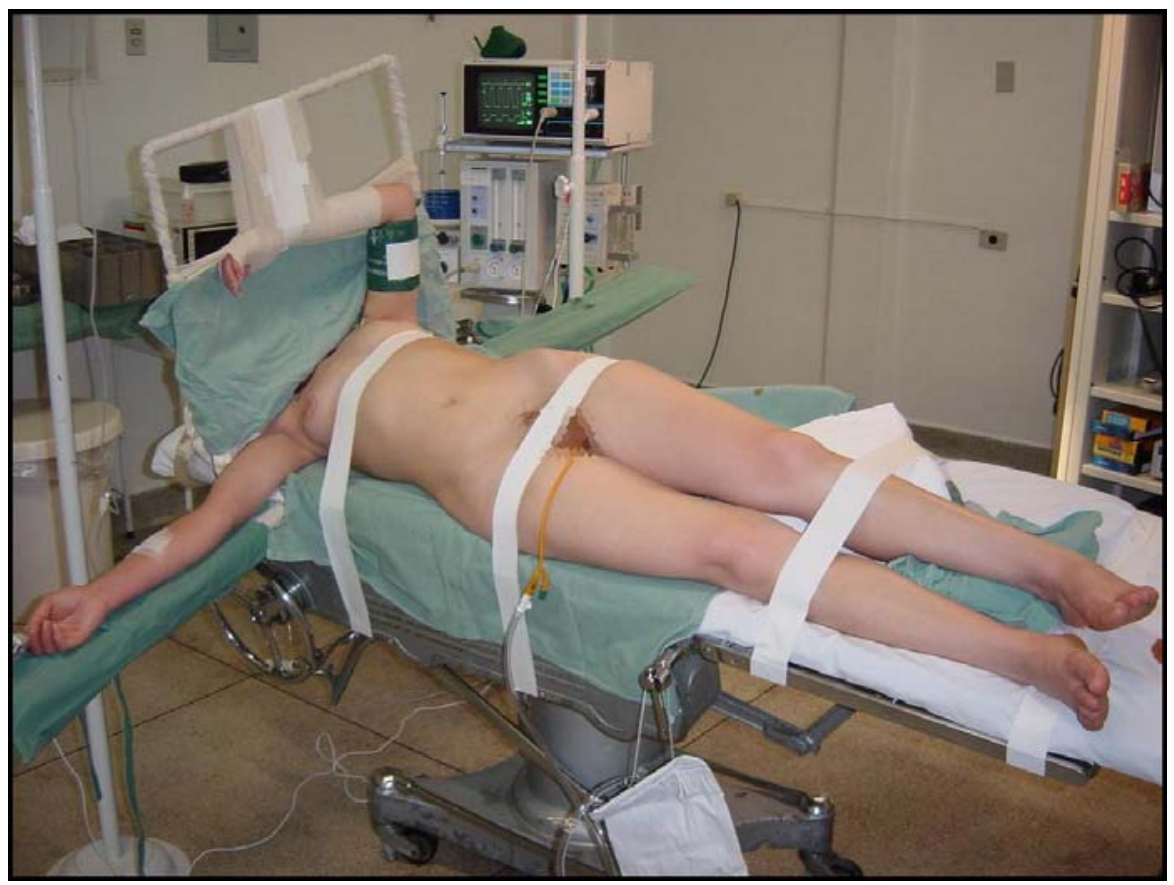

Figura 5: Posicionamento do paciente na cirurgia laparoscópica

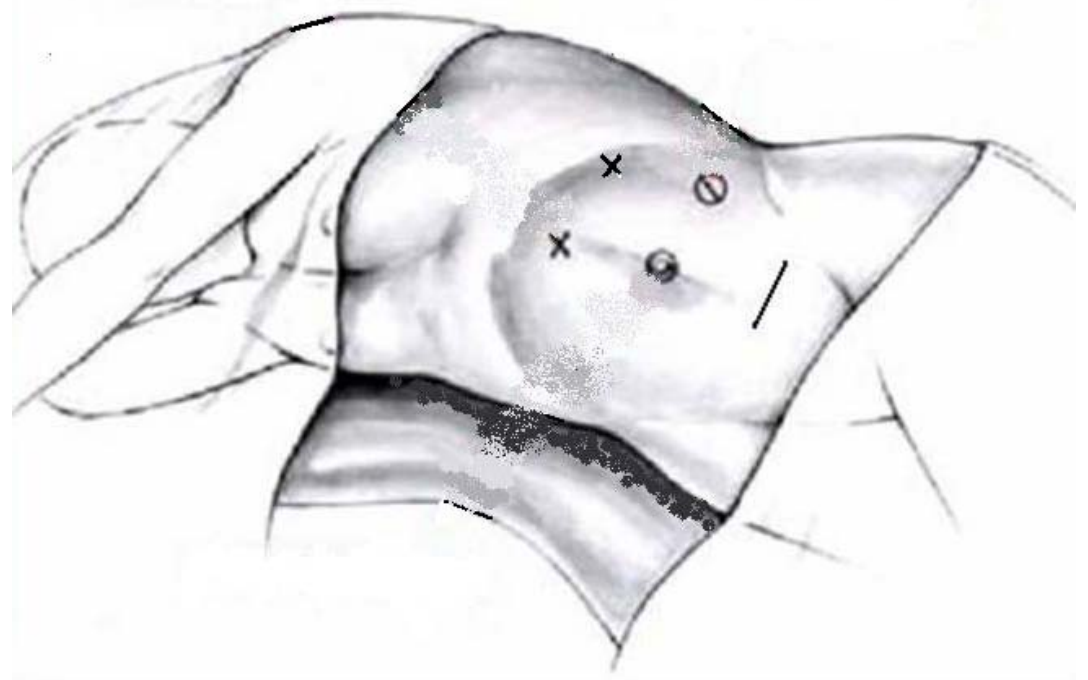

Figura 6: Distribuição do trocarter primário e trocarteres secundários $-(X)=5 \mathrm{~mm}$, (0) $=10 \mathrm{~mm}$ e posição da incisão de Pfannentiel 


\section{3 - MATERIAL BIOLÓGICO}

Fragmentos de biópsia renal

As biópsias foram realizadas por meio de incisão com bisturi no pólo superior e inferior do rim, alternadamente, em dois diferentes momentos do processo de doação e preservação. A primeira biópsia foi realizada imediatamente após a retirada do rim, após perfusão por 5 min com solução de Euro-Collins a $4^{\circ} \mathrm{C}$. A segunda biópsia foi realizada após a reperfusão do órgão, aproximadamente 45 min após o desclampeamento vascular.

Em cada momento da biópsia, procedeu-se a extração de dois fragmentos: um fragmento destinado ao isolamento e quantificação de RNA mensageiro mergulhado em $500 \mu \mathrm{l}$ de reagente RNA later (Qiagen, USA) e outro fragmento para realização de imunoistoquímica, colocado em meio Dubosq-Brasil por 30 min e depois em formol diluído em 10\%, em solução tamponada.

\section{4 - MÉTODOS}

\subsection{1 - Isolamento de RNA e Síntese de DNAc}

Os fragmentos de biópsia renal destinados ao isolamento e quantificação do RNA total foram acondicionados em tubo com $500 \mu \mathrm{l}$ de solução preservativa RNA later (Qiagen, USA), mantidos a $-80^{\circ} \mathrm{C}$ até o momento da extração. Foi realizado extração de RNA total em 32 pacientes totalizando 72 fragmentos de biópsia, os tecidos congelados foram macerados e o isolamento de RNA se deu através de TRIzol (Invitrogen, USA). Em seguida, o RNA foi quantificado através de leitura em espectrofotômetro (Beckman, DU530, Fullerton, CA, USA) nos comprimentos de onda $(\lambda)$ de 260 e $280 \mathrm{~nm}$. Para o cálculo da concentração da amostra considerou-se que a densidade ótica (DO) igual a 1 corresponde a $40 \mu \mathrm{g}$ de RNA $/ \mathrm{ml}$ no comprimento de onda de $260 \mathrm{~nm}$.

Uma alíquota de RNA foi submetida à eletroforese em gel de agarose RNAse free $1 \%$ para visualização da integridade das amostras, observando 
as duas subunidades do RNA ribossômico, $18 \mathrm{~S}$ e $28 \mathrm{~S}$, e também possíveis contaminações com DNA. (figura 7)

Após a extração, o RNA obtido foi tratado com turbo DNA-free (Ambion, USA). O tratamento do RNA com DNase tem como objetivo evitar possíveis contaminações com DNA, antes da transcrição do RNA em DNA complementar (DNAc).

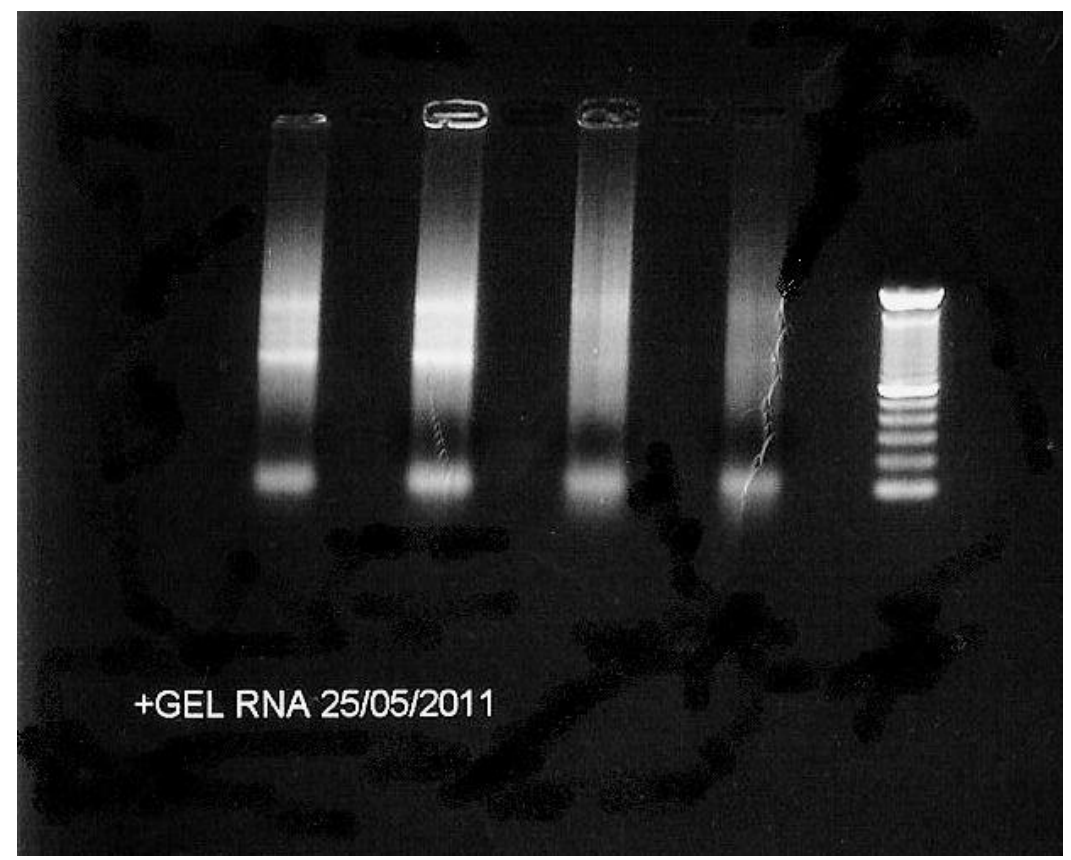

Figura 7: RNA total em gel de agarose $1 \%$ de amostras submetidas a isolamento de RNA por meio de TRizol, demonstrando integridade do RNA

Após esta etapa, prosseguimos então para a execução da transcrição reversa e síntese de DNA complementar (DNAc). Para tal, optamos por transcrever uma quantidade total de 5000ng do RNA isolado. Utilizamos solução contendo $1 \mu \mathrm{l}$ de Random Primers, $1 \mu \mathrm{l}$ de dNTP $10 \mathrm{mM}$ e água DEPC. Após um breve aquecimento a $65^{\circ} \mathrm{C}$ por $5 \mathrm{~min}$, acrescentamos $4 \mu \mathrm{l}$ de buffer, $2 \mu \mathrm{l}$ de DTT $0.1 \mathrm{M}$ e $1 \mu \mathrm{l}$ de RNAse out. Misturado todos os componentes e incubado a $37^{\circ} \mathrm{C}$ por $2 \min$ acrescentamos $1 \mathrm{ul}(200 \mathrm{U}) \mathrm{de}$ M-MLV transcriptase reversa. Nova incubação a $25^{\circ} \mathrm{C}$ por $10 \mathrm{~min}$, seguido de $37^{\circ} \mathrm{C}$ por 50 min. $O$ término desta reação se faz aquecendo as amostras a $70^{\circ} \mathrm{C}$ por 15 min. Toda incubação foi realizada em termocicladora. 
Após o término da etapa de transcrição reversa procedemos à realização do PCR em tempo real.

\subsection{2 - Real-time PCR}

No tecido renal foi pesquisada a expressão de RNAm de HO-1, HSP 70, Bcl-2, VEGF, IL-6, HIF1a, TNFa, através da técnica de PCR em tempo real com a utilização do reagente Taqman master mix (Applied Biosystems, USA) e o equipamento 7500 Real Time PCR systems (Applied Biosystems, USA). Os níveis de RNA dos diferentes fatores no tecido renal foram normalizados pela concentração do $18 \mathrm{~S}$ e ciclofilina, que são genes constitutivamente expressos nas células renais de forma constante. Os primers utilizados foram produzidos e previamente testados pela empresa Applied Biosystems (CA, USA). O mix fornecido pelo fabricante já contém a mistura de primer 5' e 3', além do probe. Na tabela 1 listamos a sequência de nucleotídeos dos primers 5 '.

Tabela 1 - Seqüência dos nucleotídeos utilizada

\begin{tabular}{ccc}
\hline Gene & Reporter Dye & Seqüência Primer 5’ \\
\hline $18 S$ & FAM & CCATTGGAGGGCAAGTCTGGTGCCA \\
Hsp70 & FAM & CGCGCGATCACCCGGAACCCGCTGG \\
Bcl-2 & FAM & TAACGGAGGCTGGGATGCCTTTGTG \\
VEGF & FAM & CAAGAAAAATGTGACAAGCCGAGGC \\
TNF- $\alpha$ & FAM & GCCCATGTTGTAGCAAACCCTCAAG \\
HO-1 & FAM & GACGGCTTCAAGCTGGTGATGGCCT \\
HIF-1 $\alpha$ & FAM & GGAGGGGAAGAGAGGTTGTATCTGC \\
II-6 & FAM & TCAGCCCTGAGAAAGGAGACATGTA \\
\hline
\end{tabular}

A concentração de primer/probe utilizada foi a recomendada pelo fabricante para um volume final de 20ul: 10ul do Taqman master mix, 1ul da solução contendo primer/probe, DEPC água $5 u$ e amostra 4 ul. A concentração de DNAc por teste foi de $100 \mathrm{ng}$ em conformidade com a sugestão do fabricante. A reação foi realizada em 40 ciclos de 15 segundos 
a $95^{\circ} \mathrm{C}$ e $1 \mathrm{~min}$ a $60^{\circ} \mathrm{C}$. No PCR em tempo real, durante a fase logarítmica da reação, ocorre acúmulo dos produtos de amplificação e a $\Delta$ Rn ultrapassa a linha de base. Para quantificação relativa, foi estabelecido um valor de $\Delta R$, que seria uma linha de corte (threshold) para cada curva de amplificação de um dado par de primers. O número do ciclo em que cada $\Delta R$ cruza 0 threshold corresponde ao limiar da curva ou Ct (curve threshold) da amostra. O valor de Ct é preditivo da quantidade de RNAm alvo presente na amostra. Quanto menor o $\mathrm{Ct}$, maior a expressão do gene. Para análise entre os grupos e principalmente do grupo aberta, utilizamos os valores de $\Delta \mathrm{Ct}$, que é a diferença entre o $\mathrm{Ct}$ do gene testado menos o $\mathrm{Ct}$ do gene $18 \mathrm{~s}$. O cálculo da quantificação relativa é feito pelo método de aproximação de Pfaffl ${ }^{(68)}$, utilizando como gene de referência o 18S. A fórmula utilizada para a quantificação relativa (QR) é:

$Q R=2^{-\Delta \Delta \mathrm{Ct}}$, onde $\Delta \mathrm{Ct}=\mathrm{Ct}$ alvo $-\mathrm{Ct}$ referência, e $\Delta \Delta \mathrm{Ct}=\Delta \mathrm{Ct}$ amostra $-\Delta \mathrm{Ct}$ controle.

Considera-se aumento da expressão individual do gene testado em relação ao gene do grupo controle quando o valor de QR é superior a 2, da mesma forma quando o QR é inferior a 0,5 há diminuição da expressão. Caso o QR se aproxime de 1, é considerado como igualdade. $\mathrm{Na}$ interpretação dos resultados expressos em QR, como a QR é uma razão que trata de valores individuais, para verificar se a média de QR apresentava diferença estatística entre os grupos, foi testada a hipótese de que o valor médio de QR era igual a 1, conferindo igualdade entre o grupo testado e o grupo controle. Ao se notar diferença estatística assume-se que houve diferença da média. Então, quando a média for significativamente inferior a 1, há diminuição da expressão, enquanto que em médias significativamente superiores a 1, considera-se aumento da expressão. 


\subsection{3 - Imunoistoquímica}

A expressão protéica de HO-1, Bcl-2, Bax e Caspase 3 nos fragmentos de biópsia renal foram estudadas pelo método de imunoistoquímica.

De cada bloco de parafina foram feitos 10 lâminas com duas secções de três $\mu \mathrm{m}$ de espessura em cada, devidamente identificadas e sinalizadas. Para garantir máxima sensibilidade, evitando reação de fundo pela interação biotina-avidina, a amplificação foi efetuada com polímeros de segunda geração, Novolink (Novocastra, UK), conforme descrição abaixo. As lâminas histológicas seguiram as etapas técnicas: desparafinização durante 30 minutos em estufa a $60^{\circ} \mathrm{C}$, imersas em Xilol (I) e depois 10 minutos em temperatura ambiente, imersas em Xilol (II). A hidratação foi realizada através de imersão em álcool absoluto duas vezes por 2 min e depois em álcool 95\%, duas vezes por 2 min, quando então foram reidratadas em água corrente. Passado esse processo inicial, foram submetidas ao bloqueio de peroxidase endógena por incubação com Peróxido de Hidrogênio 3\% (Novocastra TM peroxidase block), em seis ciclos de 5 minutos, seguida de incubação com Caseína a 0,4 \% em soro com tampão fosfato e produtos estabilizadores surfactantes, bem como Bronidox L a 0,2\% (Novocastra TM Protein Block). Após lavagem em água corrente, a depender do antígeno testado, foi feita recuperação antigênica com Tripsina ou aquecimento em panela de pressão a $95^{\circ} \mathrm{C}$ durante 3 minutos, com tampão citrato $10 \mathrm{mM}$, com $\mathrm{pH} 6,0$. A seguir procedeu-se nova lavagem em água corrente destilada e três trocas em tampão TRIS, com pH de 7,4. As lâminas foram então incubadas com o anticorpo primário por 18 horas a $4^{\circ} \mathrm{C}$. Após outra lavagem com tampão TRIS, realizada também em três trocas de 2 minutos, foi realizada a aplicação de Novocastra TM Post Primary Block, constituído por soro animal a 10\% (v/v) em soro tamponado tris/ProClin TM 950 a 0,09\%, com objetivo de ativar a penetração do polímero. Em seguida o NovoLink TM Polymer reconheceu os anticorpos primários ligados ao tecido e essa ligação, após mais uma seqüência de lavagem com TRIS, foi revelada pela 
incubação com o substrato cromógeno 3,3" diamino benzidina a 1,74\% p/v, em solução estabilizadora (DAB). A reação com a peroxidase produz um precipitado visível à microscopia, de cor castanha, no local do antígeno. Finalmente, a contra coloração foi feita com hematoxilina de Mayer (Hemalaum-Merck) e, após desidratação em bateria de álcool e xilol, os cortes foram montados com Entellan.

Os anticorpos primários utilizados foram:

HO-1: mouse monoclonal anti-human HO-1 (Clone GTS-1; Novus biological, USA)

Bcl-2: mouse monoclonal anti-human Bcl-2 (Clone 3.1, Novocastra, UK)

Bax: mouse monoclonal anti-human Bax (Clone 2D2, Thermo scientific,USA) Caspase-3: mouse monoclonal anti-human Caspase-3 (clone JHM 62, Novocastra, UK)

Cada anticorpo primário foi previamente titulado em amostras de tecido renal humano.

As lâminas foram avaliadas por um único e experiente patologista que levou em consideração a positividade celular do anticorpo, analisando os diferentes compartimentos do tecido renal, porém realizando a contagem em túbulos renais. Em relação aos fatores apoptóticos $\mathrm{Bax}$ e Bcl-2, foi realizada análise quantitativa através de contagem de células tubulares por campo em aumento de 400x. Na análise de HO-1 e Caspase 3, devido à baixa expressão das proteínas, foram considerados apenas os resultados positivo - quando havia a expressão da proteína nas células evidenciada pela presença do anticorpo - e negativo, quando não havia expressão. 


\subsection{4 - Análise Estatística}

O teste utilizado na análise estatística foi o teste Exato de Fisher, para variáveis descritivas no caso de tabelas 2x2 como para as de maior nível (Teste de Freeman-Halton). Para as variáveis contínuas, utilizou-se o teste $\mathrm{t}$ de Student para duas médias, teste de Levene para variabilidades, análise de variâncias (ANOVA) para várias médias e teste não-paramétrico de Wilcoxon. Para correlação entre as variáveis foi utilizado o coeficiente de correlação linear de Pearson. Foi utilizado o nível descritivo de 0,05 para determinar a significância das diferenças. 


\section{4 - RESULTADOS}

\section{1 - RESULTADOS CLÍNICOS}

\subsection{1 - Dados demográficos dos pacientes e doadores}

De outubro de 2009 a setembro 2011 foram analisados 55 receptores renais, dos quais em 29 pacientes o enxerto era proveniente de nefrectomia aberta e em 26 pacientes o rim doado foi retirado por via laparoscópica. Os receptores tinham idade média de 43 anos no grupo aberta e 44 anos no grupo laparoscópica, com discreta preponderância do sexo feminino no grupo aberta e distribuição igual quanto ao sexo no grupo laparoscópica. As principais causa da insuficiência renal prévia ao transplante foram glomerulopatias no grupo aberta e causa indeterminada no grupo laparoscópica. Outras doenças como hipertensão arterial, diabetes melito aparecem a seguir como doença primária nos receptores (tabela 2). A droga de indução mais utilizada foi basiliximab, pois a maioria dos pacientes eram de baixo risco imunológico (pesquisa de painel de reatividade menor que 10\%). O regime de manutenção de imunossupressão inicial incluía micofenolato mofetil ou sódico, tacrolimo e prednisona sendo o mesmo tanto nos pacientes do grupo aberta quanto no grupo laparoscópica. A partir do $3^{\circ}$ mês, de acordo com protocolo de pesquisa de imunossupressão, quatro pacientes no grupo aberta e um paciente no grupo laparoscópica foram convertidos de tacrolimo para everolimo (tabela 2). Em três casos no grupo aberta e em um caso no grupo laparoscópica o regime de imunossupressão foi alterado para outras drogas, de acordo com a necessidade.

Os doadores eram jovens na sua maioria e predominantemente do sexo feminino (tabela 3). $O$ índice de massa corporal (IMC) foi semelhante entre os grupos embora no grupo laparoscópico houvesse uma tendência ao sobrepeso. A maioria dos doadores eram aparentados (83\% no grupo aberta e $77 \%$ no grupo laparoscópica) e a utilização de doadores vivos não aparentados foi semelhante entre os grupos (tabela 3 ). 
Tabela 2 - Dados demográficos e Características clínicas dos receptores

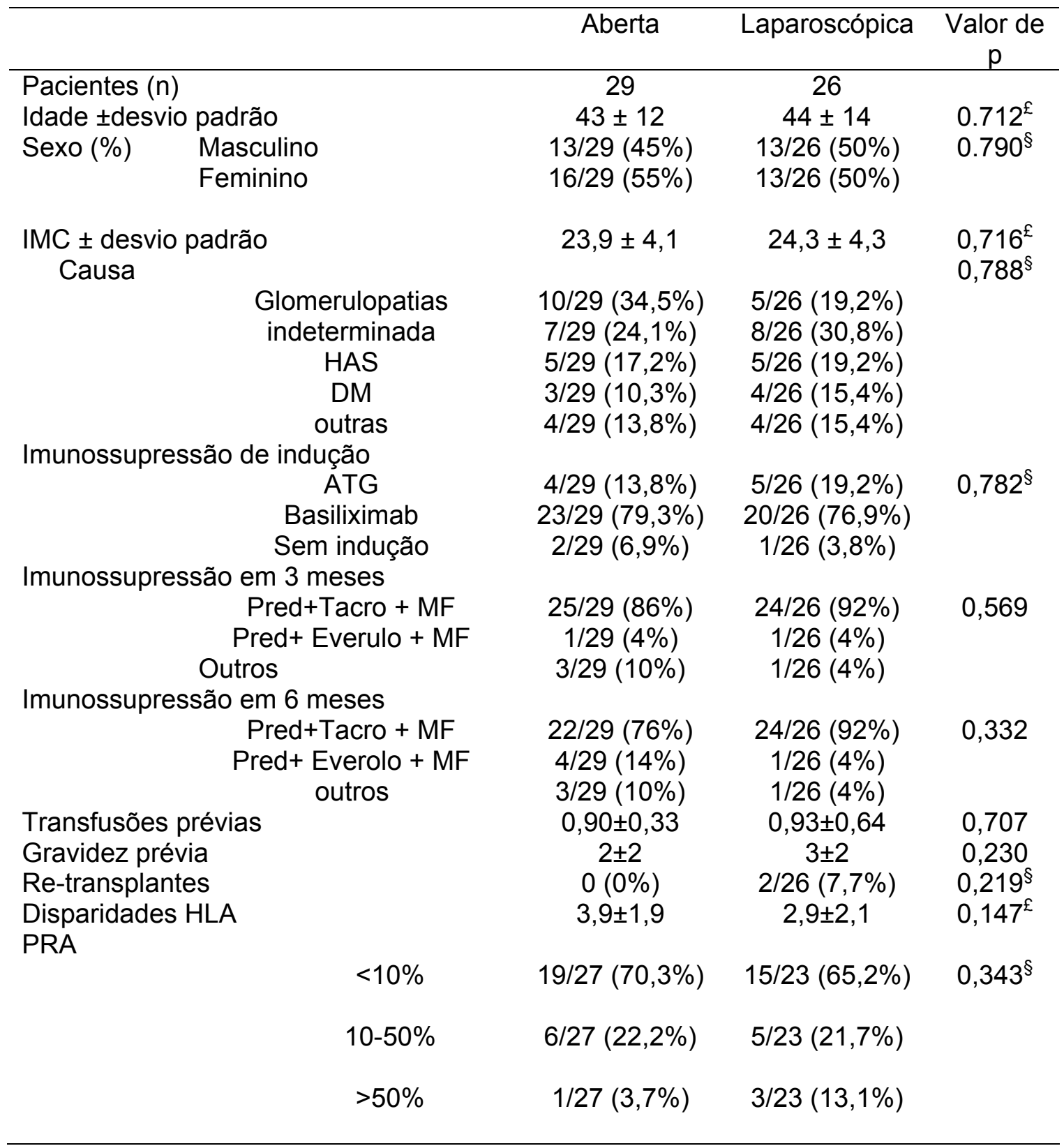

$£$ teste $\mathrm{t}$

$\S$ teste Exato de Fisher

IMC = índice de massa corporal

HAS = hipertensão arterial. DM = diabetes melito

ATG =anti-timoglobulina

$\mathrm{PRA}=$ Pesquisa de reatividade contra painel de antígenos HLA

Pred=prednisona; tacro=tacrolimo, evero=everolimo; MF=micofenolato mofetil ou sódico 
Tabela 3 - Características demográficas e clínicas dos doadores no momento do transplante

\begin{tabular}{|c|c|c|c|c|}
\hline & & Aberta & Laparoscópica & $\begin{array}{l}\text { Valor } \\
\text { de p }\end{array}$ \\
\hline Pacientes (n) & & 29 & 26 & \\
\hline Idade média $\pm \mathrm{DP}$ & & $35 \pm 10$ & $36 \pm 10$ & $0.74^{£}$ \\
\hline Idade $>50$ anos & & $2 / 29(6,9 \%)$ & $2 / 29(7,7 \%)$ & $0,999^{\S}$ \\
\hline \multirow[t]{2}{*}{ sexo doador (\%) } & masculino & $9 / 29(31 \%)$ & $5 / 26(19,2 \%)$ & $0.367^{\S}$ \\
\hline & feminino & $20 / 29(69 \%)$ & $21 / 26(80,8 \%)$ & \\
\hline $\begin{array}{l}\% \text { Doador feminino / } \\
\text { receptor masculino }\end{array}$ & & $12 / 29(41,4 \%)$ & $12 / 26(46,2 \%)$ & $0.39^{\S}$ \\
\hline IMC médio \pm DP & & $24,5 \pm 4$ & $26,2 \pm 3$ & $0,115^{£}$ \\
\hline \multirow[t]{2}{*}{ Tipo de Doador } & DVA & $\begin{array}{c}24 / 29 \\
(82,75 \%)\end{array}$ & $20 / 26(76,9 \%)$ & $0,738^{\S}$ \\
\hline & DVNA & $5 / 29(17,25 \%)$ & $6 / 26(23,1 \%)$ & \\
\hline
\end{tabular}

£ teste t

$\S$ teste Exato de Fisher

$\mathrm{DP}=$ desvio padrão

DVA=doador vivo aparentado

DVNA=doador vivo não aparentado

IMC=índice de massa corporal

\subsection{2 - Dados Cirúrgicos}

Como no Hospital de Clínicas da Faculdade de Medicina da USP não é realizado nefrectomia laparoscópica direita para doação renal, todos os casos do grupo laparoscópico foram à esquerda. No grupo de doadores nefrectomizados por cirurgia aberta, convencional, o rim doado foi o direito em sua maioria $(n=16,55 \%)$. A preferência por esta técnica foi por indicações anatômicas como presença de maior número de veias $(n=1)$, diminuição do tamanho renal $(n=9)$, presença de artérias renais múltiplas contralaterais $(n=6)$. Em 13 pacientes o rim esquerdo foi retirado por cirurgia aberta por indisponibilidade de equipe cirúrgica para realização de cirurgia laparoscópica, optando-se por nefrectomia aberta.

Quando comparados os dois grupos com relação ao número de artérias renais nos rins doados, observa-se que, no grupo aberta, quatro doadores $(14 \%)$ possuíam artérias renais múltiplas e, no grupo laparoscópica, três casos (12\%) tinham múltiplas artérias. Como já previsto, o tempo de isquemia quente foi maior no grupo laparoscópica (média de 194 segundos) do que no grupo aberta (média de 132 segundos; $p=0,005$ ) (tabela 4). 
As cirurgias para doação transcorreram sem complicações peroperatórias e a recuperação dos pacientes ocorreu de modo habitual. No pós-operatório dos pacientes transplantados observou-se que no grupo de cirurgia aberta um receptor foi reoperado no $1^{\circ}$ pós-operatório por apresentar estenose da artéria renal do enxerto devido ao deslocamento de placa ateromatosa. Entretanto, neste paciente, a creatinina atingiu nível normal a partir do $5^{\circ}$ dia. Em outro receptor do grupo aberta, foi necessário hemicolectomia esquerda no $5^{\circ}$ pós-operatório em virtude de uma obstrução funcional do cólon, o que não interferiu no decréscimo da creatinina. Estes eventos não tiveram relação com a técnica empregada na retirada do rim. Em dois casos, um em cada grupo, ocorreu fístula ureteral no pósoperatório. O paciente do grupo aberta apresentou sépsis e retardo de função renal funcional, com recuperação após uma semana.

Tabela 4 - Dados cirúrgicos no momento do transplante

\begin{tabular}{lccc}
\hline & Aberta & Laparoscópica & Valor de $\mathrm{p}$ \\
\hline Rim Direito & $16 / 29(55,2 \%)$ & $0 / 26(0 \%)$ & $<0,0001^{*}$ \\
$\quad$ Esquerdo & $13 / 29(44,8 \%)$ & $26 / 26(100 \%)$ & \\
Artérias múltiplas & $4 / 29(13,8 \%)$ & $3 / 26(11,5 \%)$ & $0,999^{*}$ \\
$\begin{array}{c}\text { Tempo de isquemia } \\
\text { quente, média, }\end{array}$ & $132 \pm 90,5$ & $194 \pm 58,3$ & $0.005^{\phi}$ \\
segundos \pm desvio \\
$\quad$ padrão)
\end{tabular}
teste $\mathrm{t}$

*Teste Exato de Fisher

\subsection{3 - Avaliação da função renal}

A maioria dos pacientes teve boa evolução após o transplante. A função retardada do enxerto foi definida como a necessidade de diálise na primeira semana após o transplante. Assim, houve três casos que apresentaram retardo da função do enxerto, necessitando de diálise na 
primeira semana no pós-operatório, um caso $(3,4 \%)$ no grupo de nefrectomia aberta e dois casos $(7,7 \%)$ no grupo de cirurgia laparoscópica. A função retardada do enxerto funcional, considerada como ausência de queda da creatinina de pelo menos $10 \%$ em 3 dias consecutivos, ocorreu em sete pacientes, quatro $(13,8 \%)$ no grupo aberto e três $(11,5 \%)$ no grupo laparoscópico, não havendo diferença estatística entre os dois grupos (tabela 5).

Tabela 5 - Função retardada do enxerto e função retardada do enxerto funcional

\begin{tabular}{ccccc}
\hline & Aberta & Laparoscópica & Total & Valor de $\mathrm{p}$ \\
\hline $\begin{array}{c}\text { Função retardada } \\
\text { do enxerto (n / \%) }\end{array}$ & $1 / 29(3,4 \%)$ & $2 / 26(7,7 \%)$ & $3 / 54(5,6 \%)$ & $0.598^{*}$ \\
$\begin{array}{c}\text { Função retardada } \\
\text { do enxerto }\end{array}$ & $4 / 29(13,8 \%)$ & $3 / 26(11,5 \%)$ & $7 / 54(13 \%)$ & $0,999^{*}$ \\
funcional (n/\%) & & & \\
total & $5 / 29(17,2 \%)$ & $5 / 26(19,2 \%)$ & $10 / 54$ & $0,999^{*}$ \\
& & & $(18,5 \%)$ & \\
\hline
\end{tabular}

*teste Exato de Fisher

A creatinina média medida do $1^{\circ}$ ao $7^{\circ}$ dia, $30^{\circ}$ dia, $3^{\circ}$ e $6^{\circ}$ mês após o transplante foi semelhante entre os grupos (tabela 6). Avaliando a curva da queda de creatinina, através do cálculo da área sob a curva da creatinina $\left(A_{S C}\right.$ ), observou-se que o decréscimo da creatinina sérica no pósoperatório foi semelhante entre os grupos da cirurgia laparoscópica ( ASC $_{\mathrm{cr}}$ média=133) e da nefrectomia aberta ( $A_{\mathrm{SS}} \mathrm{cr}_{\mathrm{r}}$ média=122; $\mathrm{p}=0,332$ ) (Figura 8). Como na cirurgia laparoscópica foi utilizado apenas rim esquerdo, a função renal foi avaliada separadamente do grupo aberta comparando o lado direito ao esquerdo. Nenhuma diferença estatística tanto da área sob a curva de creatinina ao longo dos dias $(p=0,369)$ como de ocorrência de retardo de função renal $(p=0,632)$ foi observada entre os rins direito e esquerdo na cirurgia aberta.

Com relação aos eventos clínicos ocorridos nos receptores após o transplante renal, no grupo de cirurgia laparoscópica houve cinco casos de 
rejeição aguda. Um destes pacientes apresentou elevação da creatinina no $5^{\circ}$ dia pós-operatório e foi pulsado empiricamente com metilprednisolona neste dia, com queda da creatinina para $2,36 \mathrm{mg} / \mathrm{dl}$ no $7^{\circ}$ dia. A biópsia realizada durante a pulsoterapia mostrou a presença de necrose tubular aguda. Portanto, o diagnóstico final da elevação da creatinina foi necrose tubular aguda. No grupo de cirurgia aberta ocorreram quatro casos de rejeição aguda mediada por células. Após o tratamento dois pacientes tiveram redução da creatinina para níveis abaixo de $2,5 \mathrm{mg} / \mathrm{dl}$ antes do $7^{\circ}$ pós-operatório e em um caso a creatinina se manteve em $3 \mathrm{mg} / \mathrm{dl}$ no $7^{\circ}$ dia após o transplante. Um paciente apresentou infecção por polioma vírus e teve o regime de imunossupressão alterado após 6 meses, porém a função renal se mantém preservada. Um paciente do grupo laparoscópica foi a óbito 3 meses após a cirurgia por edema agudo de pulmão, com o rim funcionante. Não ocorreram casos de perda do enxerto durante o período avaliado de 6 meses após o transplante.

Tabela 6 - Função renal avaliada pelos níveis de creatinina no pós-operatório nos grupos aberta vs laparoscópica

\begin{tabular}{cccc}
\hline & Aberta & Laparoscópica & Valor de $\mathrm{p}^{\phi}$ \\
\hline $\begin{array}{c}\text { Média da } \\
\text { creatinina } \pm \mathrm{DP}, \\
(\mathrm{mg} / \mathrm{dl})\end{array}$ & & & \\
$1^{\circ} \mathrm{dia}$ & $3,9 \pm 2,01$ & $4,1 \pm 2,10$ & \\
$2^{\circ} \mathrm{dia}$ & $2,4 \pm 1,16$ & $2,3 \pm 1,21$ & 0.709 \\
$3^{\circ}$ dia & $2,0 \pm 0,95$ & $1,9 \pm 1,28$ & 0,774 \\
$4^{\circ}$ dia & $1,9 \pm 1,13$ & $1,8 \pm 1,59$ & 0.763 \\
$5^{\circ}$ dia & $1,9 \pm 1,18$ & $2,0 \pm 1,55$ & 0,709 \\
$6^{\circ}$ dia & $2,0 \pm 1,27$ & $2,2 \pm 2,19$ & 0.898 \\
$7^{\circ}$ dia & $1,7 \pm 1,23$ & $2,2 \pm 2,42$ & 0,667 \\
$30^{\circ}$ dia & $1,3 \pm 0,33$ & $1,4 \pm 0,55$ & 0.409 \\
$3^{\circ}$ mês & $1,2 \pm 0,28$ & $1,3 \pm 0,39$ & 0.168 \\
$6^{\circ}$ mês & $1,2 \pm 0,34$ & $1,3 \pm 0,36$ & 0.242 \\
teste t & & & 0,396 \\
DP=desvio padrão & &
\end{tabular}




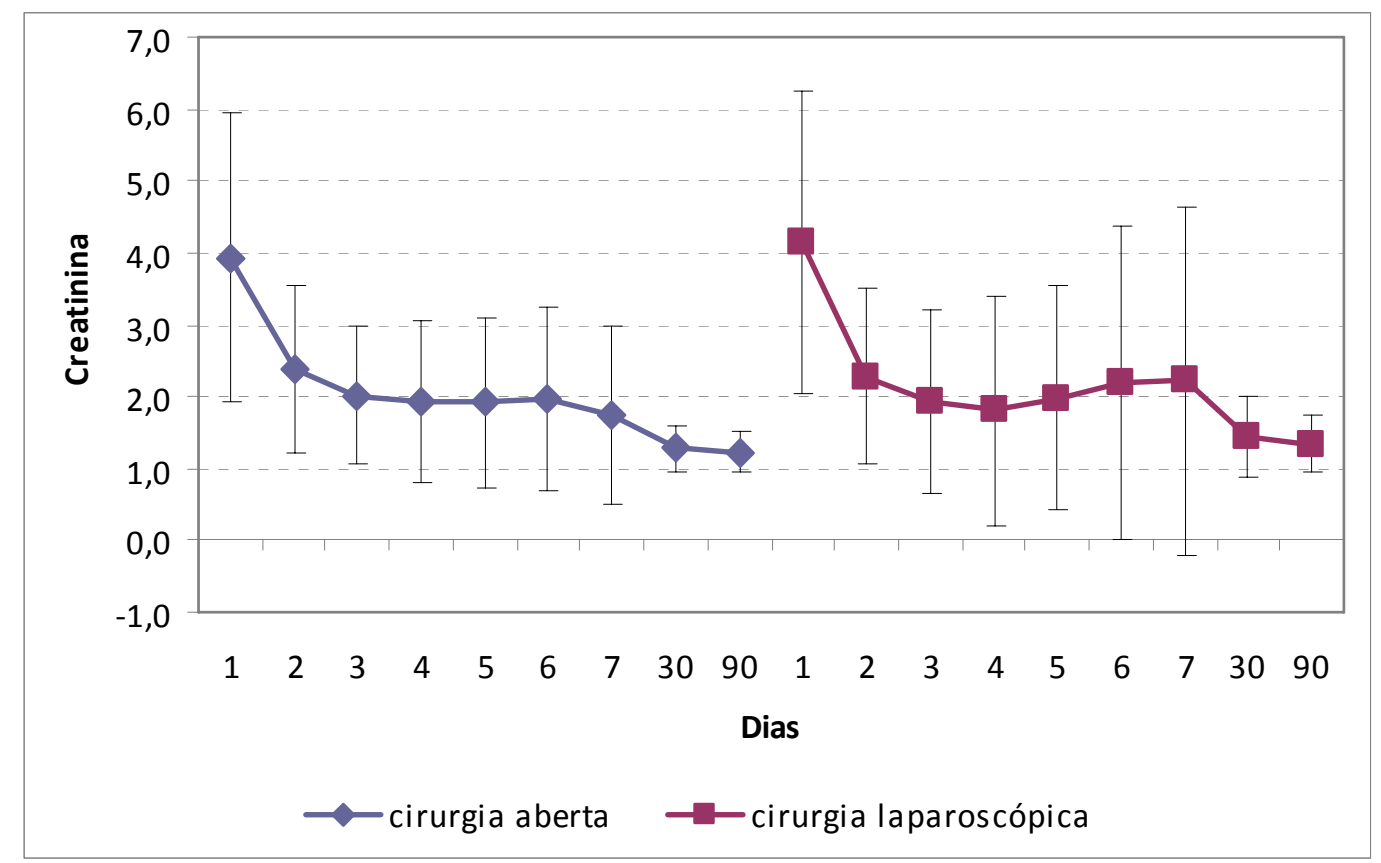

Figura 8: Curva da média e desvio padrão da creatinina no pós-operatório.

\subsection{4 -Área sob a curva de creatinina $\left(\mathrm{ASC}_{\mathrm{cr}}\right)$ e dados demográficos}

$A \mathrm{ASC}_{\mathrm{cr}}$ foi confrontada com dados demográficos do receptor e do doador a fim de se encontrar associações entre estes parâmetros. Ao se observar a média da $\mathrm{ASC}_{\mathrm{cr}}$ de acordo com o sexo do receptor, observou-se que a média da $A_{S C}$ no sexo masculino era maior que no sexo feminino tanto no grupo aberta (média=138,6, média=107,7; $p=0,008$ ) quanto no grupo laparoscópica (média=163,3; média=99,3; $p=0,001$ ). Não houve correlação significativa entre outros parâmetros do receptor como idade, IMC e pesquisa de reatividade contra painel de antígenos HLA (PRA).

Com relação aos dados do doador, encontrou-se uma média de $\mathrm{ASC}_{\mathrm{cr}}$ maior nos indivíduos que receberam o rim de doadores do sexo feminino no grupo laparoscópica (média=141,1; média=97,4; $p=0,010$ ), sem diferença no grupo aberta $(p=0,133)$. Foi observada uma associação, ainda que fraca (Pearson $r=0,378 ; p=0,048$ ), com a idade do doador no grupo aberta, sem diferença no grupo laparoscópica (Pearson $r=0,121 ; p=0,564$ ). O IMC do doador não se correlacionou com a ASC $_{c r}$ (grupo aberta: Pearson $r=0,383$; $p=0,078$, grupo laparoscópica:Pearson $r=-0,010 ; p=0,968)$. 


\subsection{5 - Função retardada do enxerto (FRE) e função retardada do enxerto funcional (FREF) e dados demográficos}

Foi avaliada a função retardada do enxerto e função retardada do enxerto funcional com os principais dados demográficos. No grupo laparoscópica observou-se uma média de idade inferior nos pacientes com FRE e FREF comparada aos pacientes sem FRE e FREF (média=32,4; média $=46,9 ; p=0,011$ ). Não foi observada diferença no grupo aberta. Não houve associação entre outros parâmetros como idade do doador, sexo do receptor, sexo do doador, IMC do receptor, IMC do doador e PRA.

4.1.6 - Tempo de isquemia quente (TIQ) e função retardada do enxerto (FRE) e função retardada do enxerto funcional (FREF)

Ao avaliar o tempo de isquemia quente e FRE e FREF, não se observa diferença entres as médias do TIQ nos pacientes com ou sem FRE e FREF grupos aberta ou laparoscópica $(p=0,228$ e $p=0,973$, respectivamente - teste não-paramétrico de Wilcoxon).

4.1.7 - Tempo de isquemia quente (TIQ) e área sob a curva de creatinina ( ASC $_{\mathrm{cr}}$ )

Avaliou-se se o tempo de isquemia quente influenciava a área sob a curva de creatinina por meio do coeficiente de correlação de Pearson. Não foi observada associação entre estas variáveis no grupo aberta (Pearson $r=$ $-0,241 ; p=0,225$ ) ou no grupo laparoscópica (Pearson $r=-0,318 ; p=0,130$ ) (Figuras 9 e 10) 


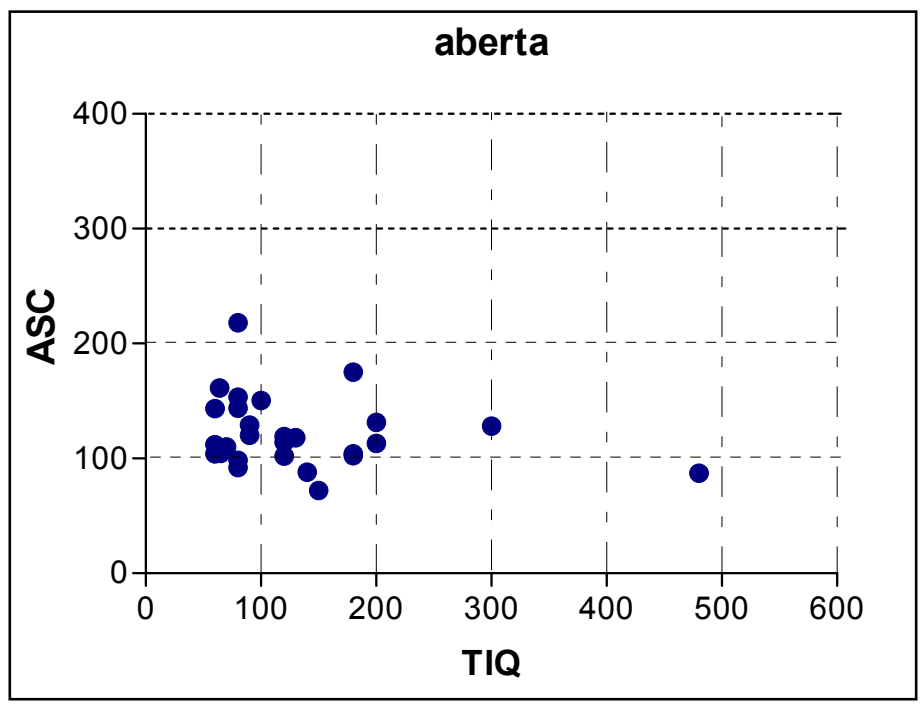

Figura 9: Diagrama de dispersão para tempo de isquemia quente (TIQ) e área sob a curva de creatinina ( $\mathrm{ASC}_{\mathrm{cr}}$ ) no grupo aberta

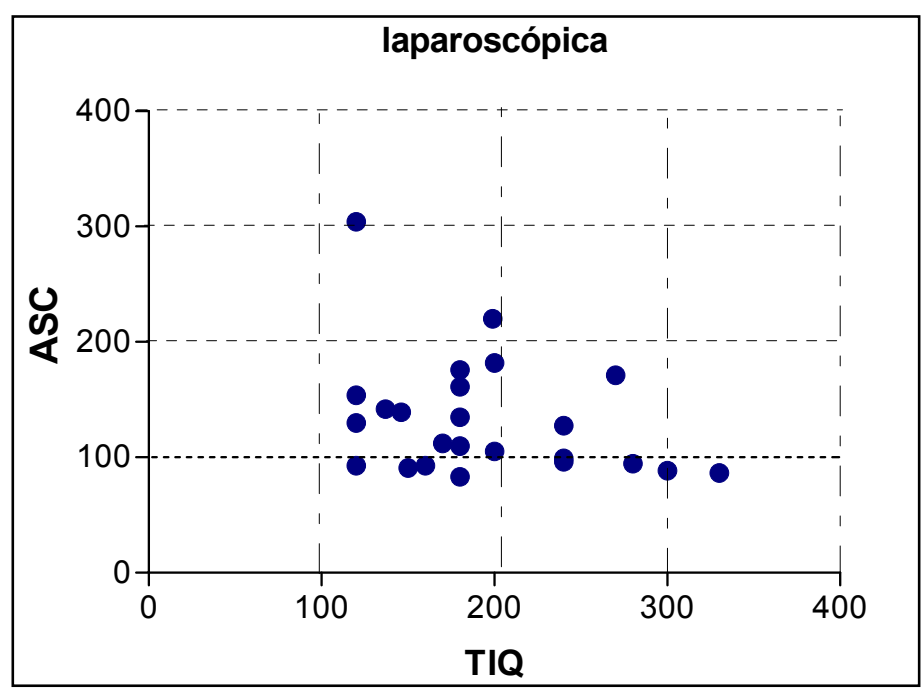

Figura 10: Diagrama de dispersão para tempo de isquemia quente (TIQ) e área sob a curva de creatinina $\left(\mathrm{ASC}_{\mathrm{cr}}\right.$ ) no grupo laparoscópica

\section{2 - EXPRESSÃO DE RNA}

A extração de RNA foi realizada em 36 pacientes, totalizando 72 amostras.

\subsection{1 - Padronização e viabilidade das amostras}

Os processos de extração do RNA total, transcrição reversa e a reação de PCR em tempo real passaram por processo de padronização e 
checagem da qualidade do RNA extraído. Foram 4 extrações de RNA a partir dos fragmentos de biópsias renais, com o total de 72 amostras. A quantidade de RNA extraído de cada amostra está detalhada no apêndice A. Os genes $18 \mathrm{~S}$ e ciclofilina são considerados genes constitutivos e foram utilizados como controles endógenos das amostras. Foram descartadas 9 amostras em que a expressão destes genes foi muito baixa, com Ct maior ou igual a 38 e 39 respectivamente. Com relação aos genes estudados, observou-se uma baixa expressão na quantidade de 100ng de RNA contido em algumas amostras estudadas e preconizadas pelo fabricante para reação de PCR em tempo real. Concluiu-se que se tratava de baixa expressão e não degradação do RNA avaliando em conjunto a expressão dos genes constitutivos nestas amostras.

Durante a segunda extração, foram excluídos da análise 18 amostras (uma amostra T-1 e uma amostra T+1 de 9 pacientes) devido ao uso de solução inadequada durante a fase de precipitação do RNA. No final de todas as extrações, estavam disponíveis para realização do PCR em tempo real e análise 45 amostras de 24 pacientes, 13 do grupo aberta e 1 no grupo laparoscópica.

Alguns genes, principalmente TNFalfa, Bcl-2, HIF-1a, apresentaram expressão praticamente inexistente em algumas amostras. Estas amostras foram excluídas da análise dos resultados de cada gene.

Nos parágrafos seguintes serão mostrados os resultados da expressão relativa de RNA de diferentes genes estudados. Apenas para relembrar, já detalhado anteriormente em métodos, os resultados da expressão relativa de RNA estão apresentados em $\triangle \mathrm{Ct}$ (Ct do gene testado menos o Ct do gene constitutivo 18S) e QR que é uma razão entre a expressão do gene alvo em relação à média da expressão do gene no grupo controle (cirurgia aberta). $\mathrm{Na}$ interpretação dos resultados expressos em $\Delta \mathrm{Ct}$, importante lembrar que quanto menor o valor do $\mathrm{Ct}$, maior a expressão do gene. Na interpretação dos resultados expressos em QR, como a QR é uma razão que trata de valores individuais, para verificar se a média de $Q R$ apresentava diferença estatística entre os grupos, foi testada a hipótese de 
que o valor médio de $Q R$ era igual a 1, conferindo igualdade entre o grupo testado e o grupo controle. Ao notar-se diferença estatística assume-se que houve diferença da média (diminuição ou aumento da expressão).

\subsection{2 - Expressão de RNA de genes antiapoptóticos e citoprotetores}

\section{$-\mathrm{Bcl}-2$}

Foram analisados 24 pacientes, num total de 39 amostras. No grupo cirurgia aberta 13 amostras foram avaliadas no momento da retirada (T-1) e 11 amostras no momento após reperfusão $(T+1)$. No grupo laparoscópico 9 amostras foram avaliadas no momento da retirada (T-1) e 6 amostras no momento após reperfusão $(T+1)$. Ao analisar os resultados quanto ao $\Delta \mathrm{Ct}$, não se notou diferença entre os grupos aberta e laparoscópica tanto no momento $\mathrm{T}-1(\mathrm{p}=0,754)$ como no momento $\mathrm{T}+1 \quad(\mathrm{p}=0,818)$ (Figura 11). A elevação de $\Delta \mathrm{Ct}$ corresponde à diminuição da expressão gênica, enquanto a diminuição do $\Delta \mathrm{Ct}$ equivale ao aumento da expressão de RNAm do gene. Comparando cada grupo nos dois diferentes momentos de biópsia, não observamos diferença estatística $(p=0,775)$ entre os momentos T-1 (média=10,29) e T+1 (média=10,94) no grupo aberta. No grupo laparoscópica, houve uma tendência $(p=0,087)$ de diminuição da expressão de $\mathrm{BCl}-2$ no momento após a reperfusão, com aumento do $\Delta \mathrm{Ct}$ entre os momentos T-1 (média=9,98) e T+1 (média=11,25) (Figura 12). 
Bcl-2

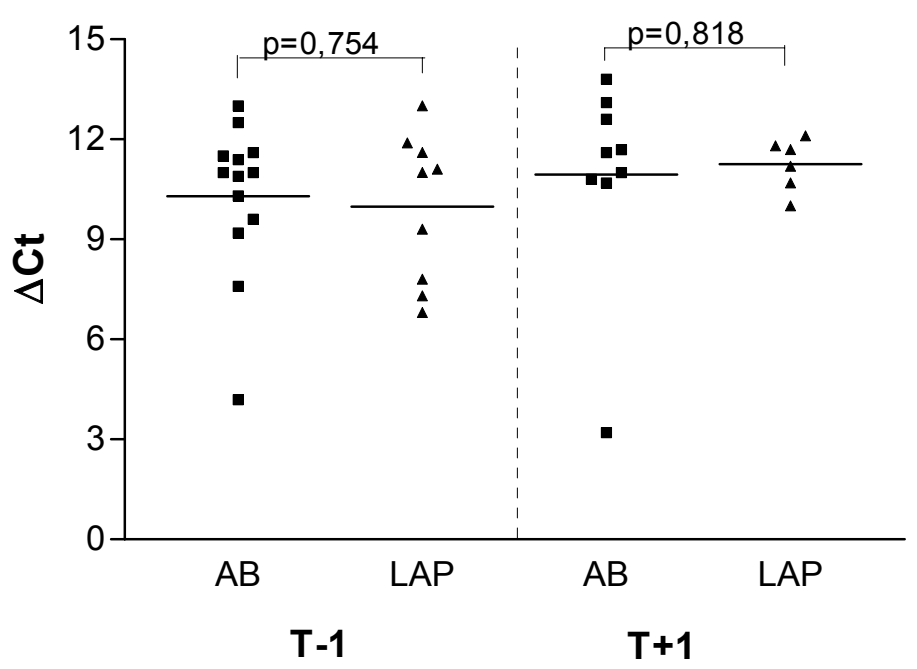

Figura 11: Valores individuais para $\triangle \mathrm{Ct}$ do gene $\mathrm{Bcl}-2$ nos grupos aberta $(A B)$ e laparoscópica (LAP) em seus respectivos momentos $\mathrm{T}-1=$ momento após retirada e $\mathrm{T}+1=$ momento após reperfusão.
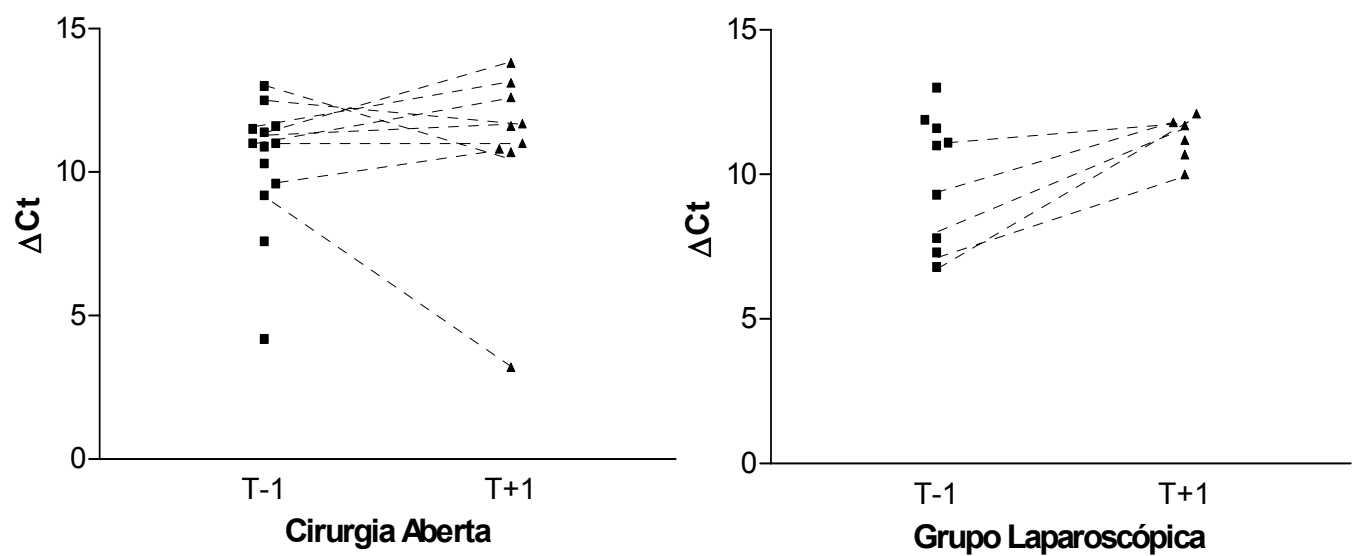

Figura 12: Observação da cinética da expressão de RNAm do gene Bcl-2 através do $\Delta$ Ct nos grupos aberta (AB) e laparoscópica (LAP)

Utilizou-se também o valor de QR para analisar o grupo aberta e laparoscópica, através do qual se obtém uma razão entre o grupo laparoscópica e seu controle que é o grupo aberta. Não foi encontrada diferença entre os grupos laparoscópica e aberta nos dois momentos T-1 $(p=0,142)$ e $T+1(p=0,683)$ (tabela 7$)$. Realizamos nova normalização entre os momentos $\mathrm{T}-1$ e $\mathrm{T}+1$ do grupo laparoscópica para se ter uma quantificação relativa entre estes momentos, utilizando-se o tempo T-1 como 
controle, e observou-se uma redução da expressão de RNAm no momento após reperfusão (média=0,47, p=0,007) (Figura 13).

Tabela 7 - Valores de QR de Bcl-2 para cirugia laparoscópica, com relação à cirurgia aberta

\begin{tabular}{lcc}
\hline Momento & Média $\pm D P$ & Valor de $p$ \\
\hline$T-1(n=9)$ & $3,23 \pm 4,11$ & 0,142 \\
$T+1(n=6)$ & $0,9 \pm 0,566$ & 0,683
\end{tabular}

T-1=momento após retirada; T+1=momento após reperfusão $\mathrm{DP}=$ desvio padrão

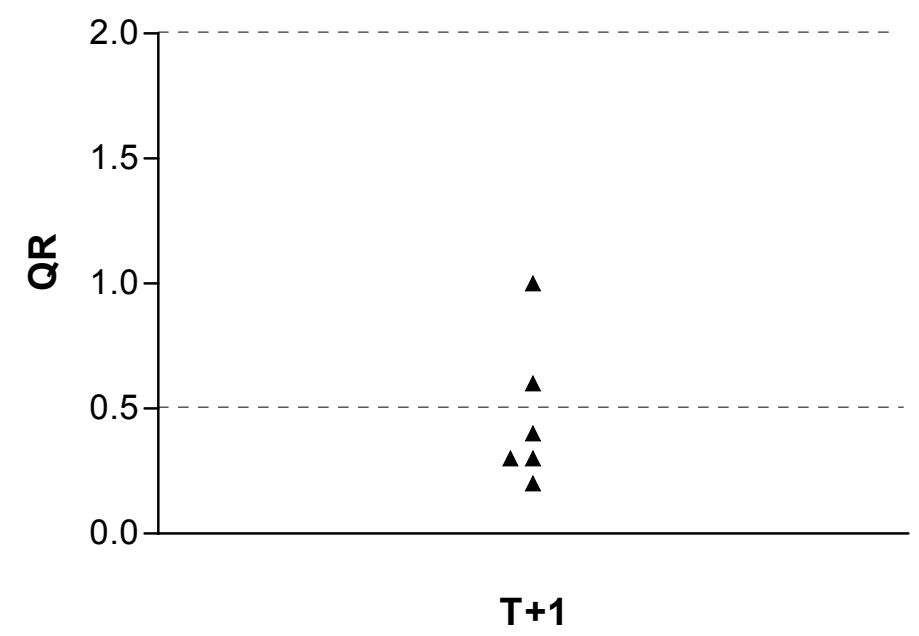

Figura 13: Expressão do gene $\mathrm{Bcl}-2$ no momento $\mathrm{T}+1$ avaliada pelaQR em relação ao momento T-1, mostrando valores abaixo de 0,5 (diminuição da expressão) e maiores que 2 (aumento da expressão)

Em resumo, não foi observada diferença entre os grupos aberta e laparoscópica com relação ao $\Delta \mathrm{Ct}$ e $\mathrm{QR}$ do gene $\mathrm{Bcl}$-2, porém houve uma redução da expressão do gene no grupo laparoscópica após a reperfusão.

\section{- Proteína de choque térmico 70 - Hsp 70}

Foram analisados 24 pacientes, num total de 38 amostras. No grupo cirurgia aberta 12 amostras foram avaliadas no momento da retirada (T-1) e 9 amostras no momento após reperfusão $(T+1)$. No grupo laparoscópica 9 casos foram avaliados no momento da retirada (T-1) e 8 casos no momento após reperfusão $(T+1)$. Os resultados avaliados pelo $\Delta C t$ não apresentaram 
diferença entre os grupos laparoscópica e aberta nos dois diferentes momentos, $\mathrm{T}-1 \quad(p=0,368)$ e $\mathrm{T}+1 \quad(p=0,853)$ (Figura 14). A elevação de $\Delta \mathrm{Ct}$ corresponde à diminuição da expressão gênica, enquanto a diminuição do $\Delta \mathrm{Ct}$ equivale ao aumento da expressão de RNAm do gene. Comparando o $\Delta \mathrm{Ct}$ de cada grupo nos dois diferentes momentos de biópsia, não observamos diferença estatística entre os momentos T-1 (média=12,01) e $T+1$ (média=11,39) tanto no grupo aberta $(p=0,286)$, quanto no grupo laparoscópica (T-1: média=10,24, T+1:média=10,98; $p=0,839)$ (Figura 15).

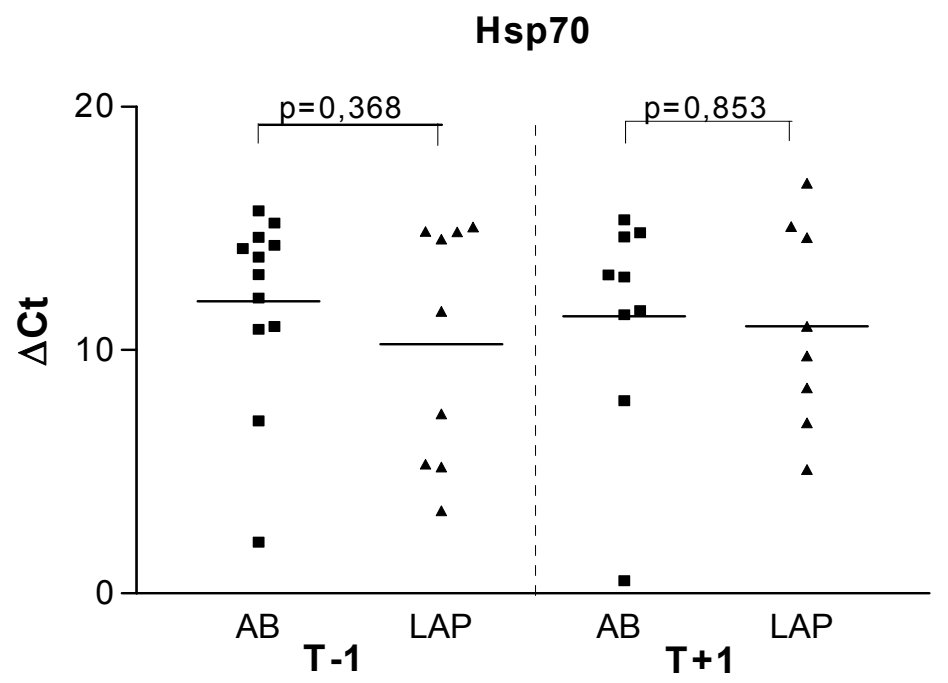

Figura 14 : Valores individuais para $\triangle \mathrm{Ct}$ do gene Hsp70 nos grupos aberta (AB) e laparoscópica (LAP) em seus respectivos momentos $\mathrm{T}-1=$ momento após retirada e $\mathrm{T}+1=$ momento após reperfusão 

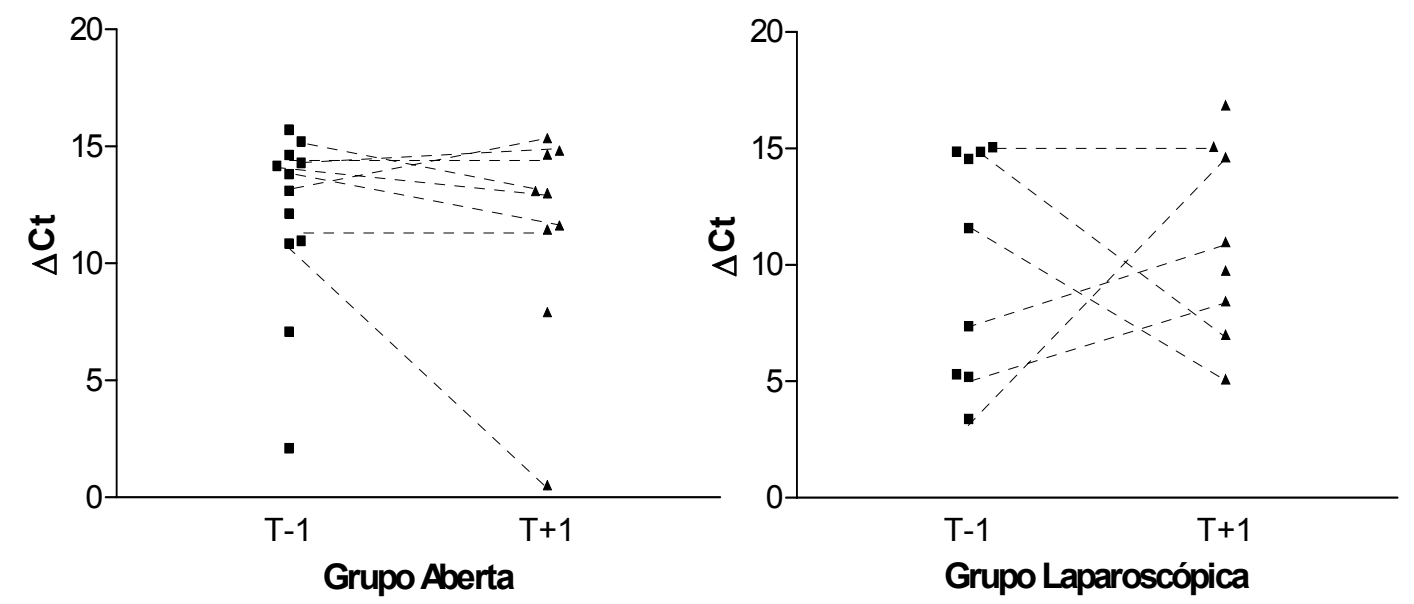

Figura 15: Observação da cinética da expressão de RNAm do gene Hsp70 através do $\Delta$ Ct nos grupos aberta (AB) e laparoscópica (LAP)

Utilizou-se também O QR para analisar o grupo aberta e laparoscópica, através da qual se obtém uma razão entre o grupo laparoscópica e seu controle que é o grupo aberta. Não foi encontrada diferença entre os grupos nos dois momentos T-1 $(p=0,144)$ e $T+1(p=0,237)$ (tabela 8). Realizamos nova normalização entre os momentos $\mathrm{T}-1$ e $\mathrm{T}+1$ do grupo laparoscópica para se ter uma quantificação relativa entre estes momentos, utilizando-se o tempo T-1 como controle, não ocorrendo diferença no momento após reperfusão (média=6,01, p=0,282) (Figura 16).

Tabela 8 - Valores de QR de Hsp70 para cirugia laparoscópica, com relação à cirurgia aberta

\begin{tabular}{|c|c|c|}
\hline Momento & Média $\pm \mathrm{DP}$ & Valor de $p$ \\
\hline $\mathrm{T}-1(\mathrm{n}=9)$ & $70,8 \pm 129,0$ & 0,144 \\
\hline$T+1(n=8)$ & $13,3 \pm 26,9$ & 0,237 \\
\hline
\end{tabular}




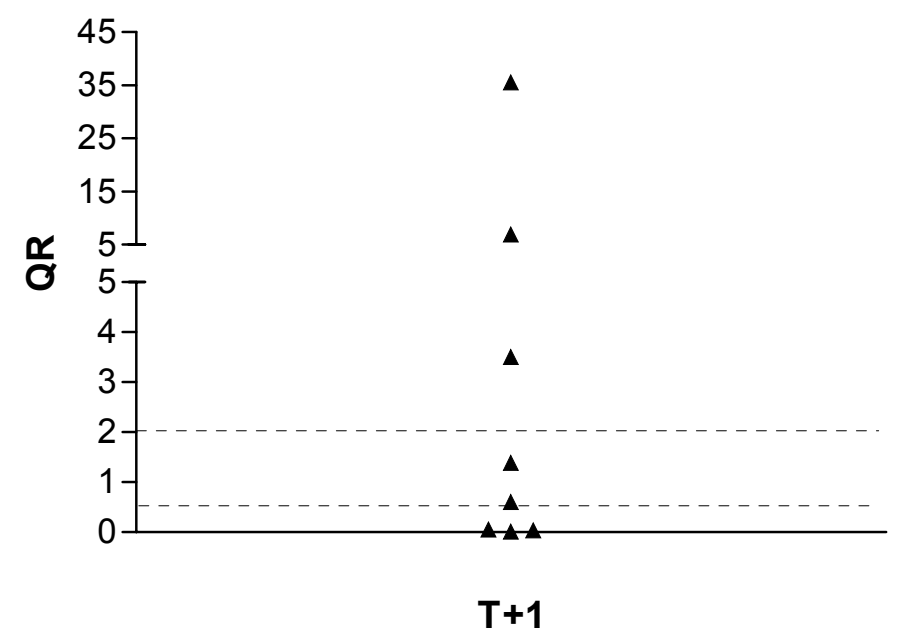

Figura 16: Expressão do gene Hsp70 no momento $T+1$ avaliada pela $Q R$ em relação ao momento $T-1$, mostrando valores abaixo de 0,5 (diminuição da expressão) e maiores que 2 (aumento da expressão), com grande variabilidade

Em resumo, não foi observada diferença entre os grupos aberta e laparoscópica com relação ao $\Delta C$ t e QR do gene Hsp 70, e também entre os momentos avaliados.

\section{- Fator de crescimento endotelial vascular - VEGF}

De um total de 24 pacientes, apenas 35 amostras puderam ser analisadas, sendo 11 amostras do grupo aberto no momento $\mathrm{T}-1$, nove amostras no grupo aberto após reperfusão $(T+1)$. No grupo laparoscópico foram analisadas 8 amostras no momento após a retirada T-1 e 7 amostras após reperfusão $(T+1)$. Os resultados avaliados pelo $\Delta C t$ não apresentaram diferença entre os grupos laparoscópica e aberta nos dois diferentes momentos $\mathrm{T}-1 \quad(p=0,637)$ e $T+1 \quad(p=0,519)$ (Figura 17). Comparando cada grupo nos dois diferentes momentos de biópsia, no grupo aberta não houve diferença entre os momentos $\mathrm{T}-1$ (média=10,66) e $\mathrm{T}+1$ (média=11,11; $\mathrm{p}=0,705)$. No grupo laparoscópica, a média do $\Delta \mathrm{Ct}$ entre o momento T-1 (média=10,38) e o momento $T+1 \quad$ (média=11,71) não foi diferente estatisticamente $(p=0,264)$ (Figura 18). 


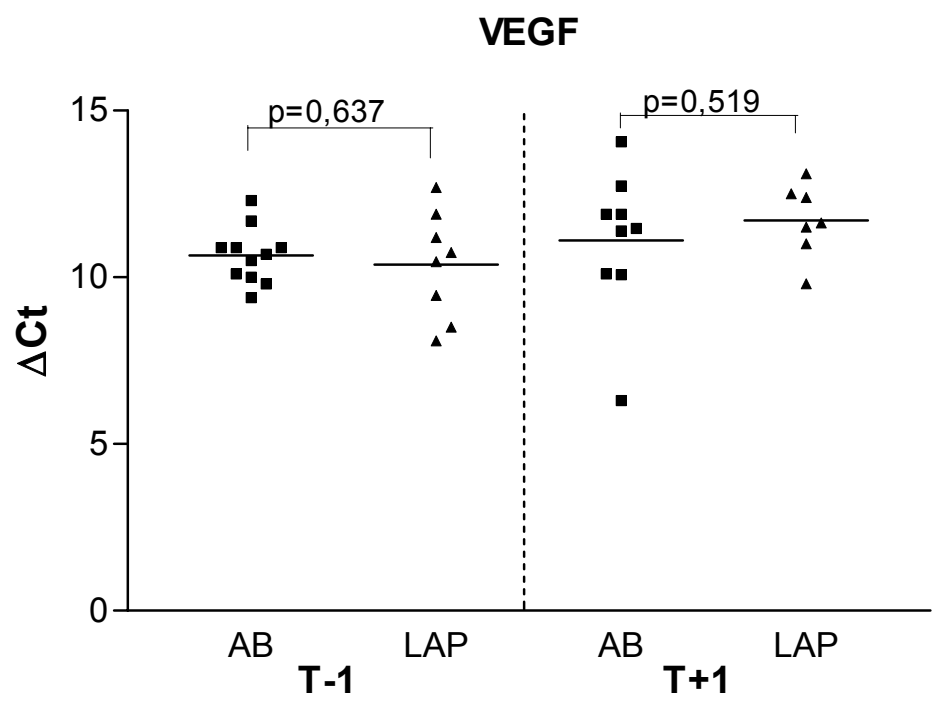

Figura 17: Valores individuais para $\triangle C$ t do gene VEGF nos grupos aberta $(A B)$ e laparoscópica (LAP) em seus respectivos momentos $\mathrm{T}-1=$ momento após retirada e $T+1=$ momento após reperfusão
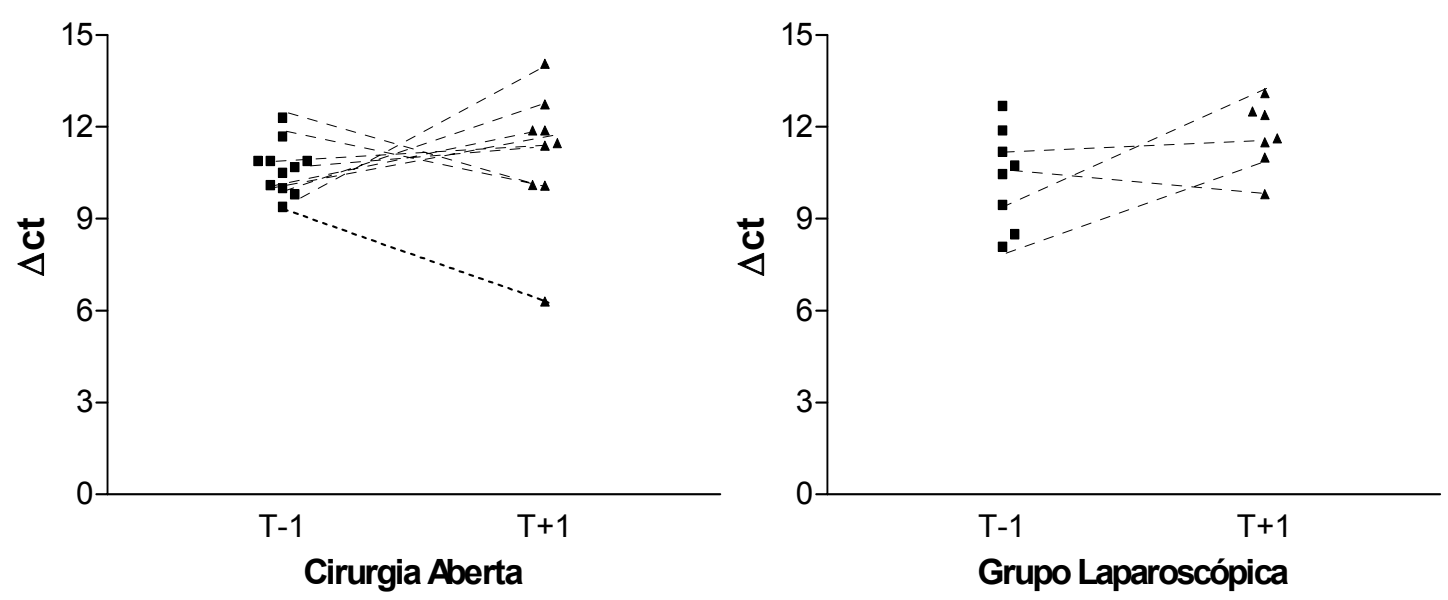

Figura 18: Observação da cinética da expressão de RNAm do gene VEGF através do $\Delta$ Ct nos grupos aberta (AB) e laparoscópica (LAP)

Utilizou-se também o valor de QR para analisar o grupo aberta e laparoscópica, através do qual se obtém uma razão entre o grupo laparoscópica e seu controle que é o grupo aberta. Não foi encontrada diferença entre os grupos nos dois momentos T-1 $(p=0,216)$ e $T+1(p=0,631)$ (tabela 9). Ao se realizar normalização entre os momentos T-1 e T+1 do grupo laparoscópica para se ter uma quantificação relativa entre estes momentos, utilizando-se o tempo T-1 como controle, notou-se diminuição 
significativa da média do QR (média=0,52, $p=0,034$ ) no momento após reperfusão (Figura 19).

Tabela 9 - Valores de QR de VEGF para cirugia laparoscópica, com relação à cirurgia aberta

\begin{tabular}{lcc}
\hline Momento & Média $\pm D P$ & Valor de $p$ \\
\hline$T-1(n=8)$ & $2,0 \pm 2,08$ & 0,216 \\
$T+1(n=7)$ & $0,85 \pm 0,75$ & 0,631
\end{tabular}

T-1=momento após retirada; $T+1=$ momento após reperfusão $\mathrm{DP}=$ desvio padrão

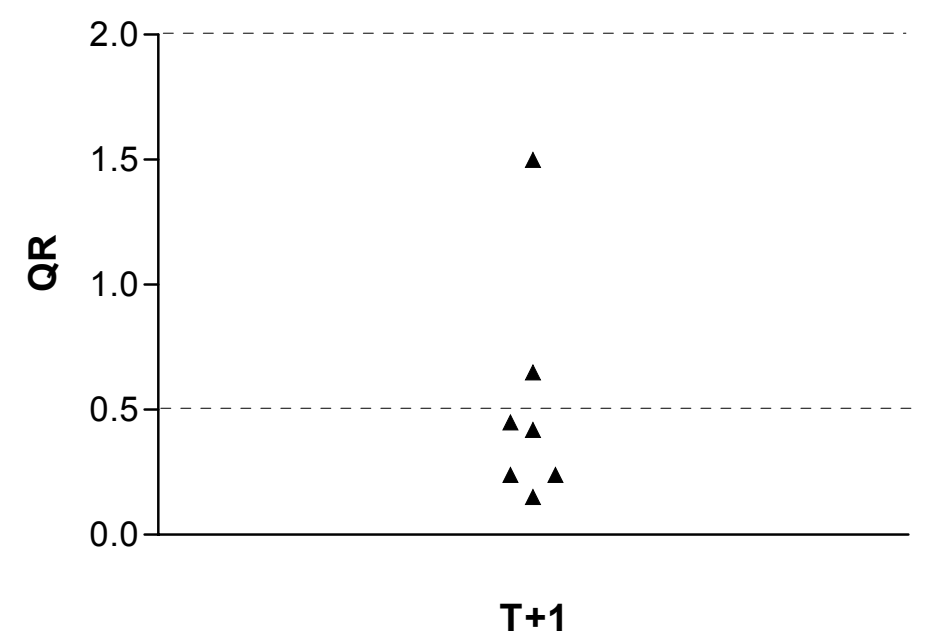

Figura 19: Expressão do gene VEGF no momento $T+1$ avaliada pela $Q R$ em relação ao momento $\mathrm{T}-1$, mostrando valores abaixo de 0,5 (diminuição da expressão) e maiores que 2 (aumento da expressão)

Em resumo, não foi observada diferença entre os grupos aberta e laparoscópica com relação ao $\Delta \mathrm{Ct}$ e QR do gene VEGF, porém houve uma redução da expressão do gene no grupo laparoscópica após a reperfusão.

\section{- Heme-oxigenase HO-1}

Foram avaliados 24 pacientes, totalizando 39 amostras. No grupo aberta foram analisadas 13 amostras no momento T-1 e 10 amostras no momento da reperfusão $(T+1)$. No grupo laparoscópico a expressão de transcritos gênicos da HO-1 foi analisada em 9 amostras no momento após retirada ( $\mathrm{T}$ - 
1) e 7 amostras no momento após reperfusão $(T+1)$. Ao analisar os resultados quanto ao $\Delta \mathrm{Ct}$, não se notou diferença entre os grupos aberta $\mathrm{e}$ laparoscópica tanto no momento $\mathrm{T}-1 \quad(\mathrm{p}=0,571)$ como no momento $\mathrm{T}+1$ $(p=0,765)$ (Figura 20). A elevação de $\Delta C t$ corresponde à diminuição da expressão gênica, enquanto a diminuição do $\Delta \mathrm{Ct}$ equivale ao aumento da expressão de RNAm do gene. Comparando cada grupo nos dois diferentes momentos de biópsia, não observamos diferença estatística entre os momentos tanto no grupo aberta (T-1: média=10,86, T+1:média=10,42; $p=0,451$, quanto no grupo laparoscópica $(T-1:$ média $=10,11, T+1$ :média= 10,90, $p=0,406)$ (Figura 21).

HO-1

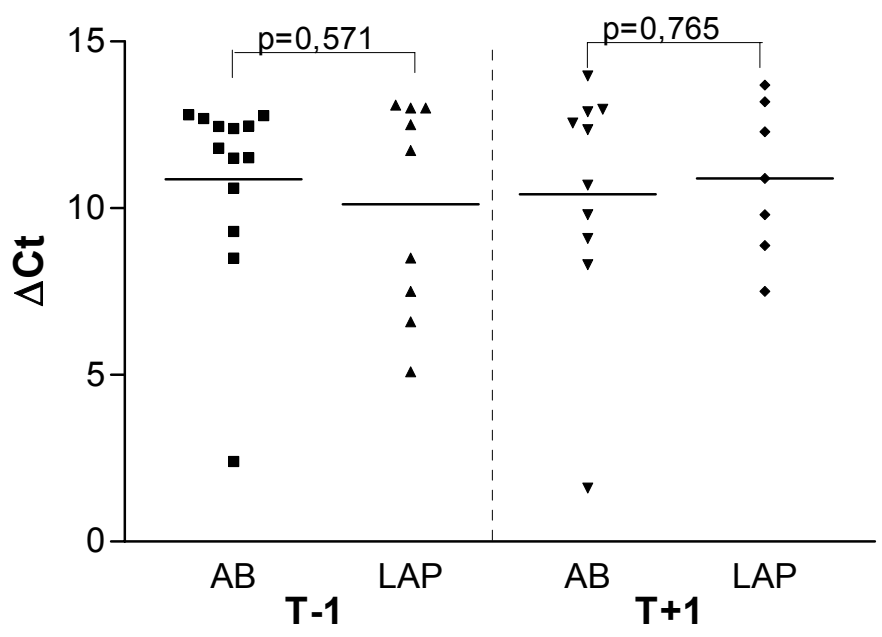

Figura 20: Valores individuais para $\triangle \mathrm{Ct}$ do gene $\mathrm{HO}-1$ nos grupos aberta $(A B)$ e laparoscópica (LAP) em seus respectivos momentos $\mathrm{T}-1=$ momento após retirada e $T+1=$ momento após reperfusão 

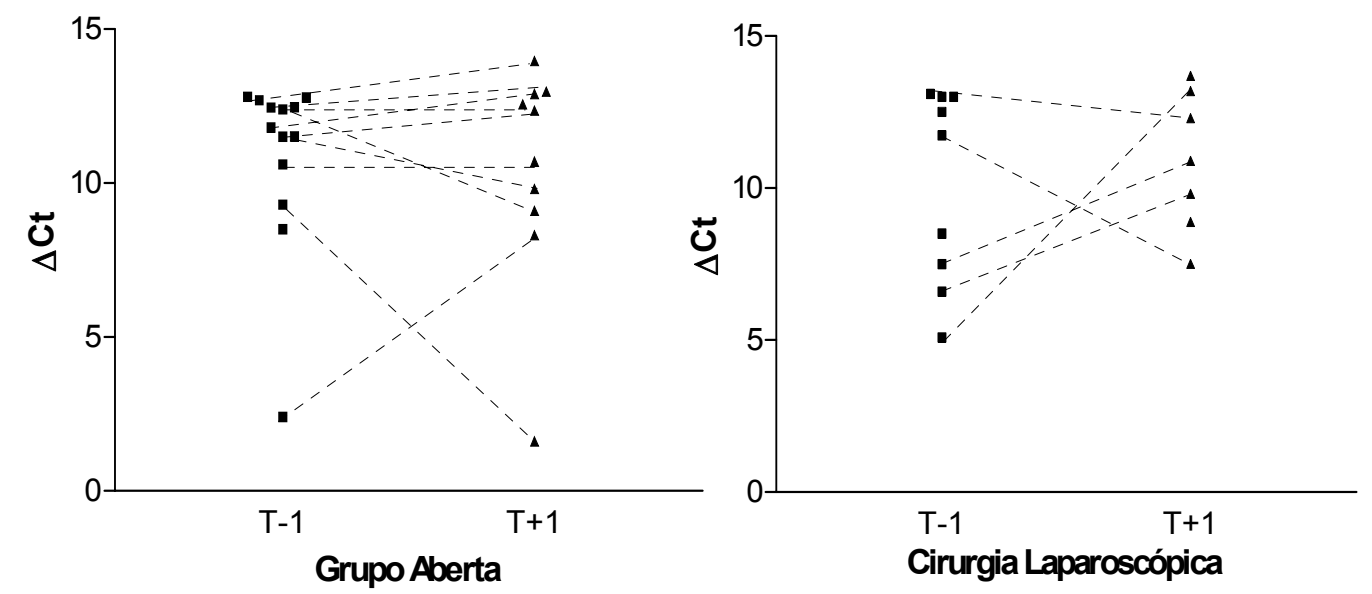

Figura 21: Observação da cinética da expressão de RNAm do gene HO-1 através do $\Delta$ Ct nos grupos aberta (AB) e laparoscópica (LAP)

Utilizou-se também o valor de QR para analisar o grupo aberta e laparoscópica, através do qual se obtém uma razão entre o grupo laparoscópica e seu controle que é o grupo aberta. Não foi encontrada diferença entre os grupos nos dois momentos T-1 $(p=0,127)$ e $T+1(p=0,410)$ (tabela 10). Realizou-se nova normalização entre os momentos T-1 e T+1 do grupo laparoscópica para se ter uma quantificação relativa entre estes momentos, utilizando-se o tempo T-1 como controle, e observou-se uma média de QR de 1,55 no momento após reperfusão, sem diferença estatística $(p=0,540)$ (Figura 22).

Tabela 10 - Valores de QR de HO-1 para cirugia laparoscópica, com relação à cirurgia aberta

\begin{tabular}{ccc}
\hline Momento & Média $\pm D P$ & Valor de $p$ \\
\hline$T-1(n=9)$ & $10,2 \pm 17,97$ & 0,127 \\
$T+1(n=7)$ & $1,93 \pm 2,78$ & 0,410
\end{tabular}

T-1=momento após retirada; T+1=momento após reperfusão $\mathrm{DP}=$ desvio padrão 


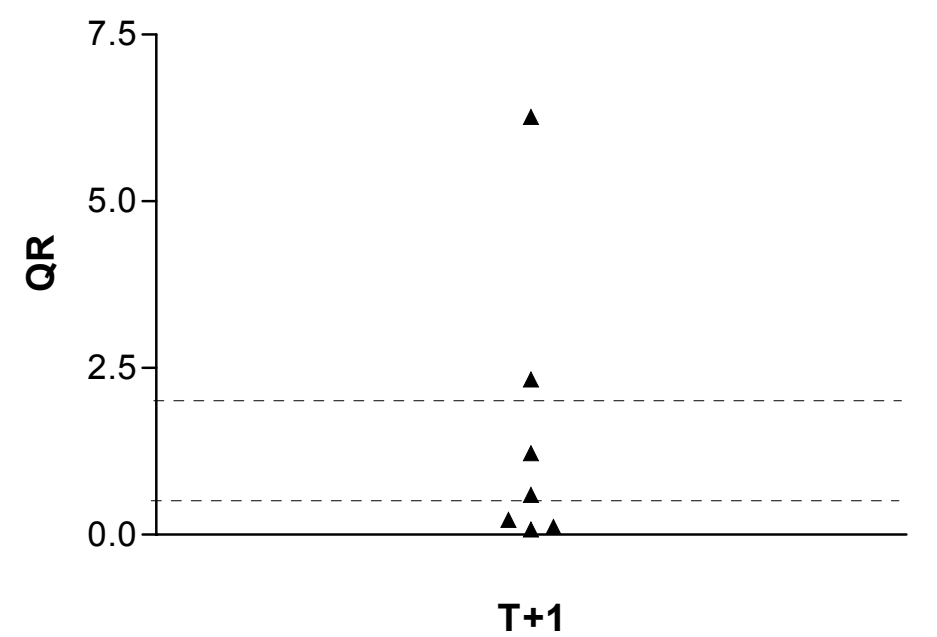

Figura 22: Expressão do gene HO-1 no momento $T+1$ avaliada pela $Q R$ em relação ao momento $T-1$, mostrando valores abaixo de 0,5 (diminuição da expressão) e maiores que 2 (aumento da expressão)

Em resumo, não foi observada diferença entre os grupos aberta e laparoscópica com relação ao $\Delta \mathrm{Ct}$ e QR do gene HO-1, e também entre os momentos $\mathrm{T}-1$ e $\mathrm{T}+1$.

\subsection{3 - Expressão de RNA de genes inflamatórios e de transcrição}

\section{- Fator de necrose tumoral (TNFa)}

Foram avaliados 24 pacientes, totalizando 29 amostras. No grupo aberta foram analisadas 11 amostras no momento T-1 e 8 amostras no momento da reperfusão $(T+1)$. No grupo laparoscópico a expressão do gene TNFa foi avaliada em 6 amostras no momento T-1 e em 4 amostras no momento após reperfusão $(\mathrm{T}+1)$. Os resultados avaliados pelo $\Delta \mathrm{Ct}$ não apresentaram diferença entre os grupos laparoscópica e aberta nos dois diferentes momentos, $\mathrm{T}-1 \quad(p=0,546)$ e $\mathrm{T}+1 \quad(p=0,497)$ (Figura 23). Comparando cada grupo nos dois diferentes momentos de biópsia, no grupo aberta não se notou diferença entre os momentos $T-1$ (média=16,1) e T+1 (média $=15,4 ; p=0,594$ ). No grupo laparoscópica, as médias do $\Delta C t$ entre o momento T-1 (média=15,1) e o momento $T+1$ (média=16,8) não tiveram diferença significativa $(p=0,500)$ (Figura 24). 
TNF $\alpha$

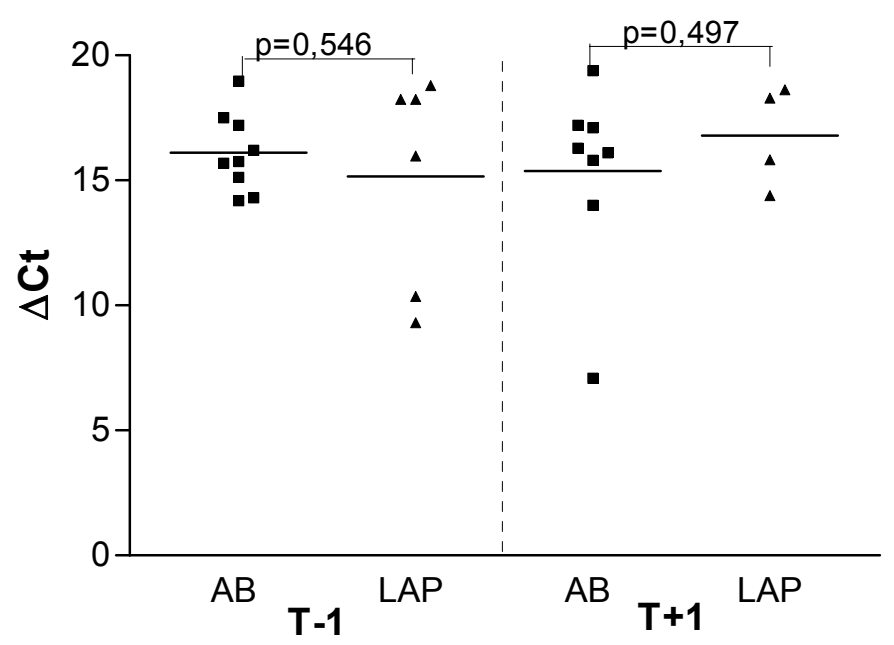

Figura 23: Valores individuais para $\triangle \mathrm{Ct}$ do gene $T N F a$ nos grupos aberta $(A B)$ e laparoscópica (LAP) em seus respectivos momentos $\mathrm{T}-1=$ momento após retirada e $\mathrm{T}+1=$ momento após reperfusão
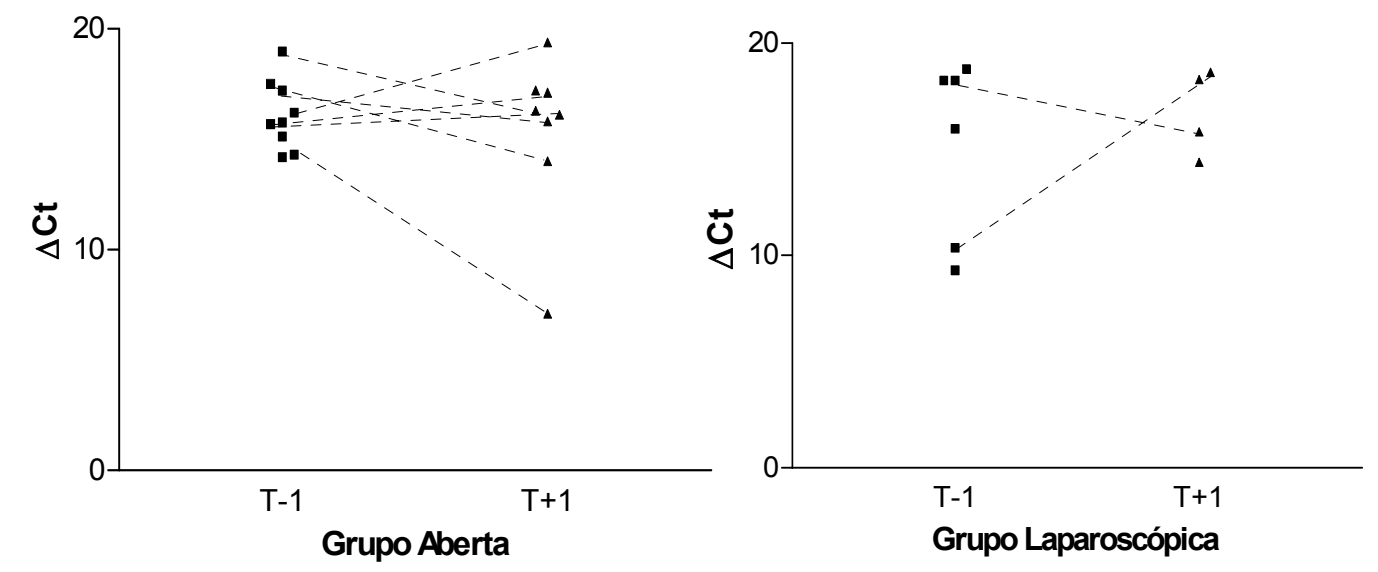

Figura 24: Observação da cinética da expressão de RNAm do gene TNFa através do $\Delta$ Ct nos grupos aberta (AB) e laparoscópica (LAP)

O valor de QR também foi utilizado para analisar o grupo aberta e laparoscópica, através do qual se obtém uma razão entre o grupo laparoscópica e seu controle que é o grupo aberta. Não foi encontrada diferença entre os grupos nos dois momentos T-1 $(p=0,213)$ e T+1 $(p=0,560)$ (tabela 11). Ao se realizar normalização entre os momentos T-1 e T+1 do grupo laparoscópica para se ter uma quantificação relativa entre estes momentos, utilizando-se o tempo T-1 como controle, obteve-se uma média do valor de $Q R$ de 0,62 , sem diferença estatística $(p=0,375)$ (Figura 25). 
Tabela 11 - Valores de QR de TNFa para cirugia laparoscópica, com relação à cirurgia aberta

\begin{tabular}{lcc}
\hline Momento & Média $\pm D P$ & Valor de $p$ \\
\hline$T-1(n=6)$ & $31,3 \pm 52,0$ & 0,213 \\
$T+1(n=4)$ & $0,72 \pm 0,85$ & 0,560
\end{tabular}

T-1=momento após retirada; $T+1=$ momento após reperfusão $\mathrm{DP}=$ desvio padrão

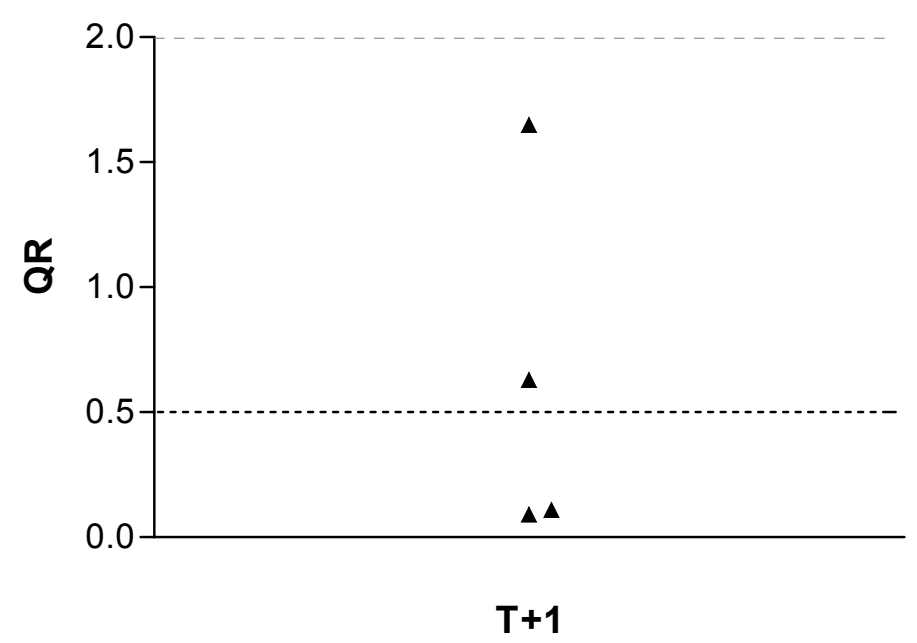

Figura 25: Expressão do gene TNFa no momento $T+1$ avaliada pela $Q R$ em relação ao momento $T-1$, mostrando valores abaixo de 0,5 (diminuição da expressão) e maiores que 2 (aumento da expressão)

Em resumo, não foi observada diferença entre os grupos aberta e laparoscópica com relação ao $\Delta \mathrm{Ct}$ e QR do gene TNFa, e também entre os momentos $\mathrm{T}-1$ e $\mathrm{T}+1$.

\section{- Interleucina 6 (IL-6)}

De 24 pacientes avaliados, foi possível a análise de 35 amostras, sendo 13 amostras do grupo aberto no momento T-1, 10 amostras no grupo aberto após reperfusão $(T+1)$. No grupo laparoscópico foram analisadas 6 amostras no momento $T-1$ e 6 amostras após reperfusão $(T+1)$. Os resultados avaliados pelo $\Delta \mathrm{Ct}$ não apresentaram diferença entre os grupos laparoscópica e aberta nos dois diferentes momentos, T-1 $(p=0,658)$ e $T+1$ $(p=0,328)$ (Figura 26). Comparando cada grupo nos dois diferentes 
momentos de biópsia, no grupo aberta não se notou diferença entre os momentos T-1 (média=13,7) e $T+1$ (média=12,7; $p=0,376$ ). No grupo laparoscópica, as médias de $\Delta \mathrm{Ct}$ no momento $\mathrm{T}-1$ (média=14,2) e T+1 (média=14,1) não foram diferentes $(p=0,314)$ (Figura 27).

\section{II-6}

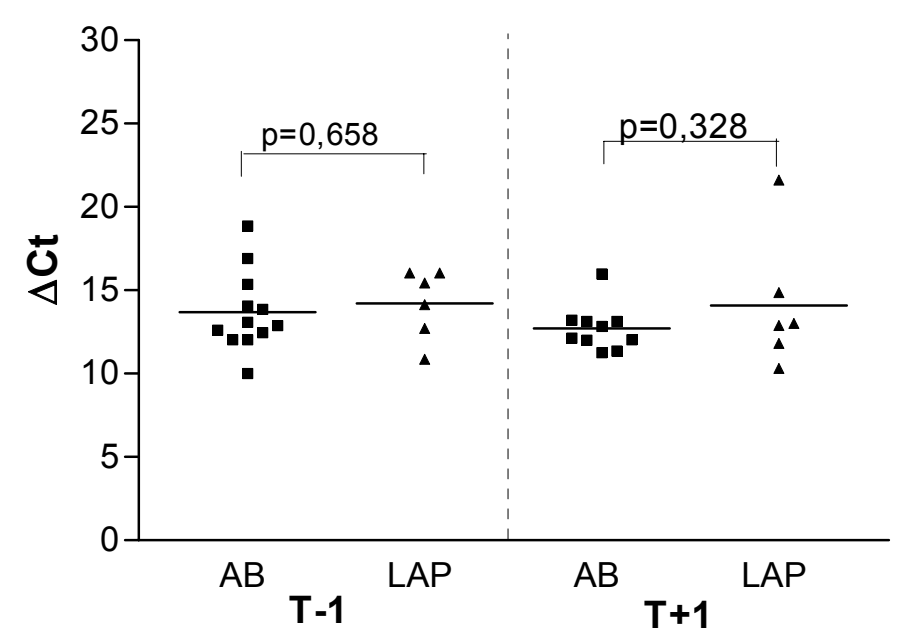

Figura 26: Valores individuais para $\Delta C t$ do gene ll-6 nos grupos aberta $(A B) e$ laparoscópica (LAP) em seus respectivos momentos T-1=momento após retirada e $\mathrm{T}+1=$ momento após reperfusão
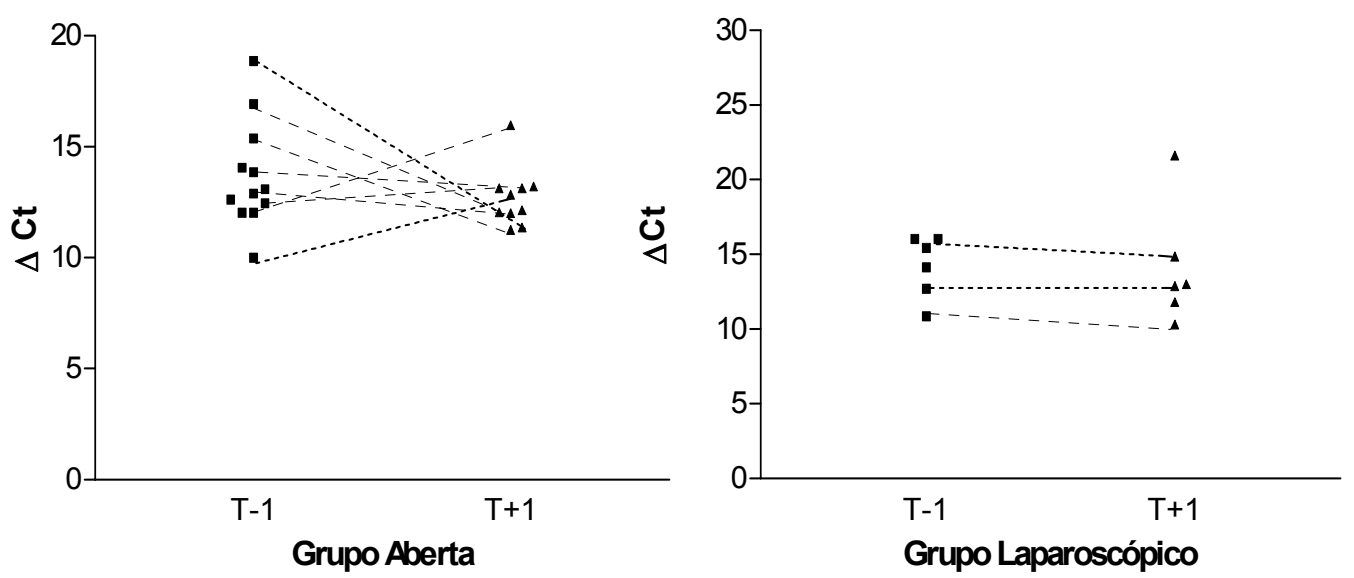

Figura 27: Observação da cinética da expressão de RNAm do gene IL-6 através do $\Delta \mathrm{Ct}$ nos grupos aberta (AB) e laparoscópica (LAP)

Utilizou-se também o valor de QR para analisar o grupo aberta e laparoscópica, através do qual se obtém uma razão entre o grupo laparoscópica e seu controle que é o grupo aberta. Não foi encontrada 
diferença entre os grupos nos dois momentos T-1 $(p=0,530)$ e $T+1(p=0,546)$ (tabela 12). Realizou-se nova normalização entre os momentos T-1 e T+1 do grupo laparoscópica para se ter uma quantificação relativa entre estes momentos, utilizando-se o tempo T-1 como controle, e observou-se uma média de QR de 4,28 no momento após reperfusão, sem diferença estatística $(p=0,208)$ (Figura 28).

Tabela 12 - Valores de QR de II-6 para cirugia laparoscópica, com relação à cirurgia aberta

\begin{tabular}{lcc}
\hline Momento & Média $\pm \mathrm{DP}$ & Valor de $\mathrm{p}$ \\
\hline $\mathrm{T}-1(\mathrm{n}=6)$ & $1,75 \pm 2,7$ & 0,530 \\
$\mathrm{~T}+1(\mathrm{n}=6)$ & $1,52 \pm 1,98$ & 0,546
\end{tabular}

$\mathrm{T}-1=$ momento após retirada; $\mathrm{T}+1=$ =momento após reperfusão $\mathrm{DP}=$ desvio padrão

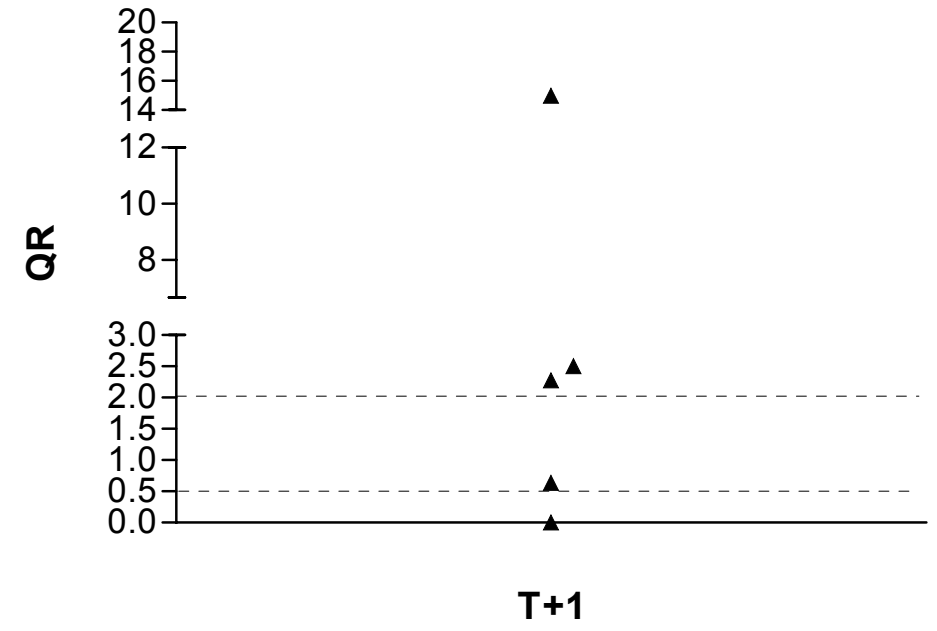

Figura 28: Expressão do gene IL-6 no momento $T+1$ avaliada pela QR em relação ao momento T-1, mostrando valores abaixo de 0,5 (diminuição da expressão) e maiores que 2 (aumento da expressão)

Em resumo, não foi observada diferença entre os grupos aberta e laparoscópica com relação ao $\Delta \mathrm{Ct}$ e QR do gene IL-6, e também entre os momentos $\mathrm{T}-1$ e $\mathrm{T}+1$. 


\section{- Fator induzível pela hipóxia 1a (HIF 1a)}

De um total de 24 pacientes, trinta e nove amostras puderam ser analisadas, sendo 13 amostras do grupo aberto no momento T-1, dez amostras no grupo aberto após reperfusão $(T+1)$. No grupo laparoscópico foram analisadas 9 amostras no momento T-1 e 7 amostras após reperfusão $(T+1)$. Os resultados avaliados pelo $\Delta C$ t não apresentaram diferença entre os grupos laparoscópica e aberta nos dois diferentes momentos, T-1 $(p=0,681)$ e $T+1 \quad(p=0,691)$ (Figura 29). Comparando cada grupo nos dois diferentes momentos de biópsia, no grupo aberta não se notou diferença estatística entre os momentos T-1 (média=10,69) e T+1 (média=10,43; $\mathrm{p}=0,658)$. No grupo laparoscópica, as médias de $\Delta \mathrm{Ct}$ no momento $\mathrm{T}-1$ (média=10,2) e T+1 (média=11,1) não foram diferentes $(p=0,372)$ (Figura 30).

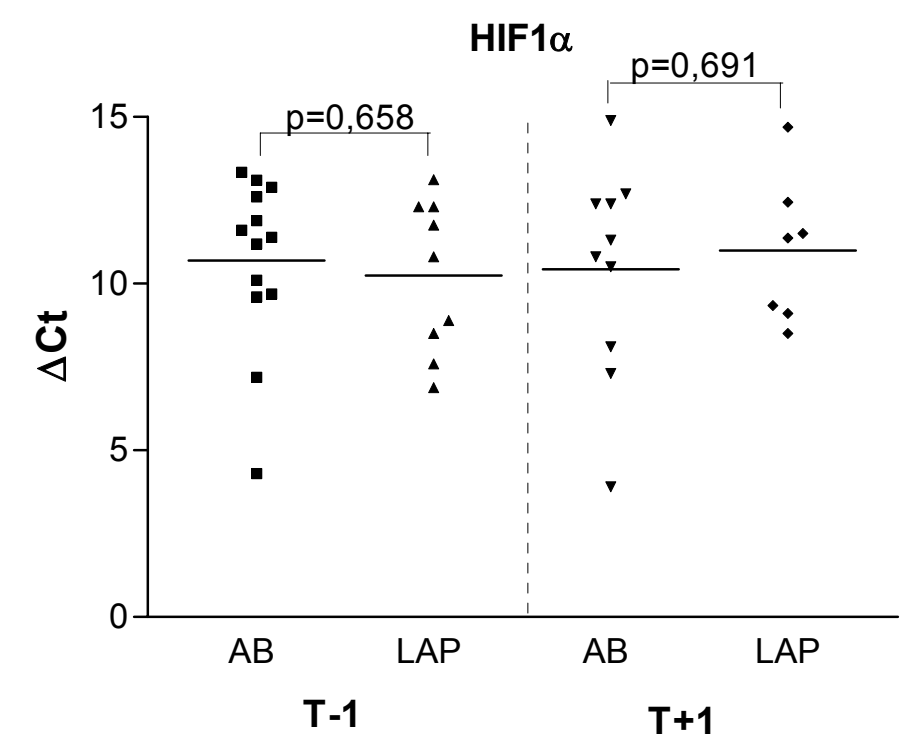

Figura 29: Valores individuais para $\triangle \mathrm{Ct}$ do gene HIF1a nos grupos aberta $(A B)$ e laparoscópica (LAP) em seus respectivos momentos $\mathrm{T}-1=$ momento após retirada e $T+1=$ momento após reperfusão 

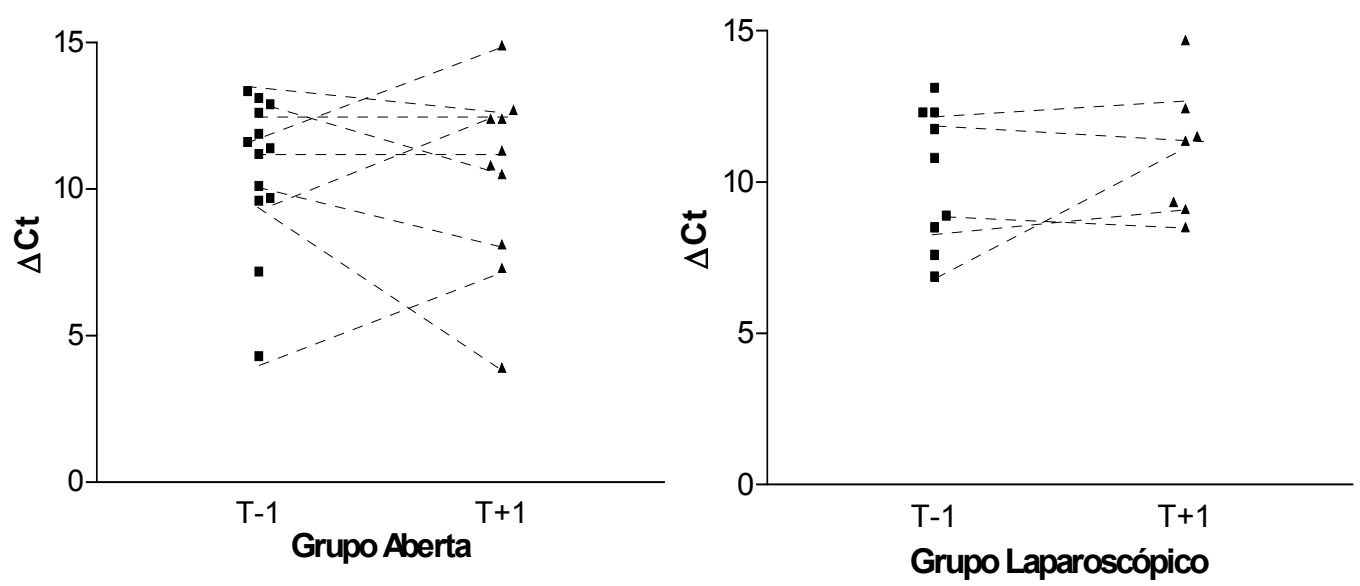

Figura 30: Observação da cinética da expressão de RNAm do gene HIF1 $\alpha$ através do $\Delta$ Ct nos grupos aberta (AB) e laparoscópica (LAP)

Utilizou-se também $O$ QR para analisar o grupo aberta e laparoscópica, através da qual se obtém uma razão entre o grupo laparoscópica e seu controle que é o grupo aberta. Não foi encontrada diferença entre os grupos nos dois momentos T-1 $(p=0,136)$ e $T+1(p=0,490)$ (tabela 13). Realizou-se nova normalização entre os momentos T-1 e T+1 do grupo laparoscópica para se ter uma quantificação relativa entre estes momentos, utilizando-se o tempo T-1 como controle, e observou-se uma média de QR de 1,23 no momento após reperfusão, sem diferença estatística $(p=0,651)$ (Figura 31).

Tabela 13 - Valores de QR de HIF1a para cirugia laparoscópica, com relação à cirurgia aberta

\begin{tabular}{ccc}
\hline Momento & Média $\pm \mathrm{DP}$ & Valor de $\mathrm{p}$ \\
\hline $\mathrm{T}-1(\mathrm{n}=9)$ & $3,68 \pm 4,8$ & 0,136 \\
$\mathrm{~T}+1(\mathrm{n}-7)$ & $1,4 \pm 1,44$ & 0,490
\end{tabular}

T-1=momento após retirada; $T+1=$ momento após reperfusão $\mathrm{DP}=$ desvio padrão 


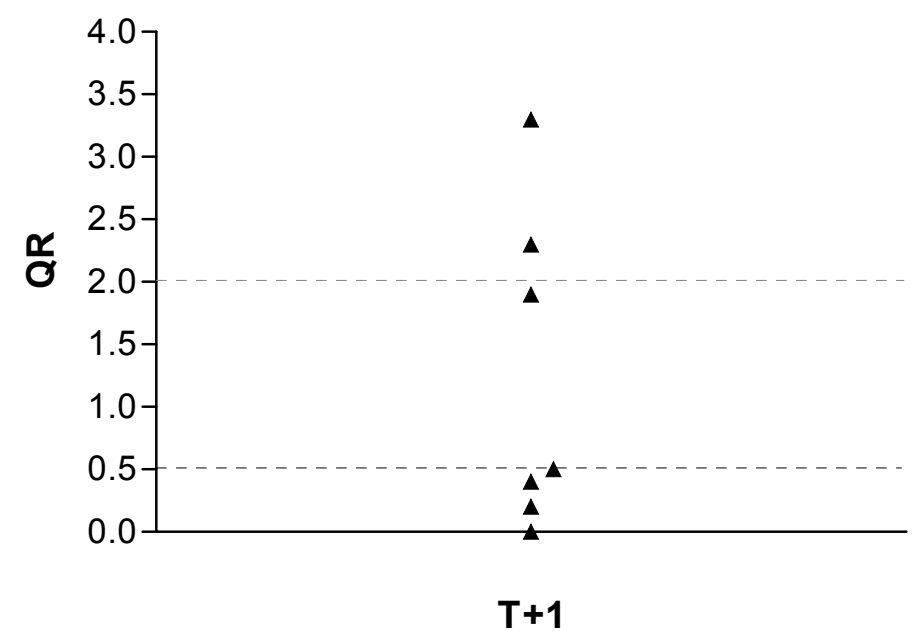

Figura 31: Expressão do gene HIF1a no momento $T+1$ avaliada pela $Q R$ em relação ao momento $T-1$, mostrando valores abaixo de 0,5 (diminuição da expressão) e maiores que 2 (aumento da expressão)

Em resumo, não foi observada diferença entre os grupos aberta e laparoscópica com relação ao $\Delta \mathrm{Ct}$ e QR do gene HIF1a, e também entre os momentos $\mathrm{T}-1$ e $\mathrm{T}+1$.

Na tabela 14 resumimos a expressão gênica do grupo laparoscópico em relação ao grupo aberta, e da cinética da expressão dos genes testados no grupo laparoscópica no momento de reperfusão em relação ao momento $\mathrm{T}-1$.

Tabela 14 - Expressão gênica dos genes testados no grupo laparoscópica em relação ao grupo aberta e o momento T-1

\begin{tabular}{|c|c|c|c|}
\hline \multirow[t]{3}{*}{ 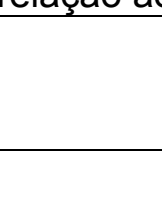 } & \multirow{2}{*}{\multicolumn{2}{|c|}{$\begin{array}{c}\text { Grupo Laparoscópica vs } \\
\text { Aberta }\end{array}$}} & \multirow{3}{*}{$\begin{array}{c}\begin{array}{l}\text { Cinética Grupo } \\
\text { Laparoscópica }\end{array} \\
\text { T-1/T+1 }\end{array}$} \\
\hline & & & \\
\hline & $T-1$ & $T+1$ & \\
\hline Bcl-2 & $=$ & $=$ & $\downarrow$ \\
\hline Hsp70 & $=$ & $=$ & $=$ \\
\hline VEGF & $=$ & $=$ & $\downarrow$ \\
\hline HO-1 & $=$ & $=$ & $=$ \\
\hline TNFa & $=$ & $=$ & $=$ \\
\hline IL-6 & $=$ & $=$ & $=$ \\
\hline HIF-1a & $=$ & $=$ & $=$ \\
\hline
\end{tabular}




\subsection{4 - Expressão dos genes e dados cirúrgicos e clínicos}

\section{Tempo de isquemia quente}

A expressão gênica dos genes avaliada pelo QR foi testada quanto à correlação com o tempo de isquemia quente. Na figura 32 temos as correlações entre os valores de QR para cada gene e o tempo de isquemia quente nos dois momentos. De modo geral se pode observar que as tendências de correlação não são muito fortes. Porém observamos uma correlação positiva entre tempo de isquemia quente e $\mathrm{HO}-1$ no momento de reperfusão (Pearson $r=0,773, p=0,042$ ) que não ocorre com outros genes (tabela 15).

Tabela 15 - Coeficientes de correlação de Pearson para os valores de QR em relação aos genes e tempo de isquemia quente

\begin{tabular}{lcccc}
\hline & \multicolumn{2}{c}{ T-1 } & \multicolumn{2}{c}{ T+1 } \\
\cline { 2 - 5 } Gene & Pearson $r$ & Valor de $p$ & Pearson $r$ & Valor de $p$ \\
\hline Bcl-2 & 0,357 & 0,346 & $-0,129$ & 0,807 \\
HIF1a & 0,421 & 0,260 & $-0,431$ & 0,334 \\
HO-1 & 0,496 & 0,599 & 0,773 & 0,042 \\
HSP70 & 0,528 & 0,144 & 0,312 & 0,451 \\
TNFa & 0,103 & 0,846 & $-0,687$ & 0,313 \\
VEGF & 0,520 & 0,187 & $-0,036$ & 0,939 \\
IL6 & 0,634 & 0,127 & 0,371 & 0,469 \\
\hline
\end{tabular}



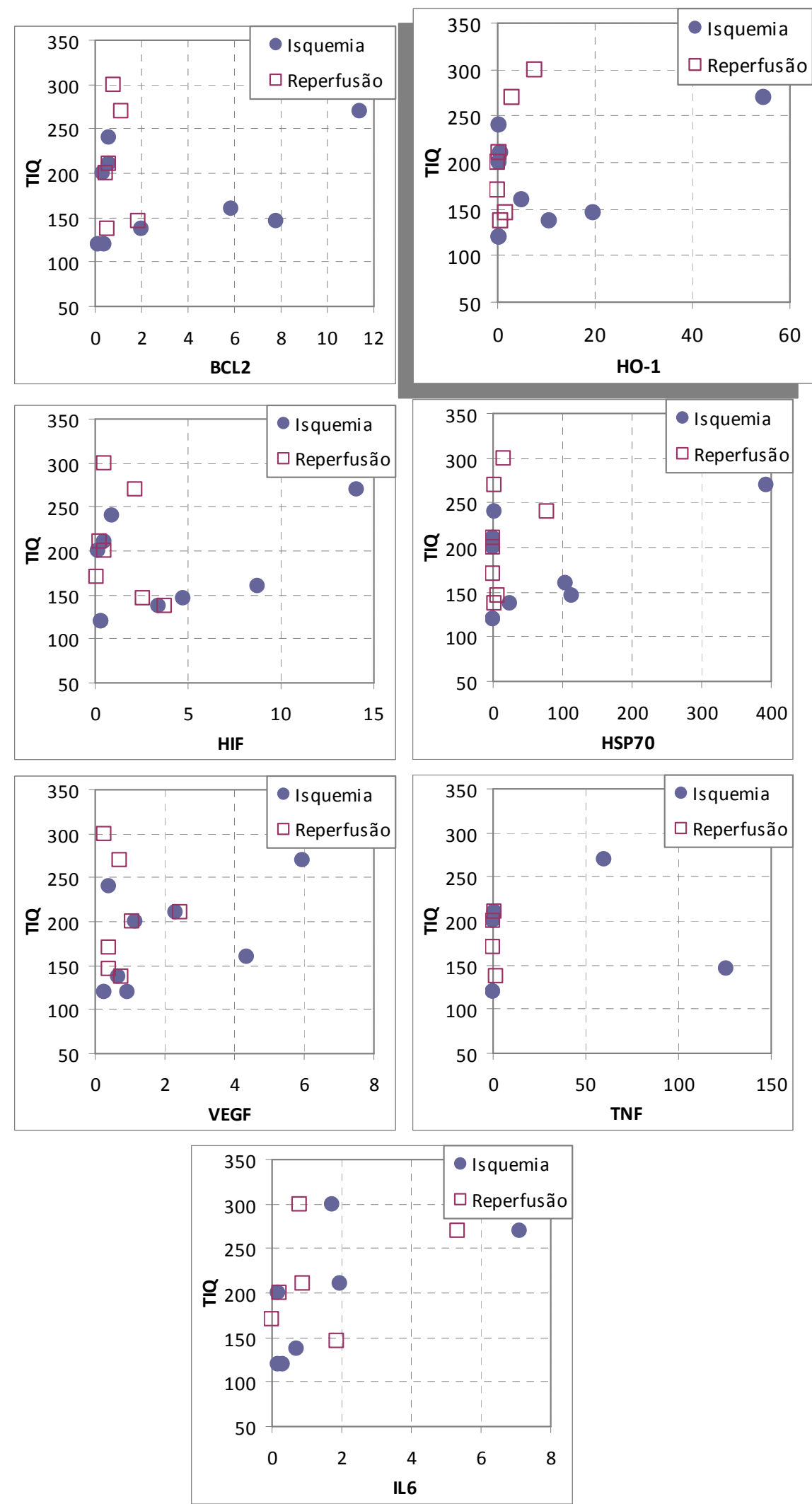

Figura 32: Diagramas de dispersão para os genes Bcl2, HO1, HIF,Hsp70, VEGF, TNF e IL6 e TIQ (tempo de isquemia quente) 


\section{Área sob a curva de creatinina ( $\mathrm{ASC}_{\mathrm{cr}}$ )}

Foi realizado correlação dos valores de QR dos genes testados no grupo laparoscópica com a área sob a curva da creatinina, que avalia o decréscimo da creatinina - quanto maior a área, mais lento é o decréscimo da creatinina no pós-operatório. De modo geral se observa que as tendências de correlação não são muito fortes (Figura 33). Na tabela 16 estão representados os Coeficientes de correlação linear de Pearson e os níveis descritivos para todos os genes. Observa-se que para VEGF no momento $T+1$ têm-se uma correlação significativa no valor de 0,885 $(p=0,019)$.

Tabela 16 - Coeficientes de correlação linear de Pearson entre os genes testados e ASC (área sob a curva de creatinina) na cirurgia laparoscópica

\begin{tabular}{lcccc}
\hline & \multicolumn{2}{c}{ T-1 } & \multicolumn{2}{c}{$\mathrm{T}+1$} \\
\cline { 2 - 5 } Gene & Pearson $r$ & Valor de P & Pearson $r$ & Valor de $p$ \\
\hline Bcl-2 & $-0,135$ & 0,750 & $-0,124$ & 0,843 \\
HIF1a & $-0,150$ & 0,722 & 0,293 & 0,573 \\
HO-1 & 0,038 & 0,929 & $-0,575$ & 0,232 \\
HSP70 & $-0,011$ & 0,980 & $-0,553$ & 0,198 \\
TNFa & $-0,299$ & 0,625 & $-0,096$ & 0,939 \\
VEGF & $-0,186$ & 0,689 & 0,885 & 0,019 \\
IL6 & $-0,075$ & 0,888 & 0,423 & 0,478 \\
\hline
\end{tabular}

T-1=momento após retirada

$T+1=$ momento após reperfusão 

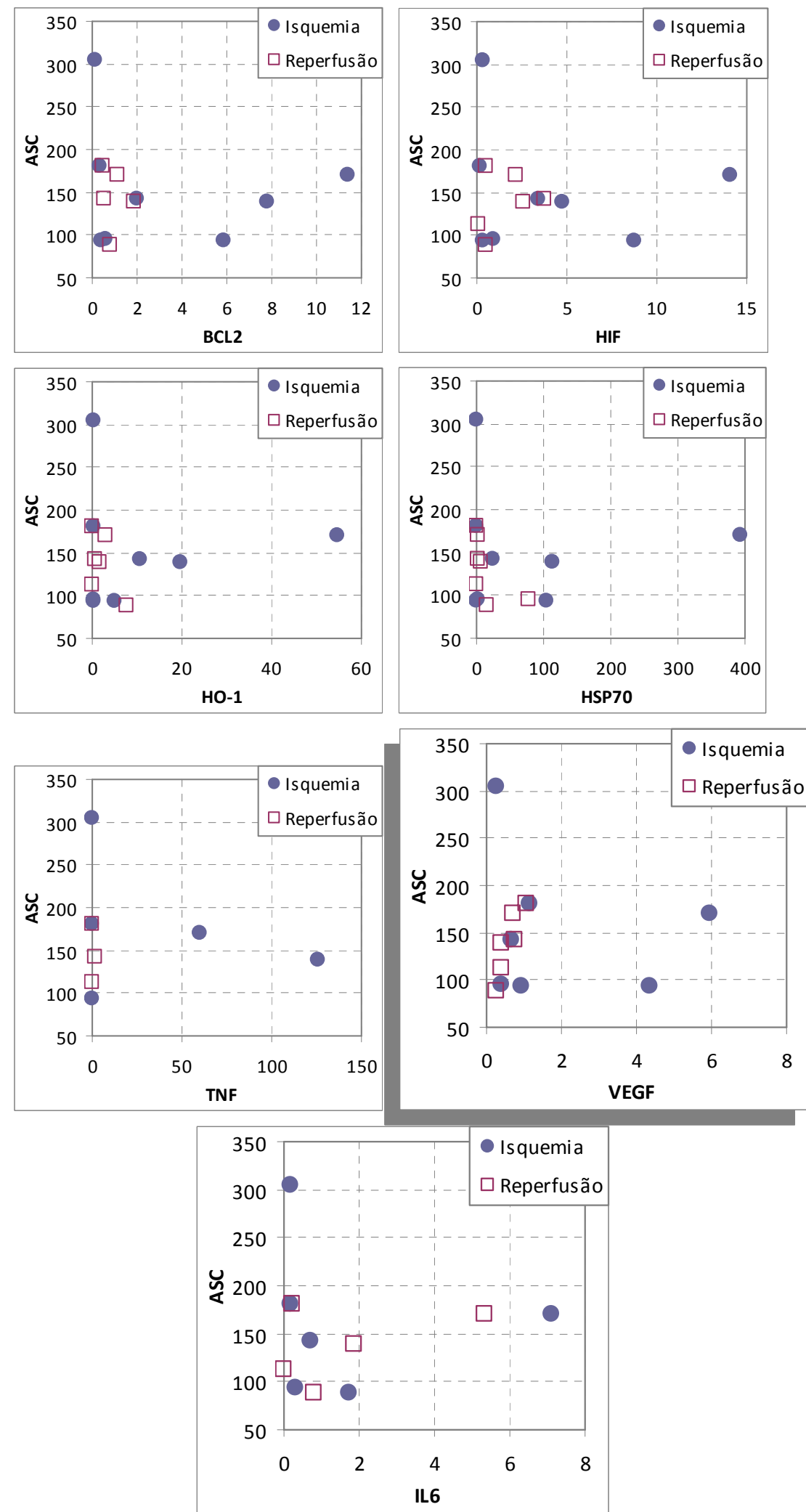

Figura 33: Diagramas de dispersão para os genes Bcl2, HIF1a, HO1, Hsp70,

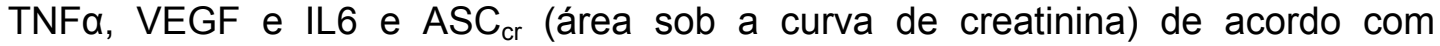
respectivos momentos isquemia $(T-1)$ e reperfusão $(T+1)$ 


\section{Função retardada do enxerto (FRE)}

A função retardada do enxerto e função retardada do enxerto funcional foi analisada em relação à sua correlação com os genes testados. De modo geral não houve associação com a expressão gênica.

\section{3 - IMUNOISTOQUÍMICA}

\subsection{1- $\mathrm{Bcl}-2$}

A expressão da proteína $\mathrm{Bcl}-2$ foi encontrada em todos os compartimentos renais, glomérulos, interstício e vasos sanguíneos. Foram quantificadas as células positivas nos túbulos renais, uma vez que este compartimento concentrou grande parte da positividade. O número de células positivas na totalidade de cada amostra foi dividido pelo número de campos avaliados (Figura 34). Foram analisadas 86 amostras de 44 pacientes. Na cirurgia aberta foram avaliadas 23 amostras no momento de isquemia ( $(T-1)$ e 22 amostras no momento de reperfusão ( $T+1)$. Na cirurgia laparoscópica foi possível a avaliação de 20 amostras no momento da isquemia ( $T-1)$ e 21 pacientes no momento da reperfusão $(T+1)$. Na tabela 17 observamos que ao se comparar os grupos aberta e laparoscópica, notase que as médias da cirurgia aberta são aparentemente menores que no grupo laparoscópica, porém devido às variabilidades dos grupos serem muito grandes, não foi observada diferença estatística. No momento reperfusão $(T+1)$ em ambos os grupos a média decresce um pouco, porém sem diferença estatística (Figura 35). 


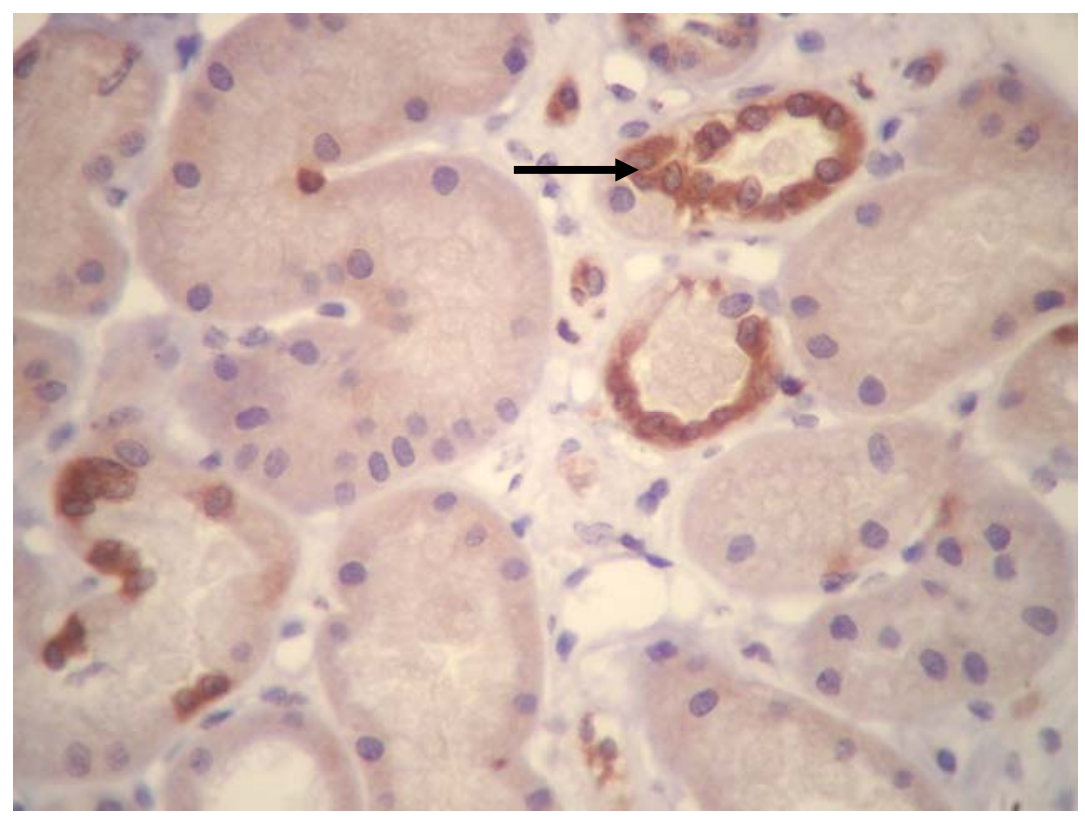

Figura 34: Reação de imunoistoquímica positiva para Bcl-2 em células de túbulos renais. Magnificação 400x

Tabela 17 - Valores da média para Bcl-2 nos grupos de cirurgia aberta e laparoscópica nos momentos T-1 (após retirada) e T+1 (após reperfusão)

\begin{tabular}{llcl}
\hline Cirurgia & Momento & $\begin{array}{c}\text { Média } \pm \\
\text { Desvio Padrão }\end{array}$ & $\mathrm{N}$ \\
\hline Aberta & $\mathrm{T}-1$ & $13,4 \pm 10,4$ & 23 \\
& $\mathrm{~T}+1$ & $11,4 \pm 10,6$ & 22 \\
Laparoscópica & $\mathrm{T}-1$ & $19,9 \pm 19,3$ & 20 \\
& $\mathrm{~T}+1$ & $16,9 \pm 17,2$ & 21 \\
\hline
\end{tabular}

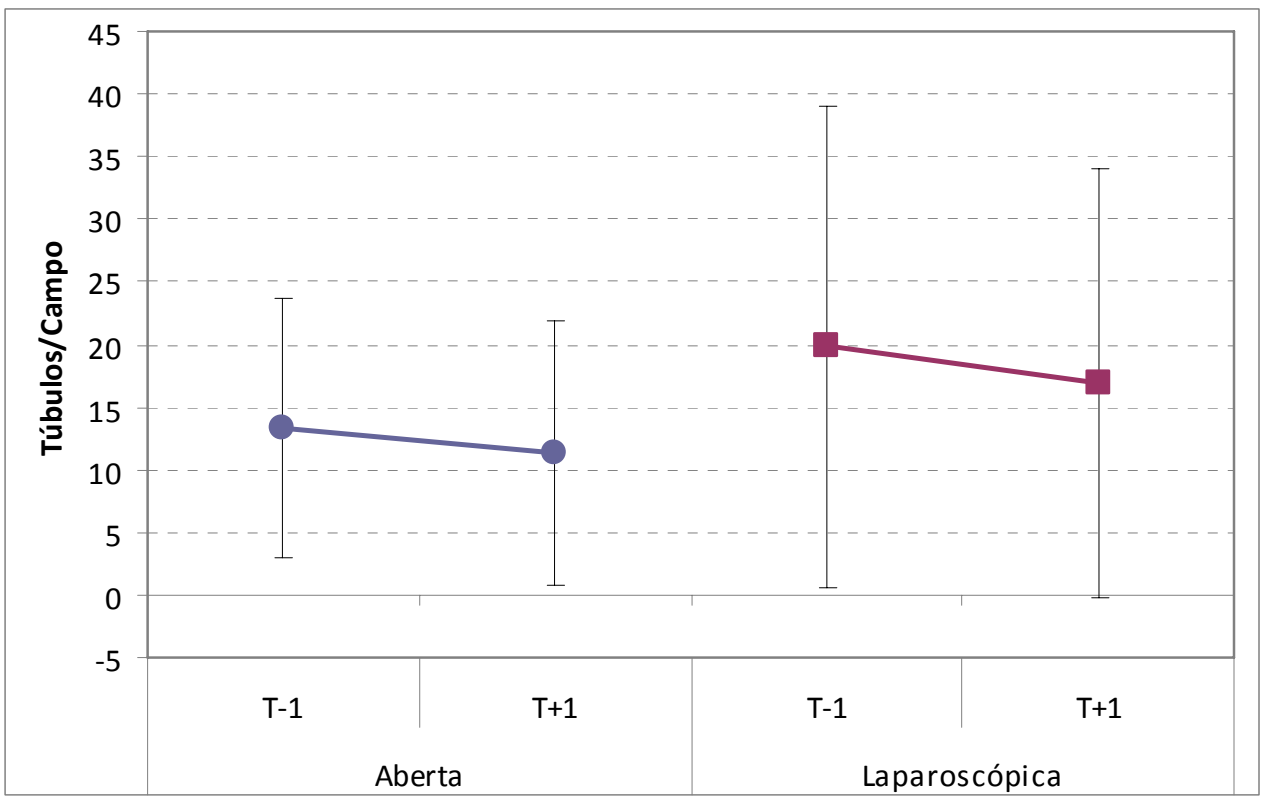

Figura 35: Médias \pm 1 desvio padrão para $\mathrm{Bcl}-2$ (sem diferença estatística, ANOVA), comparando-se os grupos e respectivos momentos 


\subsection{2 - Bax}

O número de células que expressaram positividade para o marcador de Bax nos túbulos renais por campo averiguado, da mesma forma que a proteína Bcl-2. Foi observada uma maior positividade no compartimento tubular do que no interstício, glomérulos ou vasos sanguíneos (Figura 36). A análise imunoistoquímica da proteína Bax foi realizada em 48 pacientes, totalizando 95 amostras. Na cirurgia aberta foram avaliadas 25 amostras no momento de isquemia ( $T-1)$ e 26 amostras no momento de reperfusão ( $T+1)$. $\mathrm{Na}$ cirurgia laparoscópica foi possível a avaliação de 22 amostras em cada momento. Na tabela 18 observa-se os dados referentes às médias de cada grupo. Comparando-se os grupos aberta e laparoscópica nota-se que a distribuição de Bax é a mesma entre as duas cirurgias e entre os momentos, sendo que a média decresce um pouco no momento da reperfusão, não ocorrendo diferença estatística (Figura 37).

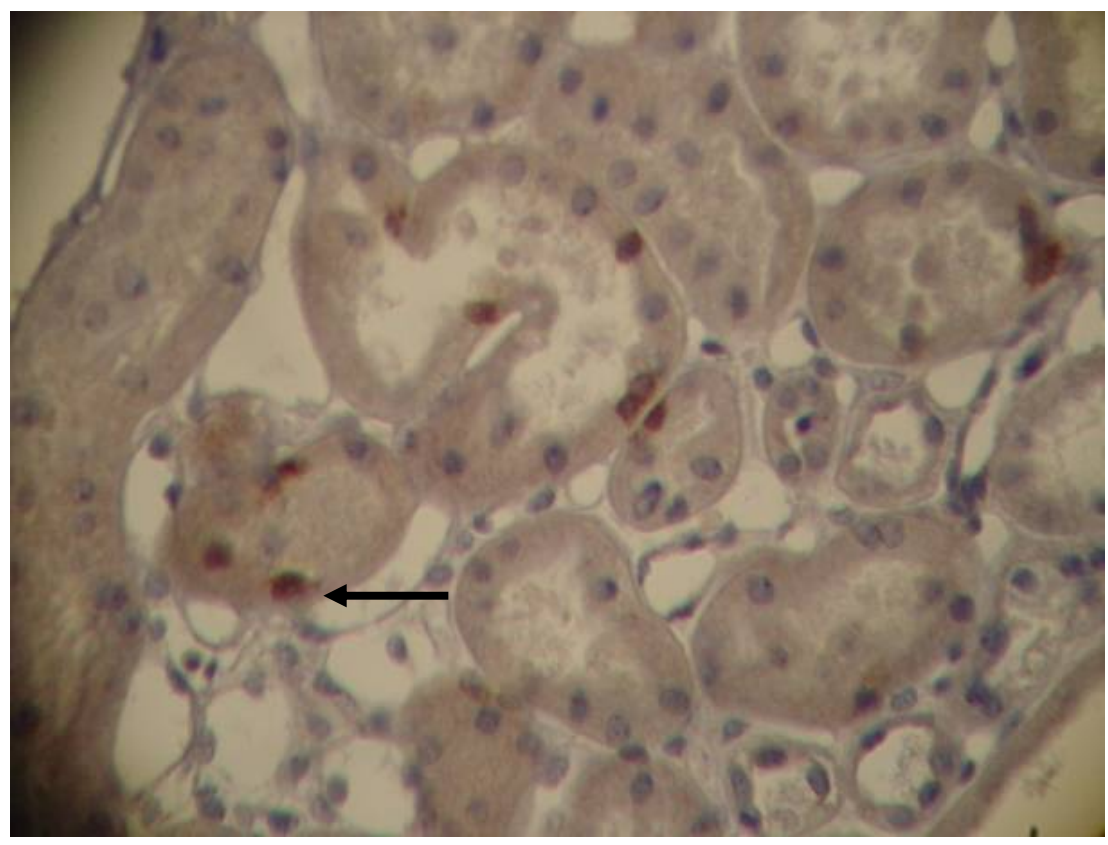

Figura 36: Reação de imunoistoquímica positiva para Bax em células de túbulos renais. Magnificação 400x 
Tabela 18 - Valores da média para Bax nos grupos de cirurgia aberta e laparoscópica nos momentos T-1 (após retirada) e T+1 (após reperfusão)

\begin{tabular}{llcc}
\hline Cirurgia & Momento & $\begin{array}{c}\text { Média } \pm \text { Desvio } \\
\text { Padrão }\end{array}$ & $\mathrm{N}$ \\
\hline Aberta & $\mathrm{T}-1$ & $2,80 \pm 3,79$ & 25 \\
& $\mathrm{~T}+1$ & $2,11 \pm 2,52$ & 26 \\
Laparoscópica & $\mathrm{T}-1$ & $2,77 \pm 3,25$ & 22 \\
& $\mathrm{~T}+1$ & $2,56 \pm 4,01$ & 22 \\
\hline
\end{tabular}

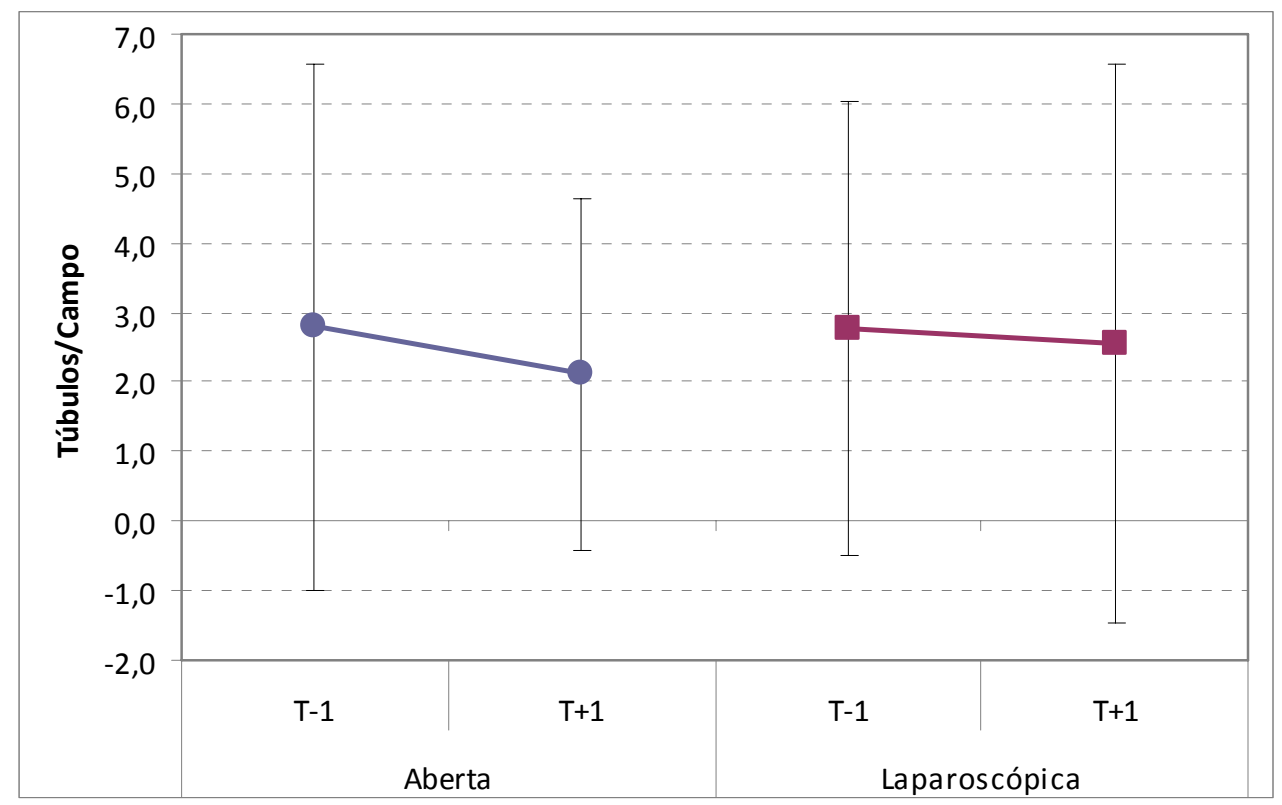

Figura 37: Médias \pm 1 desvio padrão para Bax comparando os grupos e momentos sem diferença estatística (ANOVA)

\subsection{3 - Caspase 3}

O resultado das reações imunoistoquímicas para a Caspase 3 foi avaliado em túbulos renais. A reação foi considerada negativa, quando não havia positividade para o marcador em nenhuma célula, ou positiva, quando havia positividade para a Caspase 3 em qualquer célula tubular (Figura 38). A expressão de Caspase 3, marcador de apoptose, teve baixa positividade em glomérulos e interstício. Foram avaliados 32 pacientes (58 amostras), dezesseis pacientes do grupo de cirurgia aberta e 16 pacientes do grupo de cirurgia laparoscópica. No momento após a retirada do rim ( $\mathrm{T}-1)$ puderam 
ser avaliadas 15 amostras no grupo aberta e 14 amostras no grupo laparoscópica $(T+1)$. Foi observada positividade de Caspase 3 em 5 amostras (33,3\%) no grupo aberta e em 7 amostras (50\%) no grupo laparoscópica $(p=0,462)$. Da mesma forma, no momento após a reperfusão foram analisadas 14 amostras no grupo aberta e 15 amostras no grupo laparoscópica. Em 3 casos $(21,4 \%)$ do grupo aberta e 7 casos $(46,7 \%)$ no grupo laparoscópica foi identificada positividade para a Caspase 3 $(p=0,245)$, sendo que ao se observar a cinética da expressão da proteína Caspase 3 nos momentos de isquemia $(T-1)$ e reperfusão $(T+1)$ não foi notada diferença estatística no grupo aberta e laparoscópica $(p=0,682$ e $p=0,999$, respectivamente) (Figura 39).

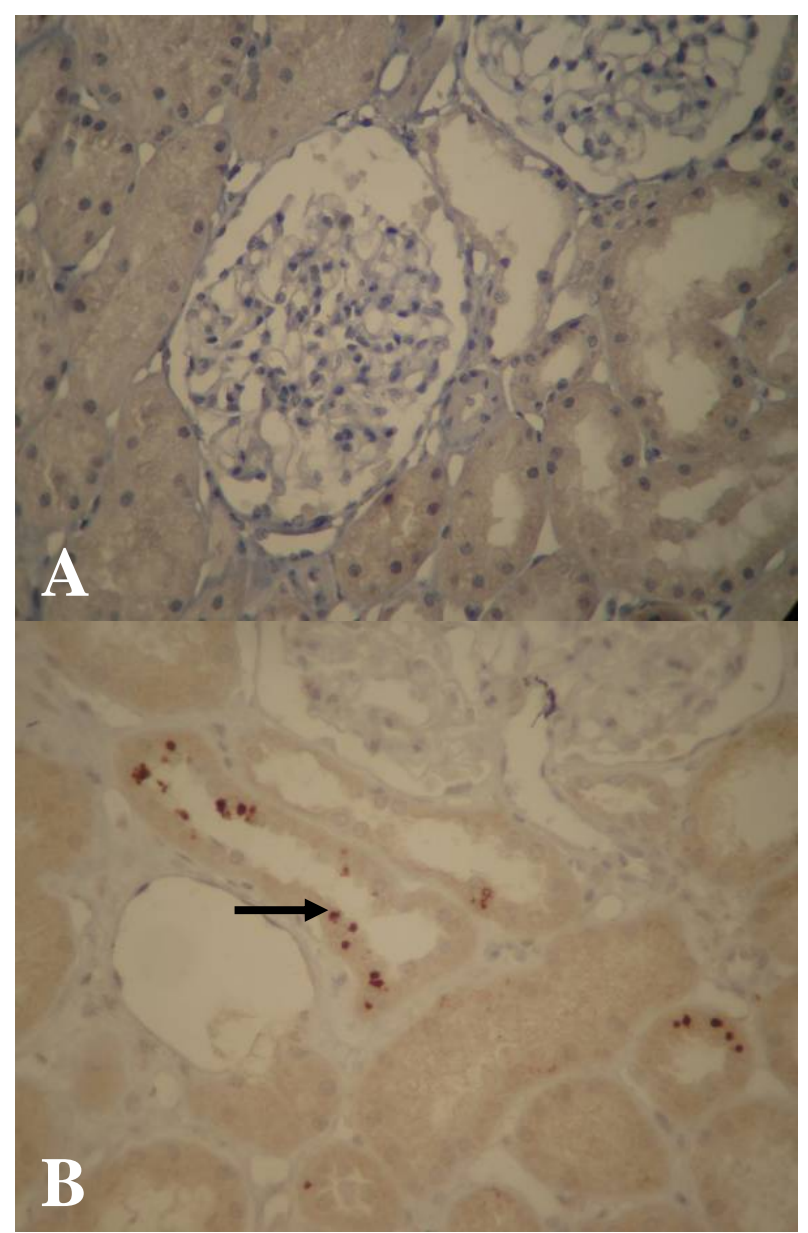

Figura 38: A) Reação de imunoistoquímica negativa para Caspase 3, B) Positividade focal da Caspase-3 em células de túbulos renais. Magnificação 400x 


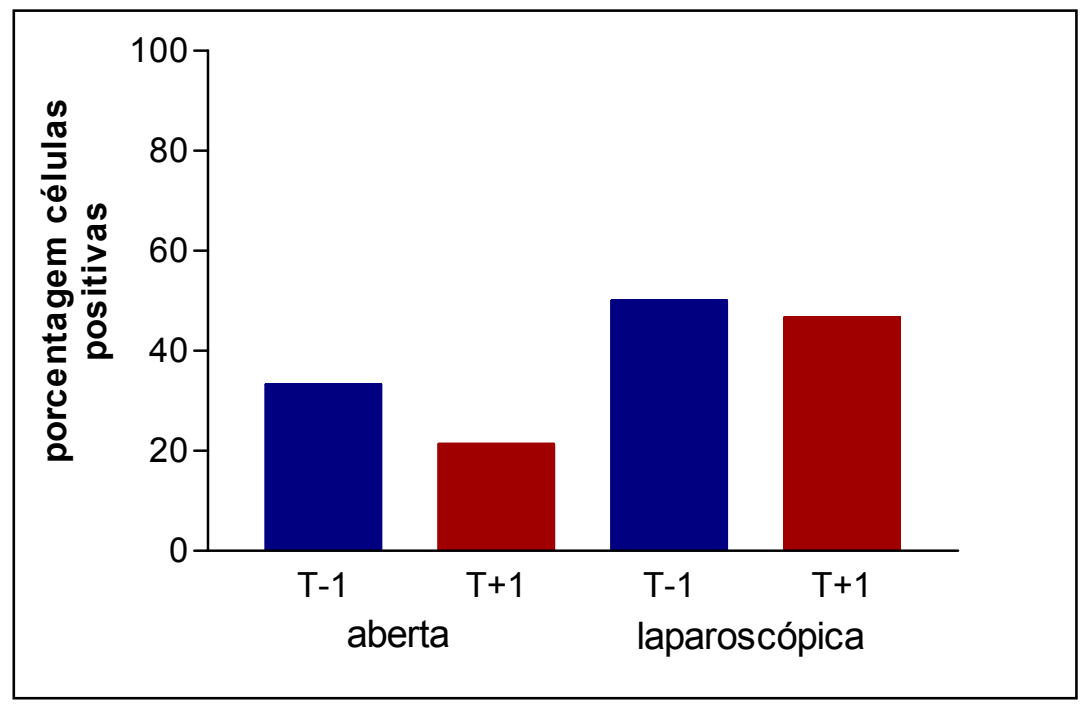

Figura 39: Comparação de positividade de Caspase 3 entre os grupos e momentos T-1 (após retirada) e T+1 (após reperfusão)

\subsection{4 - Heme oxigenase-1 - HO-1}

A expressão de heme-oxigenase 1 (HO-1) foi avaliada em túbulos renais, não sendo notada a expressão em outros locais. Em decorrência da baixa expressão de $\mathrm{HO}-1$, a reação foi considerada positiva quando havia positividade para HO-1 em qualquer célula tubular (Figura 40). Foram avaliados 20 pacientes, num total de 38 amostras nos dois momentos. No momento da retirada (T-1) foi observada uma tendência à menor expressão da proteína HO-1 no grupo laparoscópica em relação ao grupo aberta. Foram avaliadas 11 amostras no grupo aberta, sendo 7 casos (63,6\%) positivos. No grupo laparoscópica foram analisadas 7 amostras, sendo observado expressão de HO1 em apenas 1 caso $(14,3 \%)(p=0,066)$.

No momento após a reperfusão $(\mathrm{T}+1)$ foram analisadas 11 amostras do grupo aberta sendo 5 casos (45,5\%) positivos para a HO-1 e em 9 amostras avaliadas no grupo laparoscópica, 6 casos (66,7\%) expressaram a proteína $(p=0,406)$. Ao se avaliar a cinética da expressão de HO-1 foi observada uma tendência à elevação da expressão de HO-1 no momento da reperfusão $(T+1)$ em relação à retirada $(T-1)$ no grupo laparoscópica, porém sem diferença significativa $(p=0,060)$, não houve diferença entre os momentos no grupo aberta $(p=0,670)$ (Figura 41). 


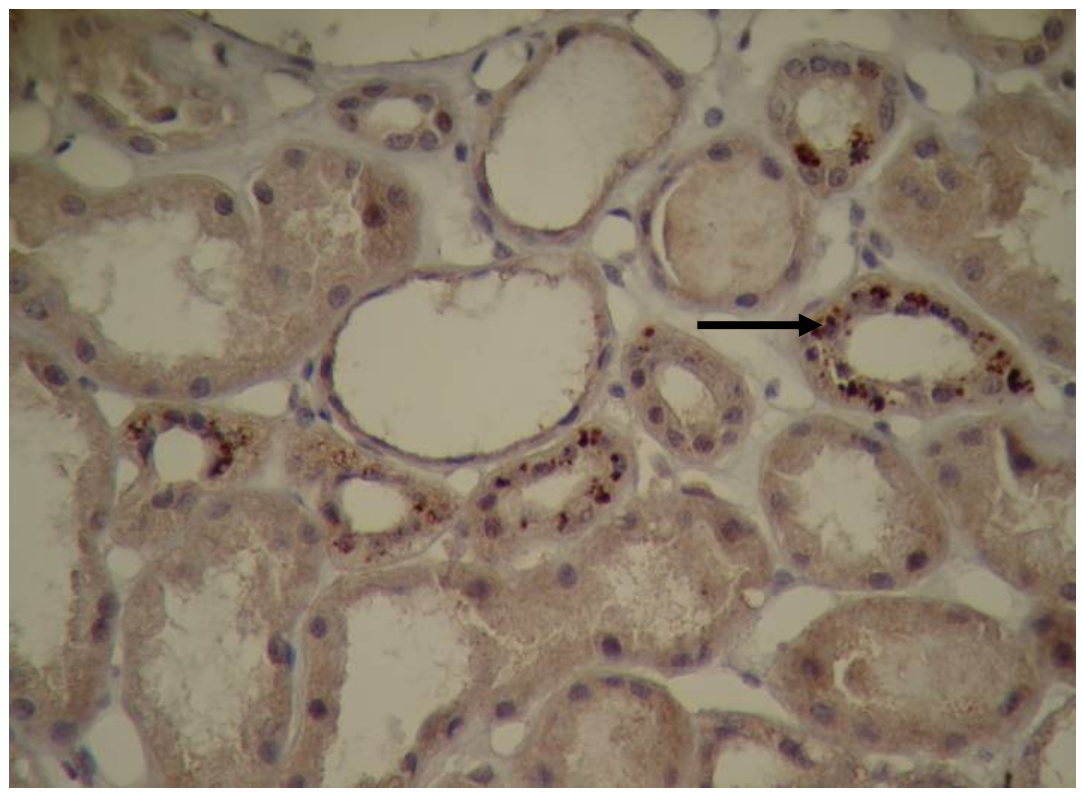

Figura 40: Reação de imunoistoquímica apresentando positividade para $\mathrm{HO}-1 \mathrm{em}$ células de túbulos renais. Magnificação 400x

\section{HO-1}

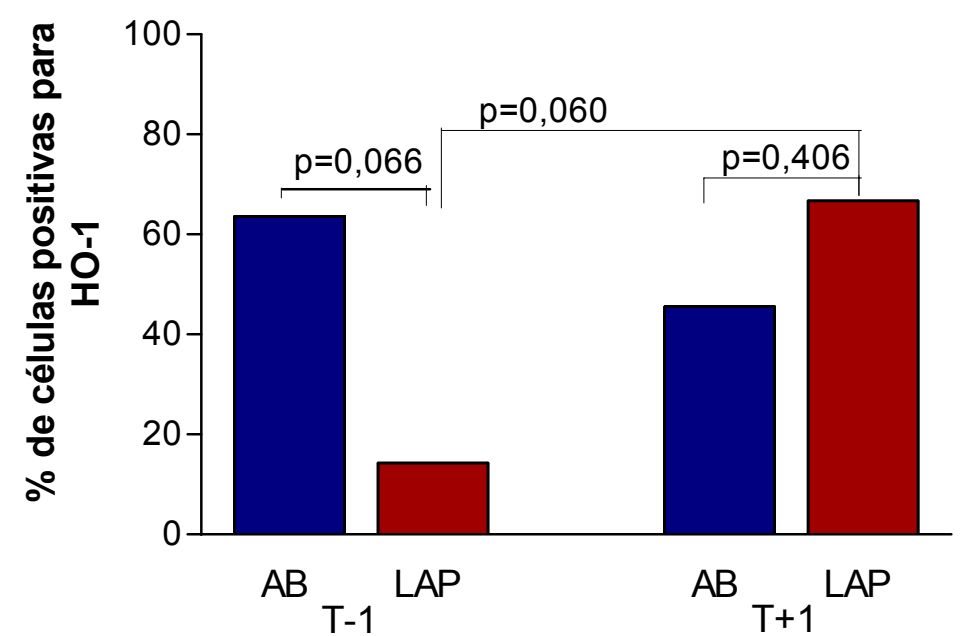

Figura 41: Comparação de positividade de $\mathrm{HO}-1$ entre os grupos aberta $(A B)$ e laparoscópica (LAP) e momentos T-1 (após retirada) e T+1 (após reperfusão) 


\subsection{5 - Análise histomorfométrica}

As amostras de pacientes do Hospital das Clínicas da Faculdade de Medicina da USP foram submetidas à análise histomorfométrica e os resultados são mostrados a seguir. No momento T-1 foram analisadas 17 amostras no grupo aberta e 11 amostras no grupo laparoscópica. No grupo aberta, no momento após isquemia (T-1) foi observado 6 casos $(35,3 \%)$ com alterações histológicas compatíveis com necrose tubular aguda (NTA), sendo um caso com NTA difusa (Figura 42). No grupo laparoscópica três amostras $(27,3 \%)$ apresentavam necrose tubular aguda focal, sem diferença estatística entre os grupos $(p=0,999)$. No momento $T+1$ foram analisadas 18 amostras no grupo aberta com alterações histológicas condizentes com necrose tubular aguda em 7 casos $(38,9 \%)$. Destes pacientes, um caso apresentou NTA difusa e em outra amostra foi visualizado NTA em grau moderado. No grupo laparoscópica foi observado NTA em 5 casos de 11 amostras $(45,5 \%)$, sem diferença estatística entre os grupos $(p=0,999)$. Na comparação dos momentos $\mathrm{T}-1$ e $\mathrm{T}+1$ de cada grupo, não foi observado diferença estatística (grupo aberta: $p=0,999$, grupo laparoscópica: $p=0,697$ ). $\mathrm{Na}$ tabela 19 os resultados morfológicos são apresentados em conjunto com os respectivos eventos clínicos. 


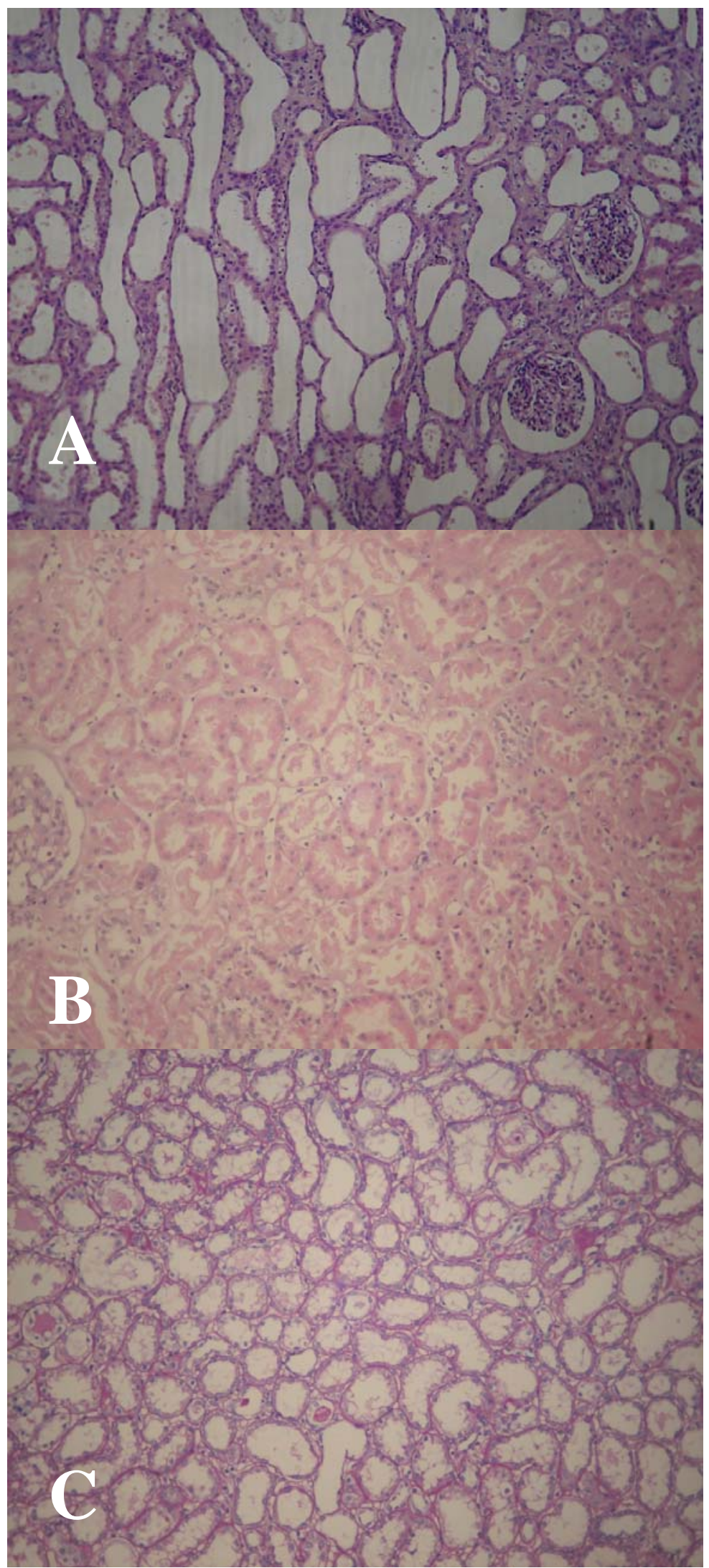

Figura 42: Exemplos histológicos de NTA focal (A), NTA moderada (B) e NTA difusa $(\mathrm{C})$ em biópsias de tempo T-1 
Tabela 19 - Achados histológicos nos pacientes do Hospital das Clínicas da FMUSP e correlação com evento clínico de retardo da função renal

\begin{tabular}{|c|c|c|c|c|c|}
\hline Grupo & Paciente & FREF & FRE & Histologia T-1 & HIstologia $t+1$ \\
\hline Aberta & 1 & $\operatorname{sim}$ & & NTA DIFUSA & NTA DIFUSA \\
\hline Aberta & 2 & & & NORMAL & NORMAL \\
\hline Aberta & 3 & & & NORMAL & NORMAL \\
\hline Aberta & 5 & & & NTA FOCAL & NTA FOCAL \\
\hline Aberta & 7 & & & $\begin{array}{c}\text { NTA EM } \\
\text { INSTALAÇÃO }\end{array}$ & $\begin{array}{l}\text { NTA EM INSTALAÇÃO } \\
\text { (pior que em T-1) }\end{array}$ \\
\hline Aberta & 10 & & & NORMÅL & NORMAL \\
\hline Aberta & 12 & & & NORMAL & NORMAL \\
\hline Aberta & 14 & $\operatorname{sim}$ & & NORMAL & NORMAL \\
\hline Aberta & 17 & & & NORMAL & NORMAL \\
\hline Aberta & 19 & $\operatorname{sim}$ & & NORMAL & NORMAL \\
\hline Aberta & 20 & & & NORMAL & NORMAL \\
\hline Aberta & 21 & & & NORMAL & NTA \\
\hline Aberta & 22 & & & NTA DISCRETA & NTA MODERADA \\
\hline Aberta & 24 & & & NORMAL & NTA FOCAL \\
\hline Aberta & 25 & & & NTA FOCAL & NTA FOCAL \\
\hline Aberta & 27 & & & NORMAL & NORMAL \\
\hline Aberta & 28 & & & $\begin{array}{c}\text { NTA EM } \\
\text { INSTALAÇÃO }\end{array}$ & $\begin{array}{l}\text { NTA EM INSTALAÇÃO } \\
\text { (pior que em T-1) }\end{array}$ \\
\hline Aberta & 29 & & & ND & NORMAL \\
\hline Laparoscópica & 31 & & & NORMAL & ND \\
\hline Laparoscópica & 32 & & & NORMAL & NORMAL \\
\hline Laparoscópica & 37 & & & ND & NTA FOCAL \\
\hline Laparoscópica & 40 & & & NORMAL & NTA \\
\hline Laparoscópica & 41 & $\operatorname{sim}$ & & NTA & NTA \\
\hline Laparoscópica & 42 & & & NORMAL & NORMAL \\
\hline Laparoscópica & 44 & & & NTA & NTA \\
\hline Laparoscópica & 46 & & & NTA FOCAL & NTA FOCAL \\
\hline Laparoscópica & 47 & & & NORMAL & NORMAL \\
\hline Laparoscópica & 48 & & & NORMAL & NORMAL \\
\hline Laparoscópica & 49 & & & NORMAL & NORMAL \\
\hline Laparoscópica & 55 & & $\operatorname{sim}$ & NORMAL & NORMAL \\
\hline
\end{tabular}

FRE = função retardada do enxerto

FREF=função retardada do enxerto funcional

NTA $=$ necrose tubular aguda

$\mathrm{ND}=$ não disponível 


\subsection{6 -Expressão protéica (imunoistoquímica) e resultados clínicos}

\section{Tempo de isquemia quente}

A correlação do tempo de isquemia quente e a expressão das proteínas apoptóticas Bax e Bcl-2 por imunoistoquímica foi realizada por meio do coeficiente de correlação linear de Pearson. Nas tabelas 20 e 21 observamos que não houve correlação significativa entre a expressão das proteínas $\mathrm{Bcl}-2$ e Bax e tempo de isquemia quente.

Tabela 20 - Coeficiente de correlação linear de Pearson entre tempo de isquemia quente e expressão das proteínas Bax e Bcl2 no grupo aberta nos momentos T-1 e $\mathrm{T}+1$

\begin{tabular}{lcccc}
\hline & \multicolumn{2}{c}{$\mathrm{T}-1$} & \multicolumn{2}{c}{$\mathrm{T}+1$} \\
\cline { 2 - 5 } IHQ & Pearson $r$ & Valor de $\mathrm{p}$ & Pearson $r$ & Valor de $\mathrm{p}$ \\
\hline Bax & $-0,193$ & 0,379 & $-0,185$ & 0,387 \\
$\mathrm{Bcl} 2$ & 0,009 & 0,967 & 0,014 & 0,953 \\
\hline IHQ= imunoistoquímica & & &
\end{tabular}

Tabela 21 - Coeficiente de correlação linear de Pearson entre tempo de isquemia quente e expressão das proteínas Bax e Bcl2 no grupo laparoscópica nos momentos $\mathrm{T}-1$ e $\mathrm{T}+1$

\begin{tabular}{lcccc}
\hline & \multicolumn{2}{c}{$\mathrm{T}-1$} & \multicolumn{2}{c}{$\mathrm{T}+1$} \\
\cline { 2 - 5 } IHQ & Pearson $r$ & Valor de $\mathrm{p}$ & Pearson $r$ & Valor de $\mathrm{p}$ \\
\hline Bax & $-0,208$ & 0,366 & $-0,301$ & 0,174 \\
Bcl2 & $-0,176$ & 0,457 & $-0,214$ & 0,352 \\
\hline
\end{tabular}

IHQ= imunoistoquímica

Para averiguar se a média do tempo de isquemia quente influenciava a positividade da expressão de Caspase 3 foi utilizado o teste nãoparamétrico de Wilcoxon, para cada grupo de cirurgia e momento, separadamente. Não foi encontrada correlação significativa (tabela 22). 
Tabela 22 - Resultados para associação de Caspase e tempo de isquemia quente, comparando os grupos de cirurgia e respectivos momentos $\mathrm{T}-1$ e $\mathrm{T}+1$

\begin{tabular}{|c|c|c|c|c|}
\hline & & Caspase & Média \pm & \\
\hline Grupo & Momento & 3 & Desvio Padrão & $\mathrm{N}$ \\
\hline \multirow{9}{*}{ Aberta } & & & $186,0 \pm$ & \\
\hline & $\mathrm{T}-1$ & Negativo & 134,0 & 9 \\
\hline & & & $100,0 \pm$ & \\
\hline & & Positivo & 51,0 & 5 \\
\hline & & & $143,4 \pm$ & \\
\hline & $\mathrm{T}+1$ & Negativo & 138,5 & 10 \\
\hline & & & $186,7 \pm$ & \\
\hline & & Positivo & 11,6 & 3 \\
\hline & & & $221,4 \pm$ & \\
\hline \multirow[t]{7}{*}{ Laparoscópica } & $\mathrm{T}-1$ & Negativo & 49,1 & 7 \\
\hline & & & $182,9 \pm$ & \\
\hline & & Positivo & 75,9 & 7 \\
\hline & & & $227,5 \pm$ & \\
\hline & $T+1$ & Negativo & 62,5 & 8 \\
\hline & & & $187,1 \pm$ & \\
\hline & & Positivo & 50,6 & 7 \\
\hline
\end{tabular}

Para a avaliação da correlação da expressão da proteína HO-1 utilizou-se o teste não-paramétrico de Wilcoxon, separadamente para cada grupo de cirurgia e momento, não tendo sido encontrado correlação significativa (tabela 23).

Tabela 23 - Resultados associação de HO-1 e tempo de isquemia quente, comparando os grupos de cirurgia e respectivos momentos.

\begin{tabular}{|c|c|c|c|c|}
\hline Cirurgia & Momento & $\mathrm{HO}-1$ & $\begin{array}{c}\text { Média } \pm \\
\text { Desvio Padrão }\end{array}$ & $\mathrm{n}$ \\
\hline \multirow{5}{*}{ Aberta } & & & $130,0 \pm$ & \\
\hline & $\mathrm{T}-1$ & Negativo & $\begin{array}{c}113,7 \\
162,3 \pm\end{array}$ & 4 \\
\hline & & Positivo & $\begin{array}{c}162,3 \\
193,3 \pm\end{array}$ & 6 \\
\hline & $\mathrm{T}+1$ & Negativo & $\begin{array}{l}168,6 \\
97,5 \pm\end{array}$ & 6 \\
\hline & & Positivo & $\begin{array}{c}26,3 \\
208,3 \pm\end{array}$ & 4 \\
\hline \multirow[t]{4}{*}{ Laparoscópica } & $\mathrm{T}-1$ & Negativo & $\begin{array}{c}65,9 \\
210,0\end{array}$ & 6 \\
\hline & & Positivo & $2500 \pm$ & 1 \\
\hline & $T+1$ & Negativo & $\begin{array}{c}62,4 \\
208,0 \pm\end{array}$ & 3 \\
\hline & & Positivo & 76,6 & 5 \\
\hline
\end{tabular}




\section{Área sob a curva da creatinina $\left(\mathrm{ASC}_{\mathrm{cr}}\right)$}

Foi realizado correlação da expressão de Bcl2 e Bax com a área sob a curva da creatinina. Na tabela 24 estão representados os coeficientes de correlação linear de Pearson e os níveis descritivos da correlação com a expressão de proteínas apoptóticas Bax e Bcl-2, não sendo observada correlação entre as variáveis.

Tabela 24 - Correlações de Pearson entre cirurgias, respectivos momentos e nível descritivo do teste $-\mathrm{ASC}_{\mathrm{cr}}$ (área sob a curva de creatinina)

\begin{tabular}{|c|c|c|c|c|c|c|c|c|}
\hline \multirow[b]{3}{*}{$\mathrm{IHQ}$} & \multicolumn{4}{|c|}{ Aberta } & \multicolumn{4}{|c|}{ Laparoscópica } \\
\hline & \multicolumn{2}{|c|}{ T-1 } & \multicolumn{2}{|c|}{$T+1$} & \multicolumn{2}{|c|}{ T-1 } & \multicolumn{2}{|c|}{$T+1$} \\
\hline & $r$ & $\begin{array}{c}\text { Valor de } \\
p\end{array}$ & $r$ & $\begin{array}{l}\text { Valor } \\
\text { de p }\end{array}$ & $r$ & $\begin{array}{l}\text { Valor } \\
\text { de } p\end{array}$ & $r$ & $\begin{array}{l}\text { Valor } \\
\text { de P }\end{array}$ \\
\hline Bax & $-0,046$ & 0,826 & 0,137 & 0,552 & 0,110 & 0,592 & $-0,045$ & 0,845 \\
\hline $\mathrm{Bcl} 2$ & $-0,051$ & 0,819 & 0,009 & 0,971 & 0,021 & 0,927 & 0,111 & 0,641 \\
\hline
\end{tabular}

A correlação da Caspase-3 e área sob a curva de creatinina foi realizada por teste não-paramétrico de Wilcoxon, para cada grupo e respectivo momento. Não foi observado correlação estatística entre as Caspase 3 e ASC (tabela 25).

Tabela 25 - Resultados para associação de Caspase 3 e ASC $_{c r}$ (área sob a curva de creatinina) entre os grupos de cirurgia e momentos avaliados

\begin{tabular}{|c|c|c|c|c|}
\hline Grupo & Momento & $\begin{array}{c}\text { Caspase } \\
3\end{array}$ & $\begin{array}{c}\text { Média } \pm \\
\text { Desvio Padrão }\end{array}$ & $n$ \\
\hline \multirow{5}{*}{ Aberta } & & & $161,37 \pm$ & \\
\hline & $\mathrm{T}-1$ & Negativo & $\begin{array}{c}24,5 \\
175,2 \pm\end{array}$ & 10 \\
\hline & & Positivo & $\begin{array}{c}29,5 \\
161,37 \pm\end{array}$ & 5 \\
\hline & $T+1$ & Negativo & $\begin{array}{c}24,5 \\
175,2 \pm\end{array}$ & 11 \\
\hline & & Positivo & $\begin{array}{c}35,9 \\
1759+\end{array}$ & 3 \\
\hline \multirow[t]{4}{*}{ Laparoscópica } & $\mathrm{T}-1$ & Negativo & $\begin{array}{c}33,1 \\
181,7 \pm\end{array}$ & 7 \\
\hline & & Positivo & $\begin{array}{c}40,6 \\
181,7 \pm\end{array}$ & 6 \\
\hline & $T+1$ & Negativo & $\begin{array}{c}43,2 \\
153,9 \pm\end{array}$ & 8 \\
\hline & & Positivo & 22,5 & 6 \\
\hline
\end{tabular}


Para a avaliação da correlação de HO-1 utilizou-se o teste nãoparamétrico de Wilcoxon, separadamente para cada grupo de cirurgia e momento, não tendo sido encontrado correlação significativa (tabela 26), não foi possível correlacionar o momento T-1 da cirurgia laparoscópica com a área sob a curva de creatinina.

Tabela 26 - Resultados para associação de HO-1 e ASC $_{\text {cr }}$ (área sob a curva de creatinina) entre os grupos de cirurgia e momentos avaliados

\begin{tabular}{|c|c|c|c|c|}
\hline \multirow[b]{2}{*}{ Cirurgia } & \multirow[b]{2}{*}{ Momento } & \multicolumn{3}{|c|}{ Média \pm} \\
\hline & & $\mathrm{HO}-1$ & Desvio Padrão & $\mathrm{n}$ \\
\hline \multirow{9}{*}{ Aberta } & & & $118,6 \pm$ & \\
\hline & $\mathrm{T}-1$ & Negativo & 21,1 & 4 \\
\hline & & & $119,4 \pm$ & \\
\hline & & Positivo & 36,5 & 7 \\
\hline & & & $125,0 \pm$ & \\
\hline & $T+1$ & Negativo & 31,4 & 6 \\
\hline & & & $103,5 \pm$ & \\
\hline & & Positivo & 17,3 & 5 \\
\hline & & & $136,7 \pm$ & \\
\hline \multirow[t]{6}{*}{ Laparoscópica } & $\mathrm{T}-1$ & Negativo & 44,1 & 6 \\
\hline & & Positivo & - & 0 \\
\hline & & & $145,2 \pm$ & \\
\hline & $T+1$ & Negativo & 49,2 & 3 \\
\hline & & & $117,7 \pm$ & \\
\hline & & Positivo & 43,7 & 4 \\
\hline
\end{tabular}

\section{Função retardada do enxerto (FRE) e função retardada do enxerto funcional (FREF)}

A associação entre função retardada do enxerto e função retardada do enxerto funcional foi testada com as proteínas Bcl-2, Bax, Caspase 3 e HO-1. Utilizou-se teste não-paramétrico de Wilcoxon em virtude da baixa incidência de FRE e FREF, não tendo sido encontrada diferença significativa entre esta variável e as proteínas Bcl-2, Bax, Caspase 3 e HO-1. 


\section{5- DISCUSSÃO}

A nefrectomia laparoscópica é um método amplamente aceito para doação renal em vários centros, tendo sido demonstrado ao longo dos anos resultados semelhantes à cirurgia aberta com relação à qualidade do rim ofertado $^{(7,69)}$. Neste trabalho apresentamos um estudo comparativo, prospectivo, entre duas técnicas de nefrectomia para doação renal em relação à resposta protetora do tecido renal.

Embora a nefrectomia de doador renal laparoscópica seja realizada há vários anos, algumas discussões ainda persistem com relação a determinados aspectos da técnica utilizada como, por exemplo, utilização de rins com múltiplas artérias e emprego do rim direito ${ }^{(70)}$. $\mathrm{Na}$ casuística apresentada neste trabalho foram incluídos pacientes com múltiplas artérias, com distribuição igual entre os grupos. A inclusão destes rins em nosso estudo foi motivada por outros trabalhos que têm demonstrado que a realização de nefrectomia de doador renal laparoscópica com múltiplas artérias é factível e não altera a função renal a curto e longo prazo quando comparado com rins com artéria única ${ }^{(71,72)}$. Neste estudo, todos os casos do grupo laparoscópica foram à esquerda e no grupo aberta a nefrectomia foi à direita em $55,4 \%$ dos casos. A indicação de nefrectomia laparoscópica direita é controversa, pois pelo menor tamanho da veia, complicações como trombose da veia renal e perda precoce do enxerto foram relativamente freqüentes no início da utilização da técnica laparoscópica ${ }^{(73)}$. Em vista disso, não se realiza nefrectomia direita de doador renal laparoscópica no Hospital das Clínicas da Faculdade de Medicina da USP. Entretanto, alguns autores relataram mudanças na técnica operatória para facilitar o emprego do rim direito, tais como, ampla mobilização dos vasos ilíacos, divisão da veia ou artéria ilíaca interna, utilização ocasional da artéria ilíaca interna, uso preferencial da artéria e veia ilíaca comum para anastomose, colocação do rim invertido quando necessário ${ }^{(74)}$. Além disso, o uso de pinças hemostáticas vasculares laparoscópicas e novos dispositivos permitiu a preservação de maior comprimento da veia renal ${ }^{(75,76)}$. Desta forma, 
atualmente alguns centros passaram a ter experiências favoráveis utilizando o rim direito em nefrectomia de doador laparoscópica ${ }^{(77-79)}$. Foi comparada, no grupo aberta, a função renal de enxertos direito e esquerdo, com resultados equivalentes quanto ao retardo de função e queda da creatinina. Portanto, a utilização maior do rim direito no grupo aberta não impactou negativamente neste grupo, de modo que os grupos aberta e laparoscópica podem ser considerados comparáveis. Em ambos os serviços transplantadores ocorreram poucas complicações nos receptores e nenhuma complicação do doador o que reflete a experiência dos dois centros, os quais realizam transplante renal e nefrectomia de doador renal laparoscópica há vários anos.

Em nosso estudo pudemos notar que o índice de massa corporal do doador no grupo laparoscópica tendia ao sobrepeso, apesar de não ser diferente do grupo aberta. Esta tendência parece estar relacionada a uma característica da população brasileira atual, chamada de transição nutricional, em que a escassez alimentar é substituída pelo excesso ${ }^{(80)}$. Kok et $\mathrm{al}^{(81)}$ observaram em estudo prospectivo em pacientes com sobrepeso, que a cirurgia laparoscópica é mais vantajosa em mulheres que em homens por sua diferença na distribuição de gordura visceral (perirenal). Além disso, a obesidade não parece afetar os resultados da cirurgia laparoscópica, mesmo em obesos mórbidos (IMC maior que $35 \mathrm{~kg} / \mathrm{m}^{2}$ ), permitindo que estes pacientes tenham os mesmos benefícios da cirurgia minimamente invasiva, sem comprometimento da função do enxerto ${ }^{(82)}$.

A manifestação clínica do dano tecidual causado pela isquemia e reperfusão renal é a ocorrência do não funcionamento imediato do enxerto decorrente da necrose tubular aguda. De acordo com a extensão da necrose tubular aguda, o paciente pode apresentar insuficiência aguda do enxerto renal sob a forma oligúrica com necessidade de suporte dialítico logo após o procedimento cirúrgico. Em um estudo de meta-análise observou-se que a função retardada do enxerto pode elevar o risco de perda do enxerto e de rejeição aguda, além de aumentar a média de creatinina em 0,66 mg/dl quando comparado com pacientes com função renal inicial satisfatória ${ }^{(83)}$. 
Mais freqüente em transplante de doadores cadavéricos, a função retardada do enxerto renal ocorre em torno de $4-10 \%$ de transplantes de doadores vivos ${ }^{(84)}$. De modo semelhante, observamos uma incidência de $5,6 \%$ de retardo de função do enxerto, não sendo notado diferença entre o grupo da cirurgia aberta e laparoscópica. Também utilizamos um critério mais amplo para avaliação da função renal, chamado de função retardada do enxerto funcional, quando o decréscimo da creatinina era inferior a 10\% em 3 dias consecutivos na primeira semana após o transplante. Da mesma forma, notamos resultados semelhantes entre os grupos aberta e laparoscópica. É descrito na literatura que o decréscimo da creatinina ocorre mais lentamente nos pacientes que receberam o rim procurado por cirurgia laparoscópica, porém sem diferença estatística entre os grupos ${ }^{(85)}$. Em nosso estudo, além de utilizar os valores pontuais de creatinina sérica ao longo dos dias, utilizamos o cálculo da área sob a curva de creatinina. Esta estratégia matemática vem sendo utilizada por outros autores com o intuito de obter uma evolução mais refinada e temporal da evolução dos enxertos após o transplante renal ${ }^{(86)}$.

Embora não tenhamos encontrado diferença na evolução da função renal nos dois grupos alguns pontos merecem ser comentados. Um deles trata da questão do sexo do doador impactando na função do enxerto. No nosso estudo, observamos que no sexo masculino a média da área sob a curva de creatinina $\left(\mathrm{ASC}_{\mathrm{cr}}\right)$ foi maior em ambos os grupos, quando comparado com o sexo feminino, principalmente no grupo laparoscópica. Além disso, no doador do sexo feminino, encontramos apenas no grupo laparoscópica, uma média maior da área sob a curva de creatinina, significando que, em rins de doadores femininos nefrectomizados por laparoscopia, o decréscimo da creatinina ocorreu mais lentamente. Dados da literatura chamam atenção para esta questão de doadores renais femininos e função renal após nefrectomia laparoscópica. Ao analisarmos fatores que pudessem estar associados à piora da função do enxerto, observamos que no sexo masculino a média da área sob a curva de creatinina $\left(\mathrm{ASC}_{\mathrm{cr}}\right)$ foi maior em ambos os grupos, quando comparado com o 
sexo feminino, principalmente no grupo laparoscópica. Além disso, no doador do sexo feminino encontramos apenas no grupo laparoscópica, uma média maior da $\mathrm{ASC}_{\mathrm{cr}}$, que significa que nestes casos o decréscimo da creatinina ocorreu mais lentamente. Em transplantes intervivos em que o rim foi retirado por laparoscopia tem-se estudado fatores de risco relacionados à função retardada do enxerto. Em estudo retrospectivo, Abreu et al (87) observaram que a doação laparoscópica de rim de doador vivo feminino para receptor masculino era um dos fatores de risco para a ocorrência de retardo de função renal, influenciando na piora da função renal pósoperatória. Nenhum fator diretamente relacionado à nefrectomia laparoscópica foi observado neste estudo. Esta associação tem sido atribuída a uma desproporção da quantidade de néfrons entre os gêneros, porém a mesma dependência é encontrada em enxertos de outros órgãos, fazendo crer que outros fatores possam estar associados, como por exemplo, a lesão de isquemia e reperfusão ${ }^{(88-90)}$.

Outro ponto a ser discutido é a questão da idade do doador e receptor na evolução da função renal nos grupos laparoscópica e aberta. Diferentemente de outros trabalhos que apontam o aumento da idade do receptor como fator de risco para retardo de função do enxerto ${ }^{(91)}$, em nosso estudo houve uma maior freqüência de função retardada do enxerto no grupo laparoscópica em receptores mais jovens. Não encontramos nenhuma outra variável que pudesse justificar esta associação entre uma idade mais jovem do receptor e função retardada do enxerto. Uma possibilidade seria uma maior porcentagem de receptores jovens hipersensibilizados, os quais poderiam ter uma maior risco de apresentar disfunção precoce do enxerto. No entanto, não observamos diferença no painel de anticorpos anti-HLA destes receptores. Observamos também uma correlação discreta entre a recuperação lenta da função renal ( $A S C_{c r}$ aumentada) e idade do doador no grupo aberta. Igualmente, outros estudos têm demonstrado que o aumento da idade do doador eleva o risco de função renal mais lenta no pósoperatório $^{(91)}$. 
Apesar do grupo laparoscópica apresentar tempo de isquemia quente maior que no grupo aberta, não foi notado uma associação com aumento da freqüência de retardo de função do enxerto ou retardo de função do enxerto funcional. Portanto, em nossa casuística, o tempo de isquemia quente ocorrido durante a retirada não foi um fator diretamente relacionado ao prejuízo da função renal. Ademais, não houve correlação do tempo de isquemia quente com a curva de decréscimo de creatinina, medida pela área sob a curva. O tempo de isquemia quente prolongado sempre foi um fator de preocupação com relação a seu efeito sobre o funcionamento do enxerto renal. Buzdon et $\mathrm{al}^{(92)}$ e Simforoosh et $\mathrm{al}^{(93)}$, estudando a conseqüência do tempo de isquemia quente em enxertos de nefrectomia laparoscópica não encontraram correlação entre maior tempo de isquemia quente e função renal diminuída. De forma diferente, Nogueira et $\mathrm{al}^{(94)}$ encontraram o tempo de isquemia quente prolongado em enxertos de doadores laparoscópicos como fator de risco para retardo de função renal. Interessante notar que embora não tenhamos observado associação entre o tempo de isquemia quente e função retardada do enxerto, observamos uma associação entre maior tempo de isquemia quente e maior expressão gênica de hemeoxigenase-1. A HO-1 é um conhecido fator de proteção em lesão de isquemia e reperfusão e a hipóxia é um dos múltiplos fatores que levam à sua indução ${ }^{(95)}$. É possivel que este aumento de heme-oxigenase reflita uma resposta adaptativa do enxerto frente a um período maior de privação de oxigênio. A elevação da heme-oxigenase-1 poderia estar agindo de modo a impedir uma lesão tecidual maior nestes casos.

Com relação à análise da HO-1 através de imunoistoquímica, é preciso salientar que a HO-1 não é uma proteína constitutiva, o que significa que já na primeira biópsia observamos uma tendência a menor expressão da proteína no grupo laparoscópica em relação ao grupo aberta. Igualmente, no período de reperfusão há uma tendência a aumento da expressão protéica da HO-1 no grupo laparoscópica em relação à primeira biópsia. Como a tradução protéica leva um período para ocorrer, a primeira biópsia representa o período de realização da nefrectomia enquanto que a segunda 
biópsia pode estar refletindo o período da isquemia quente, logo após a retirada do rim. Interessante notar que outros autores obtiveram resultados semelhantes, observando em biópsias de transplantados renais um aumento quantitativo da expressão de HO-1 no momento após reperfusão, sendo que os autores notaram nos casos em que houve um maior aumento de HO-1 do período pré-reperfusão para o período pós-reperfusão, uma associação com retardo da função renal ${ }^{(96)}$.

A modulação da intensidade da agressão gerada durante a lesão de isquemia e reperfusão tem papel fundamental na recuperação da função renal. A resposta protetora é um mecanismo que contribui de forma decisiva para minimizar os efeitos deletérios da lesão renal aguda. Dentre os fatores de proteção destaca-se o fator de crescimento endotelial vascular, cuja função reparadora está relacionada à promoção da angiogênese e estímulo da proliferação, diferenciação e manutenção das células endoteliais, além de participar da remodelagem da matriz intersticial ${ }^{(97)}$. No transplante renal, é digno de nota que inicialmente alguns autores relacionaram a expressão de VEGF à rejeição e aumento do processo inflamatório, sendo que pacientes que possuíam polimorfismo com genótipo altamente produtor de VEGF apresentavam maior associação com rejeição aguda ${ }^{(98,99)}$. Entretanto, outros dados da literatura mostram que o VEGF tem ação funcional protetora e que muito possivelmente esta ação inflamatória ou protetora dependeria do tipo do receptor (VEGF receptor 1 ou 2) ao qual o VEGF se liga, ao tipo celular e ao microambiente ${ }^{(100)}$. Reforçando esta ação protetora do VEGF, alguns autores mostraram que o tratamento com células estromais mesenquimais multipotentes auxiliam na melhora da função renal em situações de lesão isquêmica aguda, sendo que o mecanismo de ação destas células é complexo, porém envolve ações parácrinas de fatores de crescimento, principalmente do VEGF. Em nosso estudo não foi observada diferença na expressão de RNAm de VEGF entre os grupos. Porém houve redução da média de VEGF no grupo laparoscópica no momento após a reperfusão. Este achado pode significar uma diminuição da resposta protetora renal durante a retirada do rim por laparoscopia. Estudos experimentais têm 
demonstrado redução do VEGF em lesão de isquemia e reperfusão, principalmente quando o rim é submetido a períodos prolongados de isquemia ${ }^{(101),(102)}$. Ao contrário do que ocorre em outros órgãos, na lesão de isquemia e reperfusão renal aparentemente não ocorre aumento da expressão de VEGF, e sugere-se que o papel de regulação do VEGF seja exercido pela redistribuição celular da proteína pré-existente ou pelo aumento da expressão do receptor VEGFR-2 ${ }^{(103,104)}$.

A correlação da expressão de RNAm de VEGF no momento da reperfusão com a área sob a curva de creatinina significa que há aumento de VEGF quando o declínio da creatinina ocorre mais lentamente. Este achado é importante e pode traduzir uma resposta adaptativa frente a uma maior agressão tecidual. Nem sempre um aumento do fator protetor pode resultar necessariamente em melhora da função renal, portanto a associação do aumento de VEGF com um declínio mais lento da creatinina pode também corresponder a um indicador de gravidade de dano tecidual. Estudos tem demonstrado que a elevação de VEGF ocorre em situações de exposição à nefrotoxicidade, como uso de ciclosporina, sendo que o VEGF é apontado como um mecanismo de proteção frente à vasoconstrição provocada pela droga ${ }^{(105,106)}$.

Um outro gene com função protetora e avaliado em nosso estudo foi a proteína de choque térmico Hsp70. A Hsp 70 tem papel antiapoptótico, agindo tanto sobre a via depentende da ativação de caspase como sobre a via independente de caspase ${ }^{(107)}$. A Hsp70 está presente constitutivamente em túbulos renais e glomérulos de rins normais, porém em casos de rejeição aguda no transplante renal apresenta elevação de sua expressão nos locais onde normalmente está expressa ${ }^{(108)}$. Assim como outros fatores protetores, a Hsp 70 é induzida por hipóxia e tem o HIF1a como um dos mecanismos reguladores ${ }^{(109)}$. Em nosso estudo, observamos qrande variabilidade na expressão de Hsp70, com amostras apresentando elevada expressão e outras com diminuição da expressão de Hsp70, sem um padrão característico. Também não observamos diferença entre os grupos e entre os momentos avaliados. É possível que esta variabilidade possa estar 
relacionada ao polimorfismo genético do receptor para os membros da família das chaperonas Hsp70, que pode influenciar a expressão de Hsp70, alterando desta forma a resposta individual ao insulto sofrido pelo enxerto durante a lesão de isquemia e reperfusão ${ }^{(110)}$.

Além de avaliar a resposta protetora no tecido renal, analisamos também alguns genes que pudessem participar de um microambiente local inflamatório, desencadeado pela isquemia e reperfusão. Para isso então, escolhemos avaliar a expressão de TNFa e IL-6. Observamos baixa ou nenhuma expressão em várias amostras de TNFa e IL-6, principalmente no momento após reperfusão no grupo laparoscópica. Além disso, nas amostras analisadas, não foi observada diferença entre o grupo aberta e laparoscópica. Estes achados sugerem que no transplante intervivos, nos momentos após a retirada do rim ou logo após a reperfusão, a resposta inflamatória local pode ser ainda pequena e insuficiente para detectarmos variações entre os dois tipos de nefrectomia. Uma outra possibilidade a se considerar é que os dois tipos de nefrectomia induzam respostas inflamatórias diferentes de forma sistêmica, mas semelhantes no rim. Interessante notar que, em modelos de nefrectomia experimental, a cirurgia laparoscópica pode induzir o organismo a um menor grau de resposta inflamatória que a cirurgia aberta, com diminuição da expressão de IL-6 e TNFa em amostras de sangue e peritoniais ${ }^{63,111,112)}$. Alguns autores chegam a discutir a possibilidade da laparoscopia poder induzir uma resposta imunológica menor por mecanismos ainda não completamente compreendidos. Os resultados ainda não permitem confirmar tal suposição, mas existem dados mostrando que durante a cirurgia laparoscópica ocorre inibição da liberação de TNFa e IL-6 pelos macrófagos peritoneais ${ }^{(113)}$. A resposta inflamatória observada nestes trabalhos é sistêmica e reflete uma reação ao trauma cirúrgico, entretanto a resposta renal à isquemia e reperfusão pode ocorrer de modo distinto. É possível que esta baixa resposta in situ, no enxerto, possa refletir um menor infiltrado de neutrófilos que são as células responsáveis pela ativação do processo inflamatório 
local, pois a quimiotaxia destas células ocorre mais tardiamente, principalmente em doadores vivos.

A apoptose das células tubulares renais, ao contrário da necrose, é um tipo de morte celular programada que gera uma resposta inflamatória menos intensa, com menor extravasamento de conteúdo tóxico para o tecido adjacente. No entanto, tanto a apoptose como a necrose levam à morte celular e, histologicamente, isto se traduz em afinamento do epitélio tubular e descamação das células para luz tubular, caracterizando a necrose tubular aguda. Este é um evento marcante e intimamente relacionado à lesão de isquemia e reperfusão. O número de células tubulares positivas para apoptose pode ser considerado um fator preditivo da função renal do enxerto $^{(114,115)}$. Em laparoscopia, um estudo em ratos observou aumento da apoptose em rins submetidos a diferentes gradientes de pneumoperitônio, sugerindo que a lesão de isquemia e reperfusão provocada pelo elevação da pressão intra-abdominal pudesse ser a causa da apoptose ${ }^{(116)}$. Entretanto, em nosso estudo, não foi observado aumento da apoptose no grupo laparoscópico por meio da determinação da proteína Caspase-3 por imunoistoquímica. Da mesma forma, a expressão dos fatores Bcl-2 (antiapoptótico) e Bax (pró-apoptótico) não foram diferentes entre os grupos.

Importante notar que ainda não existem testes ou metodologias específicas que possam confirmar ou mesmo predizer se um tecido está realmente sendo agredido e quão intensa é esta agressão. Isto pode ser visto em nosso estudo. Embora não tenhamos observado diferença na marcação imunoistoquímica de proteínas relacionadas à apoptose, a análise histológica, morfométrica, mostrou a presença de necrose tubular aguda em até $45,5 \%$ das amostras provenientes do Hospital das Clínicas. As amostras provenientes do Hospital Santa Casa de Misericórdia de Curitiba não foram avaliadas do ponto de vista morfológico, tendo sido encaminhadas em sua totalidade para análise imunoistoquímica. Este achado de necrose tubular aguda em biópsias de doadores vivos não é inédito, já tendo sido inclusive observado pelo Departamento de Patologia do Hospital das Clínicas (dados não publicados). A distribuição da necrose tubular aguda nos rins 
acometidos foi focal o que pode justificar a pouca repercussão na função renal destes pacientes. Pacientes de ambos os grupos apresentaram necrose tubular aguda, inclusive no momento logo após a retirada do rim. Isto sugere que o processo de agressão tenha tido início em momentos prévios à extração renal. Shimizu et al ${ }^{(117)}$ estudaram histologicamente biópsias de tempo zero de rins retirados por laparoscopia para doação e observaram necrose de células tubulares e congestão capilar peritubular e glomerular, diferentemente de rins procurados por cirurgia aberta. O mesmo não foi encontrado em animais submetidos a pneumoperitônio prolongado e avaliados sete a noventa dias após a cirurgia, quando comparados ao controle ${ }^{(118)}$. Embora, em nossa casuística, tenhamos encontrado necrose tubular aguda focal na maior parte dos casos, a freqüência nos chama a atenção e nos remete ao questionamento de qual efeito teria esta agressão tecidual inicial ao longo dos anos do enxerto renal. Discute-se muito na literatura que o desenvolvimento da disfunção crônica do enxerto com a presença de fibrose intersticial e atrofia tubular seja apenas conseqüência das múltiplas agressões sofridas pelo rim. Em estudo recente, Stegall et al ${ }^{(119)}$ observaram fibrose intersticial grave em biópsias protocolares em até 5 anos após transplante intervivos em $17 \%$ dos pacientes. Quando analisados os possíveis fatores que teriam impacto no surgimento desta fibrose, os autores encontraram a ocorrência de função retardada do enxerto como um destes fatores. Portanto, alterações histológicas iniciais podem contribuir para o desenvolvimento de fibrose e repercutir no funcionamento do enxerto a longo prazo.

Um dos pontos interessantes do nosso estudo foi a possibilidade de podermos avaliar uma cinética abreviada da expressão gênica dos fatores protetores ao longo da cirurgia do transplante. A nosso ver, a primeira biópsia, realizada logo após a nefrectomia, poderia fornecer informações sobre o período de isquemia quente da nefrectomia. Como a cirurgia laparoscópica leva a um maior tempo de isquemia quente, poderíamos então observar alguma diferença entre as duas técnicas. No entanto, não encontramos tais diferenças. Pode-se discutir se não teria havido tempo 
suficiente para repercutir em mudanças na transcrição gênica. Acreditamos que esta é uma possibilidade real. O que nós encontramos foi uma diminuição da expressão gênica de Bcl-2 no momento após a retirada do rim no grupo da cirurgia laparoscópica. Acreditamos que a primeira biópsia possivelmente reproduza a expressão constitutiva destes genes e, portanto, a redução de Bcl-2 observada no momento após reperfusão possa representar uma diminuição da resposta adaptativa no grupo laparoscópica. $\mathrm{Na}$ análise da expressão da proteína através de imunoistoquímica, apesar de não ter ocorrido diferença estatística, no momento após a reperfusão há uma diminuição da média da expressão de Bcl-2, semelhante ao observado na expressão gênica.

Interessante notar que o padrão de resposta dos genes protetores VEGF e Bcl-2 foram semelhantes. Gerber et al ${ }^{(120)}$ demonstraram que uma das ações do VEGF ocorre por ativação da proteína Bcl-2. Da mesma forma, Hata et al $^{(121)}$ observaram que uma das vias de regulação da apoptose ocorre por manutenção do $\mathrm{Bcl}-2$ adjacente às células endoteliais por meio do VEGF. O HIF1 $\alpha$ é um fator de transcrição ao qual é atribuída a função de mediar a ativação da transcrição de VEGF, sendo que este eixo HIF1a/VEGF pode ainda sofrer interferência do $\mathrm{Bcl}-2$ na sua regulação ${ }^{(122,}$ 123). Entretanto, Lemos et $\mathrm{al}^{(58)}$ em estudo comparando pacientes transplantados de doadores vivos e falecidos observaram uma associação entre Bcl-2 e VEGF, sem notar a mesma relação com HIF1a. Em nosso estudo não observamos aumento da expressão de HIF1a, ou correlação entre outros genes protetores ou inflamatórios.

Nosso estudo apresenta algumas limitações. Primeiramente, a avaliação da função renal pela creatinina é um indicador clínico bem estabelecido, porém pouco preciso para avaliar risco de lesão renal. Por isso a necessidade do desenvolvimento de outros parâmetros para tentar identificar fatores preditivos de sobrevida do enxerto. Apesar dos pacientes no grupo laparoscópica e aberta apresentarem função renal equivalente durante o período de observação, é necessário um acompanhamento mais prolongado para uma conclusão definitiva. 
Um segundo aspecto é que as biópsias foram realizadas num momento precoce da lesão de isquemia e reperfusão. É importante salientar que o período entre a tradução do RNAm e a síntese protéica pode ser mais prolongado, de modo que isto pode ser um fator dificultante para a visualização da expressão final da proteína. Por motivos de praticidade e éticos não realizamos biópsias em períodos maiores, que seriam considerados ideais para análise da expressão protéica. Além disso, não é rotina a realização de biópsias protocolares que poderiam avaliar fibrose e inflamação nos rins periodicamente e poderiam nos dar mais subsídios quanto a repercussão das lesões vistas precocemente.

Tivemos algumas dificuldades técnicas para a reação de imunoistoquímica, principalmente com relação às moléculas hemeoxigenase-1 e caspase-3, em que os anticorpos utilizados perderam poder de concentração, impedindo sua utilização em maior número de pacientes. Algumas amostras das proteínas Bax e Bcl-2 não foram realizadas por que a biópsia foi de tamanho insuficiente para realização de todas as reações. Por outro lado, é importante ressaltar o número grande de amostras analisadas em se tratando de imunoistoquímica e de relevante qualidade histológica.

Apesar destas limitações, nosso trabalho permite observar aspectos ainda não estudados do mecanismo protetor da lesão de isquemia e reperfusão renal na laparoscopia para doação renal. Em resumo, laparoscopia e cirurgia aberta apresentam a mesma evolução clinica em termos de complicações e função renal, o que torna a nefrectomia laparoscópica uma técnica consolidada. A avaliação dos genes protetores não mostrou um único padrão e os achados muitas vezes não são observados simultaneamente na transcrição gênica e protéica. Mas alguns achados apontam para a diminuição de alguns genes protetores como $\mathrm{Bcl}-2$ e VEGF após a reperfusão no grupo laparoscópica. Estas diferenças não foram acompanhadas de alteração da função renal quando o parâmetro foi a creatinina sérica. No entanto, lesões histológicas ocorrem mesmo quando há pouco impacto na função renal. Talvez a análise histológica evolutiva através de biópsias protocolares, juntamente com a análise molecular da resposta 
protetora como inflamatória possam auxiliar no surgimento de marcadores histológicos de progressão da doença renal. Além disso, estes dados podem ser de fundamental importância para a implementação de ações que visem futuras intervenções terapêuticas no transplante renal intervivos. 


\section{6-CONCLUSÃO}




\section{6- CONCLUSÃO}

Os resultados deste trabalho nos permitem concluir que não houve diferença entre o grupo aberta e laparoscópica com relação à função renal e eventos cirúrgicos. Os fatores protetores e inflamatórios da lesão de isquemia e reperfusão foram expressos no tecido renal de modo semelhante entre os grupos laparoscópica e aberta. Entretanto, no grupo laparoscópica as moléculas Bcl-2 e VEGF apresentaram redução da sua expressão gênica no período após reperfusão em relação ao momento inicial da primeira biópsia, após a retirada do rim. Além disso, foi observado que a expressão de RNAm de VEGF após a reperfusão está associada ao declínio mais lento da creatinina. 
7-ANEXOS 


\section{ANEXO A}

\section{Aprovação do Comitê de Ética}

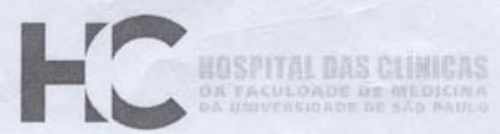

\section{APROVAÇÃO}

A Comissão de Ética para Análise de Projetos de Pesquisa CAPPesq da Diretoria Clínica do Hospital das Clínicas e da Faculdade de Medicina da Universidade de São Paulo, em sessão de 22/10/2008, APROVOU o Protocolo de Pesquisa n ${ }^{\circ}$ 0593/08, intitulado: "ESTUDO COMPARATIVO DA RESPOSTA PROTETORA DO TECIDO RENAL EM RINS DE DOADORES VIVOS SUBMETIDOS A NEFRECTOMIA LAPAROSCÓPICA OU ABERTA NA DOAÇĀO DE ÓRGÃOS" apresentado pelo Departamento de CIRURGIA, inclusive $\bigcirc$ Termo de Consentimento Livre e Esclarecido.

Cabe ao pesquisador elaborar e apresentar à CAPPesq, os relatórios parciais e final sobre a pesquisa (Resolução do Conselho Nacional de Saúde n० 196, de 10/10/1996, inciso (X.2, letra "c").

Pesquisador (a) Responsável: Prof. Dr. William Carlos Nahas

Pesquisador (a) Executante: Dr. Christiano Machado

CAPPesq, 23 de Outubro de 2008

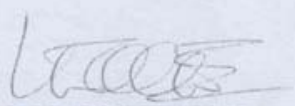

PROF, DR. CLAUDIO LEONE

Vice - Presidente da Comissão de Ética para Análise de Projetos de Pesquisa

Comissâo de Ética para Análise de Projetos de Pesquisa do HCFMUSP e da FMUSP Diretorfáclínicla do 
8-REFERÊNCIAS 


\section{8- REFERÊNCIAS ${ }^{1}$}

1. Garcia VD. A Política de Transplantes no Brasil Revista da AMRIGS. 2007;50(4):313-20.

2. Ratner LE, Ciseck LJ, Moore RG, Cigarroa FG, Kaufman HS, Kavoussi LR. Laparoscopic live donor nephrectomy. Transplantation. 1995;60(9):1047-9.

3. Percegona LS, Meyer F, Machado C, Bignelli AT, Riella MC, Santos LS. Hand-assisted laparoscopic nephrectomy in living donors. Transplant Proc. 2006;38(6):1870-1.

4. Baumert H, Ballaro A, Arroyo C, Kaisary AV, Mulders PF, Knipscheer BC. The use of polymer (Hem-o-lok) clips for management of the renal hilum during laparoscopic nephrectomy. Eur Urol. 2006;49(5):816-9.

5. Ratner LE, Kavoussi LR, Schulam PG, Bender JS, Magnuson TH, Montgomery R. Comparison of laparoscopic live donor nephrectomy versus the standard open approach. Transplant Proc. 1997;29(1-2):138-9.

6. Andersen $\mathrm{MH}$, Mathisen L, Oyen O, Edwin B, Digernes R, Kvarstein $G$, et al. Postoperative pain and convalescence in living kidney donorslaparoscopic versus open donor nephrectomy: a randomized study. Am J Transplant 2006;6(6):1438-43.

7. Tooher RL, Rao MM, Scott DF, Wall DR, Francis DMA, Bridgewater FHG, et al. A systematic review of laparoscopic live-donor nephrectomy. Transplantation. 2004;78(3):404-14.

8. Kim FJ, Ratner LE, Kavoussi LR. Renal Transplantation: Laparoscopic Live Donor Nephrectomy. Urol Clin North Am. 2000;27(4):777-85.

9. Greco F, Hoda MR, Alcaraz A, Bachmann A, Hakenberg OW, Fornara P. Laparoscopic living-donor nephrectomy: analysis of the existing literature. Eur Urol. 2010;58(4):498-509.

10. Mitre Al, Dénes FT, Piovesan AC, Simões FA, Castilho LN, Arap S. Laparoscopic nephrectomy in live donor. Int Braz J Urol. 2004;30(1):22-8.

11. Novick A. Laparoscopic live donor nephrectomy: con. Urology. 1999;53:668-70. 
12. Jacobs SC, Cho E, Foster C, Liao P, Bartlett ST. Laparoscopic donor nephrectomy: the University of Maryland 6-year experience. J Urol. 2004;171(1):47-51.

13. Percegona LS, Bignelli AT, Adamy A, Jr., Machado C, Pilz F, Meyer F, et al. Early graft function in kidney transplantation: comparison between laparoscopic donor nephrectomy and open donor nephrectomy. Transplant Proc. 2008;40(3):685-6.

14. Nanidis TG, Antcliffe D, Kokkinos C, Borysiewicz CA, Darzi AW, Tekkis PP, et al. Laparoscopic versus open live donor nephrectomy in renal transplantation: a meta-analysis. Ann Surg. 2008;247(1):58-70.

15. Massberg S, Messmer K. The nature of ischemia/reperfusion Injury. Transplant Proc. 1998;30(8):4217-23.

16. Mazzoni MC BP, Intaglietta M, Arfors KE. . Lumenal narrowing and endothelial cell swelling in skeletal muscle capillaries during hemorrhagic shock. Circ Shock. 1989;29(1):27-39.

17. Jerome $\mathrm{SN}$ KL, Korthuis RJ. . Microvascular dysfunction in postischemic skeletal muscle. J Invest Surg. 1994;7 (1):3-16.

18. Kosieradzki M, Rowinski W. Ischemia/reperfusion injury in kidney transplantation: mechanisms and prevention. Transplant Proc. 2008;40(10):3279-88.

19. Menger MD, Pelikan S, Steiner D, Messmer K. Microvascular ischemia-reperfusion injury in striated muscle: significance of "reflow paradox". Am J Physiol 1992;263((6 Pt 2)):H1901-6.

20. Lien Y. Pathogenesis of renal ischemia/reperfusion injury: lessons from knockout mice. Life Sci. 2003;74(5):543-52.

21. Eppihimer MJ GD. Ischemia/reperfusion-induced leukocyte-endothelial interactions in postcapillary venules. Shock. 1997; 8(1):16-25.

22. Springer TA. Adhesion receptors of the immune system. Nature. 1990;346(6283):425-34.

23. Kukielka GL, Smith CW, LaRosa GJ, Manning AM, Mendoza LH, Daly TJ, et al. Interleukin-8 gene induction in the myocardium after ischemia and reperfusion in vivo. J Clin Invest. 1995;95(1):89-103. 
24. Lentsch $A B$, Yoshidome $H$, Cheadle WG, Miller FN, Edwards MJ. Chemokine involvement in hepatic ischemia/reperfusion injury in mice: roles for macrophage inflammatory protein-2 and Kupffer cells. Hepatology. 1998;27(2):507-12.

25. Karakurum M, Shreeniwas R, Chen J, Pinsky D, Yan SD, Anderson M, et al. Hypoxic induction of interleukin-8 gene expression in human endothelial cells. J Clin Invest. 1994;93(4):1564-70.

26. Basile DP, Donohoe D, Roethe K, Osborn JL. Renal ischemic injury results in permanent damage to peritubular capillaries and influences longterm function. Am J Physiol Renal Physiol. 2001; 281(5):F887-99.

27. Youle RJ, Strasser A. The BCL-2 protein family: opposing activities that mediate cell death. Nat Rev Mol Cell Biol. 2008;9(1):47-59.

28. Sanz AB, Santamaria B, Ruiz-Ortega M, Egido J, Ortiz A. Mechanisms of renal apoptosis in health and disease. J Am Soc Nephrol. 2008;19(9):1634-42.

29. Thornberry NA, Lazebnik Y. Caspases: Enemies Within. Science. 1998;281(5381):1312-6.

30. Saikumar $P$, Venkatachalam MA. Role of apoptosis in Hypoxic/lschemic Damage in the Kidney. Semin Nephrol. 2003;23(6):511-21.

31. Padanilam BJ. Cell death induced by acute renal injury: a perspective on the contributions of apoptosis and necrosis. Am J Physiol Renal Physiol. 2003;284(4):F608-27.

32. Snoeijs MG, van Heurn LW, Buurman WA. Biological modulation of renal ischemia-reperfusion injury. Curr Opin Organ Transplant. 2010;15(2):190-9.

33. Castaneda MP, Swiatecka-Urban A, Mitsnefes MM, Feuerstein D, Kaskel FJ, et al. Activation of mitochondrial apoptotic pathways in human renal allografts after ischemia reperfusion injury. Transplantation. 2003;76(1):50-4.

34. Tsuchihashi S-i, Fondevila C, Kupiec-Wenglinski JW. Heme Oxygenase System in Ischemia Reperfusion Injury. Ann Transplant. 2004;9(1):84-7. 
35. Holzen JP, August C, Bahde R, Minin E, Lang D, Heidenreich S, et al. Influence of heme oxygenase-1 on microcirculation after kidney transplantation. J Surg Res. 2008;148(2):126-35.

36. Abraham NG, Cao J, Sacerdoti D, Li X, Drummomd G. Heme oxygenase: the key to renal function regulation. Am J Physiol Renal Physiol. 2009;297:F1137-52.

37. Brasile L, Buelow R, Stubenitsky BM, Kootstra G. Induction of heme oxygenase-1 in kidneys during ex vivo warm perfusion. Transplantation. 2003;76(8):1145-9.

38. Maines MD. The heme oxygenase system: a regulator of second messenger gases. Annu Rev Pharmacol Toxicol. 1997;37:517-54.

39. Soares MP LY, Anrather J, et al. . Expression of heme oxygenase-1 can determine cardiac xenograft survival. Nat Med. 1998;4(9):1073-7.

40. Otterbein LE, Bach FH, Alam J, Soares M, Hong TL, Wysk M, et al. Carbon monoxide has anti-inflamatory effects involving the mitogenactivaded protein kinase pathway. Nat Med. 2000;6(4):422-8.

41. Katori M BR, Ke B, Ma J, Coito AJ, lyer S, et al. . Heme oxygenase-1 overexpression protects rat hearts from cold ischemia/reperfusion injury via an antiapoptotic pathway. Transplantation. 2002;73(2):287-93.

42. Tullius SG, Nieminen-Kelha M, Buelow R, Reutzel-Selke A, Martins $\mathrm{PN}$, Pratschke J, et al. Inhibition of ischemia/reperfusion injury and chronic graft deterioration by a single-donor treatment with cobalt-protoporphyrin for the induction of heme oxygenase-1. Transplantation. 2002;74(5):591-8.

43. Wagner M CP, Ruf R, Mazzucchelli L, Ferrari P, Redaelli CA. Heme oxygenase attenuates ischemia/reperfusion-induced apoptosis and improves survival in rat renal allografts. Kidney Int. 2003;63:1564-73.

44. Hightower LE. Heat shock, stress proteins, chaperones, and proteotoxicity. Cell. 1991;66(7):191-7.

45. Mosser DD, Caron AW, Bourget L, Meriin AB, Sherman MY, Morimoto $\mathrm{RI}$, et al. The chaperone function of hsp70 is required for protection against stress-induced apoptosis. Mol Cell Biol. 2000;20(19):7146-59.

46. Aufricht C. Heat-shock protein 70: molecular supertool? Pediatr Nephrol. 2005;20(6):707-13. 
47. Kim BS, Lim SW, Li C, Kim JS, Sun BK, Ahn KO, et al. Ischemiareperfusion injury activates Innate Immunity in rat kidneys. Transplantation. 2005;79(10):1370-7.

48. Zhang PL, Lun M, Schworer CM, Blasick TM, Masker KK, Jones JB, et al. Heat shock protein expression Is highly sensitive to ischemia-reperfusion injury in rats kidneys. Ann Clin Lab Sci. 2008;38(1):57-64.

49. August C, Brockmann J, Vowinkel T, Wolters H, Dietl KH, Levkau B, et al. Stress associated proteins metallothionein, HO-1 and HSP 70 in human zero-hour biopsies of transplanted kidneys. Virchows Arch. 2006;449(2):1929.

50. Kelly KJ, Baird NR, Greene AL. Induction of stress response proteins and experimental renal ischemia reperfusion. Kidney Int. 2001;59:1798-802.

51. Berse B, Brown LF, Van de Water L, Dvorak HF, Senger DR. Vascular permeability factor (vascular endothelial growth factor) gene is expressed differentially in normal tissues, macrophages, and tumors. Mol Biol Cell. 1992;3(2):211-20.

52. Masuda $Y$, Shimizu A, Mori T, Ishiwata T, Kitamura H, Ohashi R, et al. Vascular endothelial growth factor enhances glomerular capillary repair and accelerates resolution of experimentally induced glomerulonephritis. Am J Pathol. 2001;159(2):599-608.

53. Kang DH, Anderson S, Kim YG, Mazzalli M, Suga S, Jefferson JA, et al. Impaired angiogenesis in the aging kidney: vascular endothelial growth factor and thrombospondin-1 in renal disease. Am $\mathrm{J}$ Kidney Dis. 2001;37(3):601-11.

54. Ferrara N. The biology of vascular endothelial growth factor. Endocr Rev. 1997;18(1):4-25.

55. Kang DH, Joly AH, Oh SW, Hugo C, Kerjaschki D, Gordon KL, et al. Impaired angiogenesis in the remnant kidney model: I. Potential role of vascular endothelial growth factor and thrombospondin-1. J Am Soc Nephrol. 2001;12(7):1434-47.

56. Baan C, Peeters A, Lemos F, Uitterlinden A, Doxiadis I, Claas F, et al. Fundamental role for $\mathrm{HO}-1$ in the self-protection of renal allografts. Am J Transplant. 2004;4(5):811-8.

57. Lemos FB, Mol WM, Roodnat JI, Uitterlinden A, ljzermans JN, Weimar $W$, et al. The beneficial effects of recipient-derived vascular endothelial 
growth factor on graft survival after kidney transplantation. Transplantation. 2005;79(9):1221-5.

58. Lemos FBC, ljzermans JN, Zondervan P, Peeters AMA, Van Den Engel S, Mol WM, et al. Differential expression of heme oxygenase-1 and vascular endothelial growth factor in cadaveric and living donor kidneys after ischemia-reperfusion. J Am Soc Nephrol. 2003;14(12):3278-87.

59. Demyttenaere S, Feldman LS, Fried GM. Effect of pneumoperitoneum on renal perfusion and function: a systematic review. Surg Endosc. 2007;21(2):152-60.

60. Ambrose JA, Onders RP, Stowe NT, Simonson MS, Robinson AV, Wilhelm $S$, et al. Pneumoperitoneum upregulates preproendothelin-1 messenger RNA. Surg Endosc. 2001;15(2):183-8.

61. Burgos F, Pascual J, Briones G, Cuevas B, Villafruela J, Correa C, et al. Influence of laparoscopic live donor nephrectomy in ischemia-reperfusion syndrome and renal function after kidney transplantation: an experimental study. Transplant Proc. 2003;35(5):1664-5.

62. Saenz J, Asuero MS, Villafruela J, Correa C, Galindo J, Cuevas B, et al. Immunohumoral response during laparoscopic and open living donor nephrectomy: an experimental model. Transplant Proc. 2007;39(7):2102-4.

63. Matsumoto ED, Margulis V, Tunc L, Taylor G, Duchene D, Johnson B, et al. Cytocine response to surgical stress: comparison of pure laparoscopic, hand-assisted laparoscopic, and open nephrectomy. J Endourol. 2005;19(9):1140-6.

64. Kurian SM, Flechner SM, Kaouk J, Modlin C, Goldfarb D, Cook DJ, et al. Laparoscopic donor nephrectomy gene expression profiling reveals upregulation of stress and ischemia associated genes compared to control kidneys. Transplantation. 2005;80(8):1067-71.

65. Grigoryev DN, Liu M, Cheadle C, Barnes KC, Rabb H. Genomic profiling of kidney ischemia reperfusion reveals expression of specific alloimmunity-associated genes: linking "immune" and "non-immune" injury events. Transplant Proc. 2006;38(10):3333-6.

66. Sammour T, Mittal A, Loveday BPT, Kahokehr A, Phillips ARJ, Windsor JA, et al. Systematic review of oxidative stress associated with pneumoperitoneum. Br J Surg. 2009;96(8):836-50. 
67. Khoury W, Schreiber L, Szold A, Klausner JM, Wienbroum AA. Renal oxidative stress following $\mathrm{CO} 2$ pneumoperitoneum-like conditions. Surg Endosc. 2009;23(4):776-82.

68. Pfaffl MW. A new mathematical model for relative quantification in real-time RT-PCR. Nucleic Acids Res. 2001;29(9):2002-7.

69. Yuzawa K, Shinoda M, Fukao K. Outcome of laparoscopic live donor nephrectomy in 2005: National survey of Japanese transplantation centers. Transplant Proc. 2006;38(10):3409-11.

70. Dols LF, Kok NF, ljzermans JN. Live donor nephrectomy: a review of evidence for surgical techniques. Transpl Int. 2010;23(2):121-30.

71. Desai MR, Ganpule AP, Gupta R, Thimmegowda M. Outcome of renal transplantation with multiple versus single renal arteries after laparoscopic live donor nephrectomy: a comparative study. Urology. 2007;69(5):824-7. Epub 2007/05/08.

72. Hsu THS, Su L-M, Ratner LE, Trock BJ, Kavoussi LR. Impact of renal artery multiplicity on outcomes of renal donors and recipients in laparoscopic donor nephrectomy. Urology. 2003;61(2):323-7.

73. Mandal AK, Cohen C, Montgomery R, Kavoussi LR, Ratner LE. Should the indications for laparoscopic live donor nephrectomy of the right kidney be the same as for the open procedure? Anomalous left renal vasculature is not a contraindication to laparoscopic left donor nephrectomy. Transplantation. 2001;71(5):660-4

74. Buell JF, Hanaway MJ, Potter SR, Koffron A, Kuo P, Leventhal JR, et al. Surgical techniques in right laparoscopic donor nephrectomy. J Am Coll Surg. 2002;195(1):131-7.

75. Turk IA, Deger S, Davis JW, Giesing M, Fabrizio MD, et al. Laparoscopic live donor right nephrectomy: a new technique with preservation of vascular length. J Urol. 2002;167:630-3.

76. Bollens R, Mikhaski D, Espinoza BP, Rosenblatt A, Hoang AD, Abramowicz D, et al. Laparoscopic live donor right nephrectomy: a new technique to maximize the length of the renal vein using a modified Endo GIA stapler. Eur Urol. 2007;51(5):1326-31.

77. Diner EK, Radolinski B, Murdock JD, Ghasemian SR. Right laparoscopic donor nephrectomy: The washington hospital center experience. Urology. 2006;68(6):1175-7. 
78. Kay MD, Brook N, Kaushik M, Harper SJ, Bagul A, Nicholson ML. Comparison of right and left laparoscopic live donor nephrectomy. BJU Int. 2006;98(4):843-4.

79. Liu KL, Chiang YJ, Wu CT, Lai WJ, Wang HH, Chu SH. Why we consistently use the left donor kidney in living related transplantation: initial experience of right laparoscopic donor nephrectomy and comparison with left nephrectomy. Transplant Proc. 2006;38(7):1977-9.

80. Acuña $\mathrm{K}$, Cruz T. Avaliação do estado nutricional de adultos e idosos e situação nutricional da população brasileira. Arq Bras Endocrinol Metab. 2004;48(3):345-61.

81. Kok NF, ljzermans JN, Schouten O, Tran KT, Weimar W, Alwaym IP. Laparoscopic donor nephrectomy in obese donors: easier to implement in overweight women? Transpl Int. 2007;20(11):956-61.

82. Heimbach JK, Taler SJ, Prieto M, Cosio FG, Textor SC, Kudva YC, et al. Obesity in living kidney donors: clinical characteristics and outcomes in the era of laparoscopic donor nephrectomy. Am $J$ Transplant. 2005;5(5):1057-64.

83. Yarlagadda SG, Coca SG, Formica RN, Jr., Poggio ED, Parikh CR. Association between delayed graft function and allograft and patient survival: a systematic review and meta-analysis. Nephrol Dial Transplant. 2009;24(3):1039-47.

84. Perico N, Cattaneo D, Sayegh MH, Remuzzi G. Delayed graft function in kidney transplantation. Lancet. 2004;364(9447):1814-27.

85. Goel M, Modlin C, Mottoo A, Derweesh I, Flechner S, et al. Fate of donor kidney: laparoscopic versus open technique. J Urol. 2004;172(6):232630 .

86. Moers C SJ, Maathuis MH, Treckmann J, van Gelder F, Napieralski $\mathrm{BP}$, et al. Machine perfusion or cold storage in deceased-donor kidney transplantation. N Engl J Med. 2009;360(1):7-19.

87. Abreu SC, Goldfarb DA, Derweesh I, Thornton J, Urbain JL, et al. Factors related to delayed graft function after laparoscopic live donor nephrectomy. J Urol. 2004;171(1):52-7.

88. Zeier M, Döhler B, Opelz G, Ritz E. The Effect of Donor Gender on Graft Survival. J Am Soc Nephrol. 2002;13(10):2570-6. 
89. Huh KH, Yun M, Kim TS, Cho A, Lee JD, et al. Measurement of donor kidney functional renal volume and glomerular filtration rate to predict allograft function during the post-transplantation period. Nephron Clin Pract. 2009;113(4):c262-9.

90. Kher A, Meldrum KK, Wang M, Tsai BM, Pitcher JM, Meldrum DR. Cellular and molecular mechanisms of sex differences in renal ischemiareperfusion injury. Cardiovasc Res. 2005;67(4):594-603.

91. Figueiredo A, Moreira P, Parada B, Nunes P, Macario F, et al. Risk factors for delayed renal graft function and their impact on renal transplantation outcome. Transplant Proc. 2007;39(8):2473-5.

92. Buzdon MM, Cho E, Jacobs SC, Jarrell B, Flowers JL. Warm ischemia time does not correlate with recipient graft function in laparoscopic donor nephrectomy. Surg Endosc. 2003;17(5):746-9.

93. Simforoosh N, Basiri A, Shakhssalim N, Ziaee SAM, Tabibi A, Moghaddam SMMH. Effect of warm ishemia on graft outcome in laparoscopic donor nephrectomy. J Endourol. 2006;20(11):895-8.

94. Nogueira JM, Haririan A, Jacobs SC, Weir MR, Hurley HA, Al-Qudah $\mathrm{HS}$, et al. The detrimental effect of poor early graft function after laparoscopic live donor nephrectomy on graft outcomes. Am J Transplant. 2009;9(2):33747.

95. Sikorski EM, Hock T, Hill-Kapturczak N, Agarwal A. The story so far: Molecular regulation of the heme oxygenase-1 gene in renal injury. Am J Physiol Renal Physiol. 2004;286(3):F425-41.

96. Ollinger R, Kogler P, Biebl M, Sieb M, Sucher R, et al. Protein levels of heme oxygenase-1 during reperfusion in human kidney transplants with delayed graft function. Clin Transplant. 2008;22(4):418-23.

97. Schrijvers BF, Flyvbjerg A, De Vriese AS. The role of vascular endothelial growth factor (VEGF) in renal pathophysiology. Kidney Int. 2004;65:2003-17.

98. Pilmore HL, M J, Painter DM, Bishop GA, McCaughan GW. Vascular endothelial growth factor expression in human chronic renal allograft rejection. Transplantation. 1999;67(6):929-33.

99. Shahbazi M, Fryer AA, Pravica V, Brogan IJ, Ramsay HM, et al. Vascular endothelial growth factor gene polymorphisms are associated with acute renal allograft rejection J Am Soc Nephrol. 2002;13: 260-4. 
100. Cross MJ, Dixelius J, Matsumoto T, Claesson-Welsh L. VEGFreceptor signal transduction. Trends Bioch Sci. 2003;28(9):488-94.

101. Basile DP, Fredrich K, Chelladurai B, Leonard EC, Parrish AR. Renal ischemia reperfusion inhibits VEGF expression and induces ADAMTS-1, a novel VEGF inhibitor. Am J Physiol Renal Physiol. 2008;294:F928-F36.

102. Constantinides CA, Tyritzis SI, Evangelou C, Kyroudi A, Liatsikos E, et al. Vascular endothelial growth factor protein expression in a renal ablation rabbit model under prolonged warm and cold ischemia. Am J Nephrol. 2008;28(3):438-45.

103. Kanellis J, Paizis K, Cox AJ, Stacker SA, Gilbert RE, et al. Renal ischemia-reperfusion increases endothelial VEGFR-2 without increasing VEGF or VEGFR-1 expression. Kidney Int. 2002;61:1696-706.

104. Kanellis J, Mudge SJ, Fraser S, Katerelos M, Power DA. Redistribution of cytoplasmic VEGFto the basolateral aspect of renal tubular cells in ischemia-reperfusion injury. Kidney Int. 2000; 57: 2445-56.

105. Alvarez Arroyo MV, Suzuki Y, Yague S, Lorz C, Jimenez S, et al. Role of endogenous vascular endothelial growth factor in tubular cell protection against acute cyclosporine toxicity. Transplantation. 2002; 74(11):1618-24.

106. Shihab FS, Bennett WM, Yi H, Andoh TF. Expression of vascular endothelial growth factor and its receptors flt-1 and kdr/flk-1 in chronic cyclosporine nephrotoxicity. Transplantation. 2001; 72(1):164-8.

107. Mayer MP, Bukau B. Hsp70 chaperones: cellular functions and molecular mechanism. Cell Mol Life Sci. 2005;62(6):670-84.

108. Trieb K, Dirnhofer S, Krumbock N, Blahovec H, Sgong R, Margreiter $\mathrm{R}$, et al. Heat shock protein expression in the transplanted kidney. Transpl Int. $2001 ; 14: 281-6$.

109. Daly PJ, Docherty NG, Healy DA, McGuire BB, Fitzpatrick JM, Watson $\mathrm{RW}$. The single insult of hypoxic preconditioning induces an antiapoptotic response in human proximal tubular cells, in vitro, across cold storage. BJU international. 2009;103(2):254-9. Epub 2008/09/11.

110. Fekete A, Viklicky O, Hubacek JA, Rusai K, Erdei G, et al. Association between heat shock protein 70 s and toll-like receptor polymorphisms with long-term renal allograft survival. Transpl Int. 2006;19(3):190-6. Epub 2006/01/31. 
111. Linares Quevedo Al, Burgos Revilla F, Villafruela Sanz JJ, Zamora Romero J, et al. Utilidad de las citocinas como marcadores de agresión quirúrgica, en el síndrome de isquemia-reperfusión y en la función postransplante renal, en un modelo experimental de autotransplante laparoscópico versus abierto. Arch Esp Urol. 2008;61(1):41-54.

112. Orenstein SB, Kaban GK, Litwin DE, Novitsky YW. Evaluation of serum cytokine release in response to hand-assisted, laparoscopic, and open surgery in a porcine model. Am J Surg. 2011;202(1):97-102.

113. Novitsky YW, Czerniach DR, Kaban GK, Bergner A, Gallagher KA, Perugini RA, et al. Immunologic effects of hand-assisted surgery on peritoneal macrophages: comparison to open and standard laparoscopic approaches. Surgery. 2006;139(1):39-45.

114. Daemen MARC, de Vries B, Buurman WA. Apoptosis and Inflammation in Renal Reperfusion Injury. Transplantation. 2002;73(11):1693-700

115. Oberbauer R, Rohrmoser M, Regele H, Mühlbacher F, Mayer G. Apoptosis of tubular epithelial cells in donor kidney biopsies predicts early renal allograft function. J Am Soc Nephrol. 1999;10:2006-13.

116. Khoury W, Jakowlev K, Fein A, Orenstein H, Nakache R, Weinbroum AA. Renal apoptosis following carbon dioxide pneumoperitoneum in a rat model. J Urol. 2008;180(4):1554-8.

117. Shimizu $T$, Tanabe $K$, Ishida $H$, Toma $H$, Yamagushi $Y$. Histopathological evaluation of 0 -h biopsy specimens of donor kidney procured by laparoscopic donor nephrectomy. Clin Transplant. 2004;18(Suppl.11):24-8.

118. Lee B, Cadeddu JA, Molnar-Nadasky G, Enriquez D, Nadasdy T, Kavoussi LR, et al. Chronic effect of pneumoperitoneum on renal histology. J Endourol. 1999;13(4):279-82.

119. Stegall MD, Park WD, Larson TS, Gloor JM, Cornell LD, Sethi S, et al. The histology of solitary renal allografts at 1 and 5 years after transplantation. Am J Transplant. 2011;11(4):698-707.

120. Gerber HP, Dixit V, Ferrara N. Vascular endothelial growth factor induces expression of the antiapoptotic proteins Bcl-2 and A1 in vascular endothelial cells. J Biol Chem. 1998;273(21):13313-6. 
121. Hata S, Fukuo K, Morimoto S, Eguchi $\mathrm{Y}$, Tsujimoto $\mathrm{Y}$, Ogihara T. Vascular smooth muscle maintains the levels of $\mathrm{Bcl}-2$ in endothelial cells. Atherosclerosis. 2001;154:309-16.

122. Forsythe JA, Jiang BH, lyer NV, Agani F, Leung SW, Koss RD, et al. Activation of vascular endothelial growth factor gene transcription by hypoxiainducible factor 1. Mol Cell Biol. 1996;16(9):4604-13.

123. Trisciuoglio D, Gabellini C, Desideri M, Ragazzoni Y, De Luca T, Ziparo E, et al. Involvement of BH4 domain of bcl-2 in the regulation of HIF-1mediated VEGF expression in hypoxic tumor cells. Cell Death Differ. 2011;18(6):1024-35.

${ }^{1}$ De acordo com estilo Vancouver 


\section{APÊNDICES}


APÊNDICE A

Resultados da extração de RNA nas diferentes amostras nos momentos após isquemia $(T-1)$ e após reperfusão $(T+1)$

\begin{tabular}{|c|c|c|c|c|}
\hline amostras & $\begin{array}{l}\text { Momento } \\
\text { cirurgia }\end{array}$ & Tipo de cirurgia & $\begin{array}{c}\text { Conc. de RNA } \\
\mathrm{ng} / \mu \mathrm{l}\end{array}$ & $260 / 280 \mathrm{~nm}$ \\
\hline 1 & $\overline{T+1}$ & ABERTA & 651,4 & 1,65 \\
\hline 2 & $\mathrm{~T}-1$ & ABERTA & 1420,9 & 1,49 \\
\hline 3 & $T+1$ & ABERTA & 1621,8 & 1,47 \\
\hline 4 & $\mathrm{~T}-1$ & ABERTA & 784,3 & 1,51 \\
\hline 5 & $T+1$ & ABERTA & 264,2 & 1,52 \\
\hline 6 & $\mathrm{~T}-1$ & ABERTA & 463,2 & 1,56 \\
\hline 7 & $T+1$ & LAPAROSCÓPICA & 544,7 & 1,59 \\
\hline 8 & $\mathrm{~T}-1$ & LAPAROSCÓPICA & 372,2 & 1,67 \\
\hline 9 & $T+1$ & LAPAROSCÓPICA & 1295 & 1,6 \\
\hline 10 & $\mathrm{~T}-1$ & LAPAROSCÓPICA & 816,3 & 1,34 \\
\hline 11 & $T+1$ & ABERTA & 513,4 & 1,62 \\
\hline 12 & $\mathrm{~T}-1$ & ABERTA & 417,3 & 1,51 \\
\hline 13 & $\mathrm{~T}+1$ & ABERTA & 334,9 & 1,65 \\
\hline 14 & $\mathrm{~T}-1$ & ABERTA & 565 & 1,73 \\
\hline 15 & $\mathrm{~T}+1$ & ABERTA & 545,8 & 1,7 \\
\hline 16 & $\mathrm{~T}-1$ & ABERTA & 561,4 & 1,5 \\
\hline 17 & $T+1$ & LAPAROSCÓPICA & 151,8 & 1,66 \\
\hline 18 & $\mathrm{~T}-1$ & LAPAROSCÓPICA & 338,2 & 1,67 \\
\hline 19 & $T+1$ & ABERTA & 460,1 & 1,52 \\
\hline 20 & $\mathrm{~T}-1$ & ABERTA & 261,5 & 1,54 \\
\hline 21 & $T+1$ & ABERTA & 444,3 & 1,71 \\
\hline 22 & $\mathrm{~T}-1$ & ABERTA & 91,2 & 1,47 \\
\hline 23 & $\mathrm{~T}+1$ & ABERTA & 799,9 & 1,51 \\
\hline 24 & $\mathrm{~T}-1$ & ABERTA & 591,3 & 1,71 \\
\hline 25 & $T+1$ & ABERTA & 1693,8 & 1,84 \\
\hline 26 & $\mathrm{~T}-1$ & ABERTA & 1018 & 1,87 \\
\hline 27 & $T+1$ & ABERTA & 752 & 1,57 \\
\hline 28 & $\mathrm{~T}-1$ & ABERTA & 477 & 1,7 \\
\hline 29 & $\mathrm{~T}+1$ & LAPAROSCÓPICA & 1261,9 & 1,72 \\
\hline 30 & $\mathrm{~T}-1$ & LAPAROSCÓPICA & 678,2 & 1,65 \\
\hline 31 & $\mathrm{~T}+1$ & ABERTA & 770,2 & 1,63 \\
\hline 32 & $\mathrm{~T}-1$ & ABERTA & 210,2 & 1,89 \\
\hline 33 & $T+1$ & LAPAROSCÓPICA & 412,7 & 1,84 \\
\hline 34 & $\mathrm{~T}-1$ & LAPAROSCÓPICA & 569,5 & 1,83 \\
\hline 35 & $T+1$ & ABERTA & 2108,4 & 1,7 \\
\hline 36 & $\mathrm{~T}-1$ & ABERTA & 1405 & 1,61 \\
\hline 37 & $T+1$ & ABERTA & 290,6 & 1,88 \\
\hline 38 & $\mathrm{~T}-1$ & ABERTA & 845,2 & 1,65 \\
\hline 39 & $T+1$ & LAPAROSCÓPICA & 712,4 & 1,61 \\
\hline 40 & $\mathrm{~T}-1$ & LAPAROSCÓPICA & 190,5 & 1,76 \\
\hline 41 & $T+1$ & LAPAROSCÓPICA & 471,1 & 1,85 \\
\hline 42 & $\mathrm{~T}-1$ & LAPAROSCÓPICA & 268,3 & 1,8 \\
\hline 43 & $T+1$ & ABERTA & 1034,1 & 1,4 \\
\hline 44 & $\mathrm{~T}-1$ & ABERTA & 1377,4 & 1,67 \\
\hline 45 & $T+1$ & LAPAROSCÓPICA & 268,7 & 1,75 \\
\hline 46 & $\mathrm{~T}-1$ & LAPAROSCÓPICA & 324 & 1,8 \\
\hline 47 & $\mathrm{~T}+1$ & LAPAROSCÓPICA & 351,9 & 1,81 \\
\hline 48 & $\mathrm{~T}-1$ & LAPAROSCÓPICA & 376,5 & 1,73 \\
\hline 49 & $T+1$ & ABERTA & 421,8 & 1,46 \\
\hline 50 & $\mathrm{~T}-1$ & ABERTA & 467,8 & 1,91 \\
\hline 51 & $T+1$ & ABERTA & 133,2 & 1,58 \\
\hline 52 & $\mathrm{~T}-1$ & ABERTA & 368,2 & 1,78 \\
\hline 53 & $T+1$ & LAPAROSCÓPICA & 1506,8 & 1,92 \\
\hline 54 & $\mathrm{~T}-1$ & LAPAROSCOPICA & 986,5 & 1,97 \\
\hline 55 & $T+1$ & ABERTA & 594,6 & 1,51 \\
\hline 56 & $\mathrm{~T}-1$ & ABERTA & 1175,0 & 1,88 \\
\hline
\end{tabular}


Resultados da extração de RNA nas diferentes amostras nos momentos após isquemia ( $T-1)$ e após reperfusão $(T+1)$ - continuação

\begin{tabular}{l|cccc}
\hline 57 & $\mathrm{~T}+1$ & LAPAROSCOPICA & 1142,6 & 1,44 \\
58 & $\mathrm{~T}-1$ & LAPAROSCOPICA & 131,3 & 1,45 \\
59 & $\mathrm{~T}+1$ & LAPAROSCOPICA & 656,4 & 1,33 \\
60 & $\mathrm{~T}-1$ & LAPAROSCOPICA & 1946,6 & 1,72 \\
61 & $\mathrm{~T}+1$ & LAPAROSCOPICA & 3940,6 & 1,59 \\
62 & $\mathrm{~T}-1$ & LAPAROSCOPICA & 1029,0 & 1,61 \\
63 & $\mathrm{~T}+1$ & LAPAROSCOPICA & 1276,1 & 1,69 \\
64 & $\mathrm{~T}-1$ & LAPAROSCOPICA & 811,3 & 1,58 \\
65 & $\mathrm{~T}+1$ & ABERTA & 820,4 & 1,70 \\
66 & $\mathrm{~T}-1$ & ABERTA & 993,2 & 1,83 \\
67 & $\mathrm{~T}+1$ & ABERTA & 1646,1 & 1,94 \\
68 & $\mathrm{~T}-1$ & ABERTA & 1393,2 & 1,84 \\
69 & $\mathrm{~T}+1$ & ABERTA & 1365,3 & 1,86 \\
70 & $\mathrm{~T}-1$ & ABERTA & 1511,5 & 1,62 \\
71 & $\mathrm{~T}+1$ & ABERTA & 1398,5 & 1,80 \\
72 & $\mathrm{~T}-1$ & ABERTA & 1962,6 & 1,74 \\
\hline
\end{tabular}




\section{APÊNDICE B}

Dados clínicos brutos dos pacientes do grupo aberta

\begin{tabular}{|c|c|c|c|c|c|c|c|c|c|c|c|c|c|c|c|c|c|c|c|c|c|c|}
\hline & idad & & idade & sexo & & & & & & $\mathbf{T}$ & & & & & & & & & & & & \\
\hline Pac & e & sexo & doador & doador & CAUSA & IMC & IMCd & transfusões & PRA & doador & TIQ & TIF & scr1 & scr2 & scr3 & scr4 & scr5 & scr6 & scr7 & scr30 & scr $3 m$ & scr6m \\
\hline 1 & 42 & $\mathrm{~m}$ & 55 & $\mathrm{~F}$ & $\begin{array}{l}\text { DESCONH. } \\
\text { nefropatia }\end{array}$ & 20,4 & & 0 & 0 & DVR & 80 & 100 & 5,0 & 4,5 & 5,1 & 5,9 & 5,5 & 5,2 & 4,0 & 2,2 & 1,6 & 1,6 \\
\hline 2 & 39 & $f$ & 32 & $\mathrm{~F}$ & Iga & 24,44 & 21,47 & 0 & 0 & DVR & & & 2,2 & 1,1 & 1,2 & 1,1 & 0,9 & & 0,9 & 0,8 & 0,8 & 0,8 \\
\hline 3 & 66 & $f$ & 35 & M & DM & 25,78 & 27 & 0 & 0 & DVR & 130 & 50 & 4,3 & 3,2 & 2,9 & 2,2 & 1,8 & 1,7 & 1,5 & 1,2 & 1,2 & 2,3 \\
\hline 4 & 40 & $f$ & 25 & $\mathrm{~F}$ & GNC & 19,82 & & & 18,05 & $d v r$ & 120 & 85 & 7,4 & 5,4 & 2,6 & 2,1 & 1,9 & 1,6 & 1,1 & 1,0 & 1,0 & 1,0 \\
\hline 5 & 34 & $\mathrm{~m}$ & 34 & $\mathrm{~F}$ & GNC & 22,2 & 22,3 & 0 & 0 & DVR & 80 & & 2,7 & 1,8 & 1,6 & 1,6 & 1,4 & 1,4 & 1,4 & 1,7 & 1,6 & 1,4 \\
\hline 6 & 22 & $\mathrm{~m}$ & 41 & $\mathrm{~F}$ & GNC & 24,03 & & & 27,06 & DVR & 200 & 100 & 10,1 & 3,9 & 2,3 & 1,8 & 1,8 & 1,6 & 1,5 & 1,4 & 1,3 & 1,5 \\
\hline 7 & 62 & $f$ & 63 & M & $\begin{array}{l}\text { RINS POLIC } \\
\text { nefrosclerose }\end{array}$ & 24,31 & 29,03 & 0 & 0 & DVNR & 65 & 45 & 4,2 & 1,7 & 1,4 & 1,6 & 3,0 & 2,4 & 1,6 & 1,1 & 1,0 & 1,1 \\
\hline 8 & 50 & $f$ & 32 & $\mathrm{~F}$ & hipert. & 26,49 & 27,55 & & 0 & DVR & 180 & 75 & 4,1 & 4,0 & 4,1 & 5,0 & 5,3 & 6,5 & 6,3 & 1,1 & 0,9 & 0,8 \\
\hline 9 & 46 & $f$ & 24 & $\mathrm{~F}$ & amiloidose & 27,56 & 19,07 & & 19,6 & $d v r$ & 180 & 90 & 2,6 & 1,0 & 1,6 & 1,2 & 1,1 & 1,4 & 1,2 & 1,0 & 1,3 & 1,2 \\
\hline 10 & 29 & $\mathrm{~m}$ & 27 & $\mathrm{~F}$ & DESCONH. & 33,56 & 20,34 & 0 & 0 & DVR & & & 6,6 & 3,9 & 2,6 & 2,3 & 2,1 & 2,0 & 1,7 & 1,7 & 1,5 & 1,5 \\
\hline 11 & 42 & $f$ & 24 & $\mathrm{~F}$ & HAS & 23,24 & 19 & 4 & 0 & DVR & 140 & 75 & 1,6 & 0,9 & 1,2 & 1,0 & 0,8 & 1,1 & & 1,0 & 0,9 & 0,8 \\
\hline 12 & 46 & $f$ & 35 & M & GNC & 25,77 & 22,1 & 1 & 0 & DVR & 150 & & 3,7 & 1,8 & 1,5 & 1,2 & 1,0 & & 0,9 & 0,7 & 0,8 & 0,8 \\
\hline 13 & 52 & $\mathrm{~m}$ & 40 & $\mathrm{~F}$ & HAS & 33,12 & 28,7 & 0 & 0 & DVR & 100 & 80 & 5,8 & 2,6 & 2,3 & 2,0 & 1,8 & 1,6 & & 1,5 & 1,8 & 1,8 \\
\hline 14 & 44 & $\mathrm{~m}$ & 27 & M & GNC & 25,99 & & 4 & & DVR & 64 & 64 & 3,9 & 3,1 & 3,3 & 3,3 & 4,1 & 3,2 & 2,5 & 1,7 & 1,4 & 1,5 \\
\hline 15 & 44 & $\mathrm{~m}$ & 29 & $f$ & HAS & 25,47 & 26,22 & & & DVR & 300 & 60 & 7,4 & 2,8 & 2,2 & 1,5 & 1,7 & 1,7 & 1,7 & 1,4 & 1,2 & 1,1 \\
\hline 16 & 25 & $\mathrm{~m}$ & 45 & $\mathrm{~F}$ & DESCONH. & 22,68 & 23,66 & & 0 & DVR & 120 & 80 & 2,3 & 1,2 & 1,2 & 1,2 & 1,4 & 1,0 & 1,0 & 1,2 & 1,5 & 1,3 \\
\hline 17 & 40 & $f$ & 46 & M & GNC & 21,78 & 31,46 . & 4 & 0 & DVNR & 90 & 50 & 1,8 & 1,8 & 1,6 & 1,6 & 1,5 & 1,7 & & 1,5 & 1,3 & 1,1 \\
\hline 18 & 58 & $f$ & 36 & M & HAS & 21,98 & & & 38,8 & DVR & 120 & 95 & 3,0 & 2,7 & 2,6 & 2,7 & 2,8 & 2,6 & 2,2 & 1,3 & 0,8 & 0,8 \\
\hline 19 & 42 & $f$ & 45 & $\mathrm{~F}$ & GNC & 18,67 & 24 & 0 & 0 & DVR & 60 & 45 & 2,4 & 2,4 & 2,1 & 2,3 & 2,2 & 1,8 & 1,5 & 1,7 & 1,4 & 1,4 \\
\hline 20 & 34 & $\mathrm{~m}$ & 39 & $\mathrm{~F}$ & DM & 31,46 & 29,47 & 2 & 0 & DVNR & 60 & 49 & 3,4 & 2,6 & 1,9 & 1,7 & 1,7 & 1,8 & 1,4 & 1,1 & 1,2 & 1,1 \\
\hline 21 & 48 & f & 24 & $\mathrm{~F}$ & DESCONH. & 22,2 & & 0 & 40 & DVR & 70 & 48 & 3,2 & 1,7 & 1,5 & 1,3 & 1,2 & 1,1 & & 1,3 & 1,2 & 1,3 \\
\hline 22 & 53 & f & 28 & $\mathrm{~F}$ & GNC & 23,8 & 21,79 & 1 & 0 & DVR & 60 & & 2,3 & 1,3 & 1,3 & 1,3 & 1,2 & & & 1,0 & 1,3 & 1,2 \\
\hline 23 & 25 & $f$ & 24 & $M$ & $\mathrm{GnF}$ & 20,02 & 23,15 & & 92,78 & DVR & 480 & 80 & 3,1 & 1,2 & 0,7 & 0,7 & 0,8 & 0,9 & 0,8 & 1,0 & 1,0 & 0,9 \\
\hline 24 & 52 & $f$ & 32 & M & DESCONH. & 14,22 & 23,42 & 0 & 14 & DVR & 80 & 50 & 1,5 & 1,0 & 1,0 & 1,0 & 1,2 & 1,0 & 1,0 & 1,1 & 1,0 & 0,9 \\
\hline 25 & 47 & $\mathrm{~m}$ & 33 & $\mathrm{~F}$ & DESCONH. & 19,2 & 24,16 & 0 & 0 & DVNR & 90 & 100 & 4,1 & 2,5 & 2,2 & 1,9 & 1,5 & 1,6 & & 1,2 & 1,3 & 1,2 \\
\hline 26 & 60 & $\mathrm{~m}$ & 35 & $\mathrm{~F}$ & $\mathrm{DM}+\mathrm{HAS}$ & 22,73 & 23,32 & & 25 & DVR & 180 & 100 & 4,0 & 2,1 & 1,4 & 1,3 & 1,4 & 1,3 & 1,1 & 1,2 & 1,1 & 1,3 \\
\hline 27 & 33 & $f$ & 29 & M & $\begin{array}{c}\text { RVU } \\
\text { HIPOPLASIA }\end{array}$ & 23,97 & 25,14 & 2 & 0 & DVR & 80 & 44 & 1,8 & 1,3 & 1,2 & 1,2 & 1,3 & 1,2 & & 1,1 & 1,1 & 1,1 \\
\hline 28 & 23 & $\mathrm{~m}$ & 45 & $\mathrm{~F}$ & RENAL & 24,69 & 28,02 & 0 & 0 & DVR & 80 & 100 & 4,3 & 2,8 & 2,3 & 2,0 & 1,5 & 1,8 & 1,5 & 1,7 & 1,7 & 1,6 \\
\hline 29 & 45 & $\mathrm{~m}$ & 39 & $\mathrm{~F}$ & DESCONH. & 23,75 & 29,73 & 0 & 0 & DVNR & 200 & 70 & 5,3 & 2,6 & 2,0 & 2,4 & 1,9 & 1,7 & 1,3 & 1,1 & 1,4 & 1,4 \\
\hline
\end{tabular}

IMC = índice de massa corporal; IMCd=índice de massa corporal do doador

PRA=pesquisa do painel de reatividade para antígeno HLA

$\mathrm{TIQ}=$ tempo de isquemia quente, TIF = tempo de isquemia fria

Scr= creatinina sérica 
Dados clínicos brutos dos pacientes do grupo laparoscópica

\begin{tabular}{|c|c|c|c|c|c|c|c|c|c|c|c|c|c|c|c|c|c|c|c|c|c|c|}
\hline $\mathrm{Pac}$ & idade & sexo & $\begin{array}{c}\text { idade } \\
\text { doador }\end{array}$ & $\begin{array}{c}\text { sexo } \\
\text { doador }\end{array}$ & CAUSA & IMC & $\mathrm{IMC} \mathrm{d}$ & transfusões & PRA & doador & $\mathrm{TIQ}$ & TIF & scr1 & scr2 & scr3 & scr4 & scr5 & scr6 & scr7 & scr30 & scr3m & scr6m \\
\hline 1 & 28 & $\mathrm{~m}$ & 25 & $\mathrm{~F}$ & desconhecida & 19,38 & & & 27,6 & DVR & 200 & 78 & 6,7 & 4,0 & 3,5 & 3,3 & 4,80 & 5,5 & 6,2 & 1,2 & 1,1 & 1,2 \\
\hline 2 & 60 & $\mathrm{~m}$ & 29 & $\mathrm{~F}$ & HAS & 33,03 & 23,37 & 0 & 0 & DVR & & & 3,91 & 2,6 & 2,3 & 1,7 & 1,55 & & 1,6 & 1,3 & 1,3 & 1,6 \\
\hline 3 & 39 & $f$ & 47 & $\mathrm{~F}$ & desconhecida & 19,53 & 30,75 & 0 & 0 & $d v r$ & 146 & 45 & 2,0 & 1,6 & 1,4 & 1,4 & 1,43 & 1,4 & 1,2 & 1,9 & 1,2 & 1,4 \\
\hline 5 & 49 & $f$ & 28 & $F$ & PNC & 31,25 & 27,82 & & 0 & $d v r$ & 120 & 120 & 5,0 & 1,4 & 1,3 & 0,9 & 1,10 & & & 1,0 & 1,0 & 1,0 \\
\hline 6 & 66 & $\mathrm{~m}$ & 41 & $F$ & $\begin{array}{c}\text { HAS } \\
\text { nefrosclerose }\end{array}$ & 24,22 & & & 40 & $d v r$ & 240 & 150 & 5,1 & 3,3 & 2,2 & 1,9 & 1,60 & 1,5 & 1,3 & 1,3 & 1,5 & 1,4 \\
\hline 7 & 45 & $\mathrm{~m}$ & 46 & $\mathrm{~F}$ & hipert. & 22,49 & 26,57 & & 14 & $d v n r$ & 240 & 105 & 7,9 & 2,2 & 1,3 & 1,4 & 1,70 & 1,3 & 1,3 & 1,0 & 1,0 & 1,1 \\
\hline 8 & 39 & $f$ & 25 & M & $\mathrm{dm}$ & 18 & & 0 & 0 & DVNR & 280 & & 1,5 & 1,3 & 1,0 & 0,8 & & & & 1,0 & 1,3 & 1,2 \\
\hline 10 & 31 & $\mathrm{~m}$ & 52 & $\mathrm{~F}$ & $\begin{array}{l}\lg A \\
\text { gota abuso }\end{array}$ & 22,59 & 24,96 & 0 & 0 & DVR & 180 & 47 & 5.2 & 3,3 & 2,4 & 2,4 & 2,65 & 2,4 & 2,4 & 1,6 & 1,7 & 1,7 \\
\hline 11 & 49 & $\mathrm{~m}$ & 43 & $\mathrm{~F}$ & AINE & 25,72 & 24,6 & 0 & 0 & DVNR & 137 & 50 & 2,8 & 2,0 & 1,7 & 2,6 & 2,26 & 1,6 & 1,6 & 1,7 & 1,4 & 1,1 \\
\hline 12 & 22 & $\mathrm{~m}$ & 42 & $F$ & gesf & 17,81 & 31,89 & 0 & 0 & DVR & 199 & 37 & 4,96 & 3,3 & 2,12 & 1,9 & 1,95 & 2,36 & 1,88 & 2,7 & 2,38 & 2,3 \\
\hline 13 & 73 & $f$ & 49 & M & $\begin{array}{c}\text { desconhecida } \\
\text { TX }\end{array}$ & 25,61 & 27,59 & 0 & & DVR & 330 & 50 & 2,3 & 1,1 & 0,7 & 0,7 & 0,8 & & 0,8 & 0,9 & 1,1 & 1,1 \\
\hline 14 & 53 & $\mathrm{~m}$ & 23 & M & HEPÁTICO & 25,08 & 23,29 & & 66,45 & $d v r$ & 180 & 60 & 5,7 & 2,6 & 1,6 & 1,2 & 1,4 & 1,6 & 1,5 & 1,6 & 1,3 & 1,2 \\
\hline 15 & 51 & $f$ & 35 & $\mathrm{~F}$ & desconhecida & 20,29 & 26,5 & 1 & 76 & DVR & 180 & 60 & 2.7 & 1,4 & 1,2 & 1,0 & 1,1 & 1,2 & 1,5 & 1,2 & 1,1 & 1,2 \\
\hline 16 & 39 & $\mathrm{~m}$ & 32 & $\mathrm{~F}$ & desconhecida & 21,66 & & & & dvnr & 270 & 95 & 4,4 & 2,7 & 2,1 & 1,5 & 1,8 & 1,6 & 1,8 & 1,8 & 2,1 & 1,6 \\
\hline 18 & 61 & $\mathrm{f}$ & 35 & $\mathrm{~F}$ & GNC & 23,87 & 21,07 & 2 & 0 & DVR & 240 & & 3,8 & 1,6 & 1,1 & 1,4 & 1,1 & 0,9 & & 1,0 & 1,1 & 1,1 \\
\hline 19 & 54 & $\mathrm{~m}$ & 25 & $\mathrm{~F}$ & DM & 31,58 & 30,35 & 0 & 0 & DVR & 180 & 64 & 4,3 & 2,8 & 2,2 & 2,1 & 2,2 & & & 2,3 & 1,4 & 1,9 \\
\hline 20 & 38 & $f$ & 31 & $\mathrm{~F}$ & GNC & 29,09 & 24,98 & 0 & 0 & DVR & 170 & & 10,84 & 5,4 & 2,8 & 1,6 & 1,76 & & & 1,0 & 1,0 & 0,9 \\
\hline 21 & 40 & $f$ & 36 & $\mathrm{~F}$ & $\begin{array}{c}\text { DM } \\
\text { nefrosclerose }\end{array}$ & 24,16 & 27,41 & & 18,43 & DVR & 200 & 100 & 2 & 1,3 & 1 & 0,9 & 1,4 & 1,2 & 0,9 & 1,1 & 1,4 & 1,2 \\
\hline 22 & 29 & $\mathrm{~m}$ & 55 & $\mathrm{~F}$ & hipert. & 23,72 & 27,22 & & 6,58 & DVR & 120 & 75 & 2,7 & 1,5 & 1,4 & 1,4 & 1,1 & 1,6 & 1,5 & 1,7 & 1,9 & 1,6 \\
\hline 23 & 21 & $f$ & 38 & $\mathrm{~F}$ & desconhecida & 20,47 & 32,72 & 0 & 56 & DVR & 150 & 90 & 3,3 & 1,6 & 1,3 & 1,1 & 1,0 & 0,9 & & 1,1 & 0,9 & 1,1 \\
\hline 24 & 41 & $f$ & 54 & $\mathrm{~F}$ & desconhecida & & & & & & 210 & 80 & 3,1 & & 3,5 & & 4,0 & & 3,5 & 3,0 & & \\
\hline 25 & 46 & $\mathrm{~m}$ & 41 & $\mathrm{~F}$ & desconhecida & 24,57 & 24,9 & & 19,41 & $d v r$ & 120 & 60 & 4,0 & 1,6 & 1,7 & 1,7 & 1,5 & 1,4 & 1,3 & 1,5 & 1,4 & 1,6 \\
\hline 26 & 40 & $\mathrm{~m}$ & 35 & $\mathrm{~F}$ & HAS & 25,95 & 21,64 & 1 & 0 & DVNR & 120 & 100 & 5,9 & 5,0 & 7,1 & 8,9 & 7,9 & 9,6 & 11,1 & 1,8 & 1,9 & 1,6 \\
\hline
\end{tabular}

